\title{
MONTE DO FACHO, DONÓN (O HÍO / PROV. PONTEVEDRA) 2003. INFORME SOBRE LAS EXCAVACIONES EN EL SANTUARIO DE BEROBREO
}

\author{
POR \\ THOMAS G. SCHATTNER \\ JOSÉ SUÁREZ OTERO \\ $y$ \\ MICHAEL KOCH \\ Instituto Arqueológico Alemán
}

PALABRAS CLAVE: Santuarios galaico-romanos, arae, ubicaciones de arae, recintos, inscripciones.

KEY WORDS: Galaico-roman Sanctuaries, Arae, settings of arae, enclosures, inscriptions.

\section{RESUMEN}

La excavación en el Monte do Facho forma parte de un proyecto de investigación dedicado al estudio de la romanización de los santuarios indígenas en el occidente hispánico. La primera campaña llevó al hallazgo del santuario de la divinidad Berobreo, hasta ahora desconocida. Se encontraron 57 aras, algunas de ellas in situ. Además, se observó la existencia de los sitios exactos ('ubicaciones') de la colocación de las aras. Algunas ubicaciones forman parte de una recinto mayor. El santuario se fecha en los siglos III y IV d.C. Se construyó encima de un castro anteriormente abandonado.

\section{SUMMARY}

Excavations on Monte do Facho is part of a greater project about the romanization of indigenous sanctuaries in the western part of Hispania. The first campaign led to the discovering of the sanctuary itself, in which the formerly unknown deity Berobreus was worshipped. About 57 altars have been found, some of them in situ. Further, the exact settings of the altars could be observed. Some of the settings are placed in an enclosure. The sanctuary dates from the III $\mathrm{rd}$ and IV th century A. D. and has been built on the ruins of an formerly abandoned castro.

\section{INTRODUCCIÓN Y DEFINICIÓN DE OBJE- TIVOS}

Las excavaciones del Monte Facho (figuras 1-12, láminas 1-13) forman parte de un reciente proyecto de investigación del departamento madrileño del Instituto Arqueológico Alemán y comprenden a su vez las excavaciones que se están llevando a cabo en el santuario dedicado al dios Endovélico situado en la colina de São Miguel da Motta /Alandroal (Portugal). Ambas excavaciones están situadas en el nor- te y en la parte central del sur de la Península Ibérica respectivamente. Se prevén futuras excavaciones en los santuarios de Andévalo (prov. Huelva) y Postoloboso (prov. Ávila). La definición de tareas observa tanto aspectos locales como regionales y suprarregionales dentro de un marco de amplia dispersión geográfica, contexto en el que también tiene lugar la investigación en torno al santuario de Panoias, en el norte de Portugal, que ya fue realizada por arqueólogos del Departamento en los años sesenta ${ }^{1}$. Se trata hasta la fecha del único santuario autóctono en el oeste de la península ibérica del que se tiene una cierta representación arqueológica. Limitarse a la parte occidental de la Península Ibérica garantiza una cierta uniformidad en el campo de investigación, dado que se trata de zonas «celtizadas», esto es, indogermánicas, como son las provincias de Gallaecia, Lusitania, Vettonia y de Baeturia Celtica ${ }^{2}$.

El objetivo del presente proyecto consiste en investigar el proceso de romanización en los santuarios autóctonos a partir de una selección de ejemplos. La transmisión escrita ofrece únicamente una imagen parcial y contradictoria de los dioses autóctonos prerromanos y de sus cultos. Aún menor es la información sobre los cambios sufridos bajo la influencia de los nuevos arquetipos romanos. La arqueología de campo es un recurso que nos ofrece nuevas perspectivas. Por un lado, debido a que el planteamiento de cuestiones nos lleva al epicentro de dicho proceso de aculturación y por otro lado

Sobre el tema, el último resumen publicado por G. Alföldy, MM 38, 1997, 176 y sigs. - De forma abreviada en Th. G. Schattner (ed.), Archäologischer Wegweiser durch Portugal (1998) 83 y sig. ${ }^{\circ} 55$.

2 La reciente obra de $M$. Almagro ofrece una breve representación de las imágenes aparecidas en el contexto arqueológico-histórico de estos paisajes y sus respectivos pueblos: M. Almagro-O. Arteaga-M. Blech-D. Ruiz Mata-H. Schubart, Protohistoria de la Península Ibérica (2001) 357 y sigs. 
porque es de prever que en los santuarios se encuentren suficientes hallazgos en buen estado como para poder llegar a emitir una afirmación con toda seguridad. El proyecto de investigación tiene como objetivo poder llegar a ofrecer una imagen arqueológica de los cultos y santuarios autóctonos y de su historia romana, que concuerde con los elementos de tipo epigráfico o literario. Ello supondría una aportación al proceso de la romanización, de la conquista e influencia cultural por parte del Imperio Romano de las regiones hispánicas, muy distintas entre sí.

El tema de por sí no es desconocido. El primero en darlo a conocer fue el portugués José Leite de Vasconcellos con su famosa obra en tres volúmenes Religióes da Lusitania (I 1897, II 1905, III 1913), en la que recogía toda la sabiduría antigua a partir de las fuentes literarias y epigráficas y con el que asentaba un punto de partida para futuras investigaciones. La investigación llevada a cabo por Vasconcellos es de tipo filológico, si bien también incluye de manera esporádica algunos hallazgos arqueológicos ${ }^{3}$. El historiador José María Blázquez prosiguió con esta investigación, dedicándole numerosas monografías que representan una parte esencial del trabajo realizado a lo largo de su vida ${ }^{4} . \mathrm{Su}$ metodología es similar a la de Vasconcellos. Sus publicaciones comprenden listas inéditas completas de los nombres de dioses prerromanos de la Península Ibérica con más de doscientos nombres en total. En lo sucesivo cabe mencionar especialmente las investigaciones llevadas a cabo por J. L. Ramírez, J. J. Urruela, M. Pastor, A. Tovar, A. Tranoy y J. d'Encarnação. Por lo general, están orientadas a divinidades individuales, por lo que pueden ofrecer cierta información sobre el culto, o bien sobre las manifestaciones religiosas a grosso modo de una región o provincia ${ }^{5}$. En épocas anteriores

${ }^{3}$ J.M. Garcia, Religióes antigas de Portugal, aditamentos $e$ observações às «Religiões da Lusitânia» de J. Leite de Vasconcelos, fontes epigráficas (1991) ofrece una actualización de la obra de Vasconcellos sobre los nombres divinos, que incluye una más reciente bibliografía sobre epigrafía.

4 Aportaciones a las religiones primitivas de Hispania (1957). - Religiones primitivas de España (1962). - Diccionario de las religiones prerromanas de Hispania (1975). Versión en alemán: Die Mythologie der Althispanier, en: Wörterbuch der Mythologie, editado por W. Haussig (1973) $707 \mathrm{ff}$. - Imagen y mito. Estudios sobre religiones mediterraneas e ibéricas (1977). - Einheimische Religionen Hispaniens in der römischen Kaiserzeit. ANRW II 18,1 (1986) 163 y sigs. - Religiones en la España antigua (1991). - Religiones primitivas de Hispania (1991). - Historia de las religiones antiguas (1993). - Mitos, dioses, héroes en el Mediterraneo antiguo (1999). - Religiones, ritos y creencias funerarias de la Hispania prerromana (2001).

${ }^{5}$ Las obras correspondientes de estos autores están citadas en la sinopsis de investigación de J.M. Blázquez, ANRW II 18,1 (1986) 163 y sigs. Respecto al noroeste de la Península
J. Mangas ${ }^{6}$ y F. Marco Simón ${ }^{7}$ estuvieron tratando el tema de manera monográfica bajo un prisma diferente ${ }^{8}$.

Todas estas investigaciones toman como punto de partida común los campos de la filología y la Historia Antigua, en los que el problema es esclarecido en primer lugar por las fuentes literarias y/o por la tradición epigráfica. Los hallazgos arqueológicos son tratados muy puntualmente y por encima. Por lo general, representan altares con inscripciones y con una u otra representación en relieve. Los monumentos escultóricos también son comentados esporádicamente.

Los santuarios mismos no son dados a conocer, bien porque no han sido excavados o sólo una pequeña parte, o bien porque aún no han sido objeto de investigación ${ }^{9}$. De hecho, a excepción del santuario de Panoias, apenas se conoce suficientemente el significado de los demás santuarios ${ }^{10}$. Así pues, la imagen surgida a partir de los santuarios autóctonos y del culto a los dioses practicado en ellos es bastante borrosa. Para avanzar en este sentido, esta nueva investigación tiene como objetivo tratar el problema de manera global, relacionando o comparando los hallazgos epigráficos con su contexto arqueológico. La sinopsis deja entrever que será posible llegar a establecer nuevos puntos de vista.

Por regla general, de casi todos los doscientos nombres conocidos de dioses autóctonos existe un único comprobante, que acostumbra a ser casi siempre una inscripción en un altar. El dios Endovélico es una excepción: se conocen más de 80 inscripciones procedentes del templo dedicado a él en São Miguel da Motta - altares, aunque también bases de estatuas-, que permiten que nos formemos una idea sobre ciertas cuestiones individuales sobre la divini-

Ibérica, cabe mencionar las siguientes monografías: B. García Fernández-Albalat, Guerra y religión en la Gallaecia y la Lusitania antiguas (1990).

${ }^{6}$ e.g. Religiones indígenas en Hispania. Historia de España Antigua II. Hispania romana (1978) 579 y sigs. - Die römische Religion in Hispanien während der Prinzipatszeit. ANRW II 18,1 (1986) 276 y sigs. - La Dea Asturica, Cuadernos Municipales Astorga 1 (1987). - El culto de Apolo en Hispania. Testimonios epigráficos, en: Mélanges $P$. Lévêque (1991) 171 y sigs.

${ }^{7}$ e. g. Illud tempus. Mito y cosmogonía en el mundo antiguo (1988). - Flamen dialis. El sacerdote de Júpiter en la religión romana (1996). - Die Religion im keltischen Hispanien. Archaeolingua, Series Minor 12 (1998).

${ }^{8}$ Por último, sobre el tema (con bibliografía): M. Salinas de Frías, La religiosidad de las poblaciones antiguas de Salamanca y el Norte de Cáceres, Palaeohispanica 1, 2001, 151 y sigs.

${ }^{9}$ Compárese con el mapa actual de distribución de los santuarios autóctonos más relevantes de F. Marco Simón, Die Religion im keltischen Hispanien (1998) 63 Fig. 7.

10 Véase, además, la bibliografía de la nota 1. 
dad misma, sobre la clientela y también sobre el santuario. Es decir, sobre los edificios ubicados en el interior, así como sobre el resto del decorado. También si tenemos en cuenta el marcado carácter local de la mayoría de dioses autóctonos, Endovélico vuelve a ser una excepción, ya que quizás también se encuentren santuarios dedicados a él en Postoloboso (prov. Ávila) y en Andévalo (prov. Huelva). Una reflexión basada en la relación existente entre los nombres de Vélico en Postoloboso y el topónimo Andévalo, una relación que ha sido constatada desde el siglo XVIII. Sin embargo, las investigaciones lingüísticas más recientes se alejan de esa hipótesis y descartan cualquier tipo de conexión entre ambos topónimos ". Se espera que con la ayuda de nuevas investigaciones arqueológicas sea posible dar con una explicación.

La existencia de lazos suprarregionales entre Endovélico-Vélico-Andévalo contrastaría en cierta manera con los dioses autóctonos mencionados, característicamente tópicos ${ }^{12}$. Por otro lado, mostraría una amplia difusión, ya documentada en el caso de algunos dioses celtas en la Península Ibérica a escala suprarregional (e.g. Ataecina) ${ }^{13}$ e incluso más allá de los Pirineos (Bormanicus/Bormanus, Lucoubus o Lugovibus/Lugoves, Toudadigoe/Teutates) ${ }^{14}$. También en este caso quedaría demostrado el carácter excepcional del dios Endovélico y los dioses emparentados con él.

Y no únicamente para Endovélico, también sería válido para todos esos dioses autóctonos romaniza-

11 En la actualidad, a modo de resumen sobre esta cuestión, J. Cardim Ribeiro, Endovellicus, en: Religiões da Lusitânia. Loquuntur saxa. Catálogo de la exposición de Lisboa (2002) 80 y sigs. Con referencias a J.C. Búa, Estudio Lingüistico de la Teonimia Lusitano-Gallega (Tesis doctoral no impresa, Salamanca).

12 J. Leite de Vasconcellos, Religiões da Lusitania III (1913) 125 y, por último, Cardim Ribeiro, op. cit. 81 y passim, así como A. Guerra ibid. 63 y passim.

${ }_{13}^{13}$ e.g. J. M. Blázquez, Diccionario de las religiones prerromanas de Hispania (1975) 39 y sigs. s. v. Ataecina; J. M. Abascal Palazón, Las inscripciones latinas de Santa Lucía del Trampal (Alcuéscar, Cáceres) y el culto de Ataecina en Hispania. AEspA 68, 1995, 31 y sigs.; A. U. Stylow, Nuevo testimonio emeritense de Ataecina, Revista de Estudios Extremeños 53, 1997, 11 y sigs.; J. Alvar, Ataecina. Une déesse celto-lusitanienne, en: Imago antiquitatis. Religions et iconographie du monde romain. Mélanges offerts à Robert Turcan (1999) 47 y sigs

${ }_{14} \mathrm{~J}$. Untermann, Los teónimos de la región lusitano-gailega como fuente de las lenguas indígenas, en: Actas del III coloquio sobre lenguas y culturas paleohispánicas, Lisboa 1980 (1985) 354; del mismo autor, Anotaciones al estudio de las lenguas prerromanas del noroeste de la Península Ibérica, en: Galicia da romanidade á xermanización. Actas do encontro cientifico en homenaxe a Fermín Bouza Brey, Santiago de Compostela 1992 (1993) 374; del mismo autor, La toponimia antigua como fuente de las lenguas hispano-celtas, en: $\mathrm{Pa}$ laeohispanica 1, 2001, 194. (por cortesía de J. Untermann). dos. Esto es, que preservan altares que se ajustan a los cánones romanos, con inscripciones en latín. Sus anteriores orígenes prerromanos se basan por lo general en la clasificación lingüística de sus nombres, los cuales son de origen celta/indogermánico ${ }^{15}$.

Los altares objeto de la presente investigación ya fueron tratados anteriormente de alguna manera en el curso de investigaciones anteriores a raíz de hallazgos encontrados en ellos, por lo que puede decirse que, hasta un cierto punto, nos resultan conocidos desde el punto de vista arqueológico. Pudimos llegar a conocer el nombre de cada dios gracias a las inscripciones de los altares. Sin embargo, los puntos de partida de anteriores investigaciones eran radicalmente distintos, en ningún caso orientados a cuestiones relacionadas con los dioses, motivo por el que en ningún caso se llegó a localizar el emplazamiento del altar, motivo por el que su exacta ubicación quedó desconocida. Las investigaciones anteriores partían siempre de hallazgos de superficies, por lo general altares, en São Miguel da Motta /Alandroal (Portugal), aunque también esculturas de mármol de mayor y menor tamaño que, al igual que en Postoloboso (provincia de Ávila) habían sido reutilizados en la construcción de pequeñas iglesias. En Postoloboso se encontraron veintiún altares ${ }^{16}$.

El hecho de incluir el templo del dios Berobreo en Galicia supone un punto de referencia en sentido metodológico y a la vez una norma externa al centro del contexto del dios Endovélico y de los dioses que pudieran estar emparentados con él. Este santuario gallego cuenta, al igual que con los santuarios de São Miguel da Motta y Postoloboso, con un gran número de hallazgos de altares. Con anterioridad al comienzo de las excavaciones fueron encontradas cuarenta y dos piezas que nos dejan entrever una cierta importancia del dios Berobreo ${ }^{17}$. De los santuarios incluidos en la nueva investigación, el de

\footnotetext{
I5 e.g. B. J. de Alarcão, Portugal romano (1973) 167 y sigs. - Primicia en lo relativo a Endovélico de Miguel Perez Pastor, Disertación sobre el Diós Endovellico y noticia de otras deidades gentílicas de la España antigua (1760), v. Vasconcellos, op.cit. 116 y posteriormente también confirmado por éste, ibid. 125 con referencias a su propio artículo aparecido en la Revue Celtique 22, 1901, 308 y sigs. - Sobre etimología v. también a modo de resumen J.M. Blázquez, Religiones primitivas de Hispania, I. Fuentes literarias y epigráficas (1962) 155 y sigs.

${ }^{16} \mathrm{~F}$. Fernández Gómez, Excavaciones arqueológicas en E1 Raso de Candeleda II (1986) 881 y sigs. Cap. 22.3.2.

${ }^{17} \mathrm{~V}$. el siguiente capítulo sobre el estado de las investigaciones. II. El santuario de Berobreo. Yacimiento y estado previo de la investigación en el capítulo de G. Gamer sobre hallazgos en altares de santuarios (Formen römischer Altäre auf der Iberischen Halbinsel, MB 12 [1989] 134 y sigs.), los santuarios del capítulo introductorio de este informe ocupan la mayor parte de la obra.
} 
Berobreo es el único que posiblemente se sitúa en una población. Los demás santuarios se encuentran en las afueras, al menos según lo que se ha podido ver hasta la fecha en el transcurso de las investigaciones.

\section{HISTORIA DE LA INVESTIGACIÓN}

\section{A. El yacimiento}

El accidente geográfico conocido como Monte do Facho se alza $189 \mathrm{~m}$ en extremo occidental de la península do Morrazo (provincia de Pontevedra), inmediatamente encima de una costa acantilada - Costa da Vela o Soavela - y bañada por las aguas del Océano Atlántico; las coordenadas geodésicas son: $42^{\circ} 16^{\prime} 40 \gg \mathrm{N}$ y $08^{\circ} 51^{\prime} 35 » \mathrm{~W}$. Pertenece a la parroquia de S. Andrés do Hio, ayuntamiento de Cangas de Morrazo, y el lugar más cercano, de donde también parten los principales accesos al monte, es el de Donón. Hoy en día es un espacio ocupado mayoritariamente por una vegetación de monte bajo dominada por el tojo, entre el que se está implantando un bosque de eucalipto que sustituye, a su vez, a una repoblación anterior de pinos, como fruto de los constantes incendios que asolaron este monte en los últimos veinte años.

Arqueológicamente el primer episodio constatado corresponde a un momento avanzado del Bronce Final. Conocido exclusivamente por un repertorio cerámico hallado en superficie, expresa un asentamiento datable en los siglos IX-VII a. C. que se proyectaba a lo largo de la ladera Este, desde la cima hasta el pie del monte, sin que haya evidencias de estructuras defensivas, a las que, por otra parte, esa disposición dificultaría, tanto por su topografía como por su amplitud ${ }^{18}$.

A pesar de la entidad y el interés de esa primera ocupación del monte, éste, en tanto que yacimiento arqueológico, ha sido conocido fundamentalmente por albergar un típico asentamiento de la edad del Hierro ${ }^{19}$. Un castro que elige la ladera norte y en

${ }^{18}$ J. Suárez Otero, Las hachas de talón sin anillas y la introducción del Bronce Atlántico en Galicia, Boletín Auriense XXX, 2000, 9-36.

${ }^{19}$ Primera mención en Alvarez Limeses, Geografía del reino de Galicia. Provincia de Pontevedra (Barcelona 1927); después en J. F. Filgueira Valverde y A. García Alén, Carta arqueológica de la Provincia de Pontevedrta (Pontevedra 1956); aunque la primeras referencias a características y hallazgos no se harán hasta la publicación de F. Bouza Brey, J. $\mathbf{M}^{\mathrm{a}}$. Álvarez Blázquez y E. Massó Bolivar, Las arás del santuario galaico-romano de Donón (Hío, Cangas), Cuadernos de Estudios Gallegos 78, 1971, 64-81. El estado de la cuestión actual en F. Fariña Busto y J. Suárez Otero, El santuario menor medida la noroeste y está definido por un doble recinto amurallado que engloba la cima y la parte alta de configuración aterrazada dichas laderas, aunque manifiesta en la parte norte una expansión hacia cotas más bajas y de mayor pendiente. La fortificación se completaba con un pequeño foso y terraplén en el ángulo noroeste, allí donde se disponía también la entrada principal al castro. Finalmente, hay que añadir dos grandes basureros («concheiros») situados extramuros en las laderas oeste y este, respectivamente ${ }^{20}$.

En el interior de ambos recintos se pudo apreciar la existencia de la típica arquitectura castreña, construida con piedra local y en la que predomina la línea curva. Los contenidos hasta ahora exhumados hablan principalmente de una ocupación tardía dentro de la evolución de la cultura castreña, caracterizada por las producciones alfareras de la zona, propias, fundamentalmente, de los dos siglos antes del cambio de era; no obstante, hay que señalar una aparente escasez de los rasgos mas avanzados dentro de dicha etapa y del material romano, que se refiere exclusivamente a restos anfóricos. Todo ello y a pesar de la presencia de algún vidrio, que estas excavaciones relacionan con el Santuario, permite suponer una pervivencia del poblado no más allá de la primera mitad del siglo I d.C., sino del cambio de era. No podemos descartar, sin embargo, matizaciones futuras, o algún uso habitacional restringido hasta tiempos posteriores. Lo que sí parece confirmado es una presencia humana en tiempos anteriores, pues entre la cerámica conocida se detectan también especies que podrían corresponder a los siglos IV y III a.C., aunque con una incidencia más limitada en el registro. Una escasez lógica si atendemos a la falta de trabajos de campo científicos ${ }^{21}$; también, porque la mayor parte del material proviene del segundo recinto y el basurero de la ladera Oeste, y por lo tanto correspondería a un posible crecimiento del poblado en un momento avanzado de su existencia.

galaico-romano de $\mathrm{O}$ Facho (O Hío, Pontevedra), Boletín Auriense XXXII, 2002, 25-52.

${ }^{20}$ En el concheiro Oeste, el único conocido hasta ahora, se realizaron sondeos para estudiar la fauna marítima y sus implicaciones paleoeconómicas, vid. J. M. Vázquez Varela, Bases paleoetnológicas para el estudio de la pesca en la cultura castreña: Una investigación preliminar, Boletín Auriense VI, 1976, 83-86.

${ }^{21}$ Se han realizado excavaciones por parte del Museo de Pontevedra a principios de los años 70 , pero no tenemos noticias de los mismos, a pesar de que el área fue importante y fruto de ellos es un importante conjunto de cerámicas que se conservan en el Museo de Pontevedra. De tiempos más recientes nos consta la realización de sondeos en el concheiro Oeste, pero no tenemos más información que referencias a los contenidos faunísticos de los mismos. 


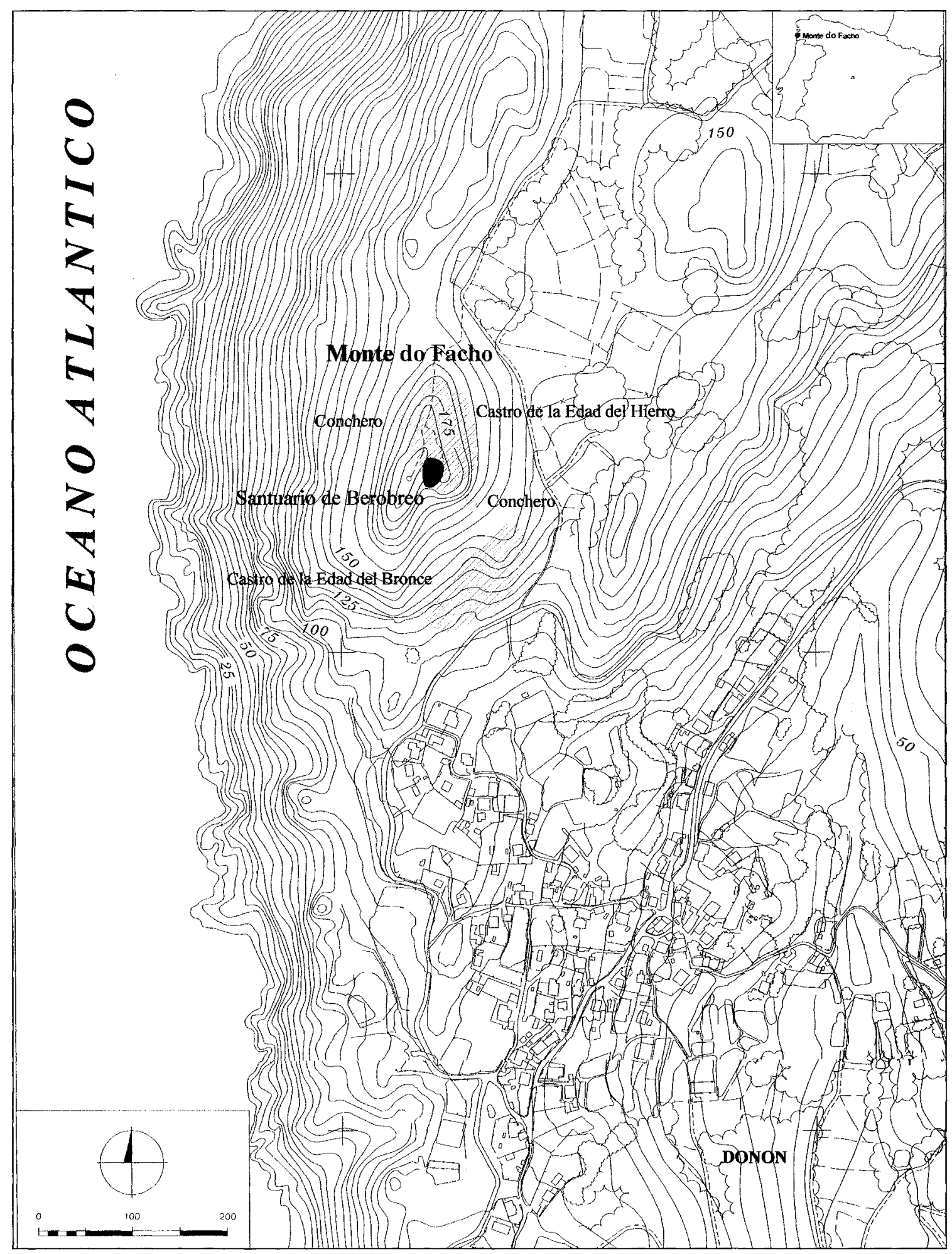

Fig. 1. Plano regional de la península de Morrazo con el Monte do Facho y el caserío de Donón. 
Sin duda lo más conocido de este yacimiento es la aparición de ese conjunto de altares romanos, a los que ya hicimos referencia en la introducción. Su propia condición nos remite a una ocupación del lugar en época romana, en aparente contradicción con las conclusiones que respecto al poblado acabamos de exponer. Sin poder entrar todavía en las coordenadas cronológicas precisas de esta ocupación, sí podemos adelantar que dadas las características de los monumentos nos movemos en un marco laxo a situar entre fines del siglo I y el siglo $\mathrm{v}$, entre la implantación definitiva de la cultura romana y la de la religión cristiana. En consecuencia a partir de la desaparición del yacimiento castreño y sin poder precisar las fechas, asistimos a la implantación de un lugar de culto con rasgos aparentemente romanos, aunque como veremos con un importante trasfondo indígena, sin que ello parezca generar una continuidad en el uso habitacional del monte, al menos con las dimensiones que ocurrió en las etapas precedentes, y sin que conozcamos de momento que relación pudo haber entre ambas realidades, si es que la hubo: continuidad de un antiguo centro de culto existente dentro del poblado de la Edad del Hierro o creación ex novo.

Finalmente, después de siglos de aparente abandono, hemos de constatar una última utilización del monte como puesto de vigilancia militar entre mediados del siglo XVIII y mediados del XIX ${ }^{22}$. Formaba parte de una amplia estructura de vigilancia costera, creada y planificada por las autoridades militares españolas. De esta etapa queda la garita de piedra que hoy corona el monte y el propio nombre con que éste se conoce: O Facho. La abundancia de restos de tejas y algunas cerámicas que aparecen superficialmente, parecen ser la expresión arqueológica de una etapa que está, por otra parte, bien referenciada documentalmente.

\section{B. Historia de la investigación}

Las primeras referencias al Monte do Facho hablaban exclusivamente de su condición de «castro», en el sentido genérico del término, sin datos más allá de su ubicación geográfica. Tendremos que esperar a los años 60 , cuando las inquietudes arqueológicas de José María y Enrique Massó hagan posible sacar del olvido a este yacimiento con el hallazgo en él de un importante conjunto de aras romanas. Aras que, como «pedras con letras e con ${ }^{22}$ Sánchez García, J. A., Faros. Historia y construcción de
las señales luminosas de un finisterre atlántico. Fundación Caixa Galicia, 2004. debuxos», habían sido conocidas desde siempre por los vecinos del lugar de Donón ${ }^{23}$, pues aparecían esparcidas en el Facho y sus inmediaciones, y habían sido utilizadas en ocasiones como parte de los muros de cierre de las fincas situadas a los pies del monte. A partir de ese hallazgo y hasta nuestros días se ha ido configurando un conjunto numeroso de elementos, de los que, frente a unos pocos remiten a elementos de carácter arquitectónico - fragmentos de columnas-, la mayoría son identificables como aras romanas, bien por las inscripciones que presentan, bien por su morfología.

El primer grupo de piezas fue el hallado por los Massó y dado a conocer en 1971 por F. Bouza Brey, J. Ma. Alvárez Blázquez y E. Massó Bolivar ${ }^{24}$. Consistía en un lote de quince elementos que pasaron a las colecciones del Museo Municipal «Quiñones de León» de Vigo, con la inclusión de una pieza completa y anepígrafa aparecida en el lugar de A Curuxana, dentro de la llanura litoral que se extiende al pie de la ladera Este del Facho y que es el tránsito obligado entre este y la ensenada de Barra; lugar donde se constata también la existencia de un enclave habitacional de época romana. Formaba parte también de ese conjunto un capitel de labra simple y tosca, realizada en granito local, que habla de la existencia de una construcción aún por definir. Finalmente, la referencia a dos piezas desaparecidas, una que formaba parte de las paredes de la garita existente en la cima del monte, y otra que fue utilizada por un vecino del lugar de Donón en los cimientos de una construcción anexa a su vivienda. De alguna de estas piezas había dado cuenta con anterioridad Pedro Díaz Álvarez en las páginas del Faro de Vigo, lo que permite saber que la recogida de elementos se había desarrollado entre los años 1963 y $1970^{25}$. Posteriormente (1978), Isidoro Millán insistió en el asunto con una reinterpretación de la epigrafía presente en este conjunto, aportando interesantes aproximaciones y valoraciones sobre le topónimo y onomástica de los epígrafes, pero sin incluir nuevas piezas.

Años después y fruto de la actividad desplegada en la zona por el colaborador del Museo de Pontevedra, D. José Suárez Mariño, fueron apareciendo nuevos testimonios del conjunto, de los que un total de diecinueve piezas ingresaron en febrero de 1978 en el

${ }^{23}$ Información oral de María Rosa García, refrendada por otros vecinos del lugar. De hecho fue uno de estos quien puso sobre la pista de la existencia de las aras a los mencionados arqueólogos aficionados.

${ }^{24}$ F. Bouza Brey, J. Ma Álvarez Blázquez y E. Massó Bolivar, Las aras del santuario galaico-romano de Donón (Hío, Cangas), Cuadernos de Estudios Gallegos 78, 1971, 64-81. 
mencionado museo, localizándose posteriormente alguna más. De las primeras se dio noticia gráfica y una primera aproximación interpretativa por parte de Francisco Fariña en la Gran Enciclopedia Gallega $(1977)^{26}$, pero el trabajo, a realizar por dicho investigador y José Suárez Otero y que debía recogerlas y estudiarlas en su totalidad, así como su contexto, sólo saldría a la luz recientemente $(2002)^{27}$. No obstante, el conjunto no quedó inédito, pues fue incluido en el volumen correspondiente a la provincia de Pontevedra del nuevo Corpus de Inscripciones Romanas de Galicia (1994) ${ }^{28}$ y después tratado también con amplitud por A. Rodríguez Colmenero (1999) ${ }^{29}$, sin olvidar la mención realizada con anterioridad por A. Tranoy en su síntesis sobre la Galicia romana ${ }^{30}$.

Los trabajos citados se centraron fundamentalmente en la epigrafía, cuya general parquedad ha llevado, en realidad, a que se tratase casi exclusivamente de la identidad de la deidad o deidades a las que están dirigidas. Salvo unos primeros titubeos, constatables en la obra de Bouza et alii y debidos fundamentalmente a la escasez de aras conocidas, la convicción generalizada es de que se trata de una única deidad para todo el conjunto de los monumentos, con lo que estos responderían a un lugar de culto dedicado a dicha divinidad. En un primer momento identificado el nombre como LIBER, que Isidoro Millán entendió y analizó como VIBERO ${ }^{31}$, o el IRIBEROBREO de A. Tranoy, después de los hallazgos de 1977 la cuestión cambio sustancialmente, pues a partir de ellos la lectura coincidente de los distintos autores a girado en torno a LARIBEROBREO, variando sólo la diferenciación en distintas partes de este epígrafe. Así, Ia interpretación propuesta inicialmente por F. Fariña, y posteriormente por el mismo y J. Suárez Otero, será la de LARI BERO BREO ${ }^{32}$, mientras que para G. Baños y $G$. Pereira será LARIBERO BREO, basándose funda-

\footnotetext{
${ }^{25}$ P. Díaz Álvarez, Noticias de prehistoria en torno a Vigo y su ría (Vigo 1973).

${ }^{26}$ F. Fariña Busto, voz DONÓN in Gran Enciclopedia Gallega, vol. IX (Coruña 1977), 177-179

${ }^{27} \mathrm{~F}$. Fariña Busto y J. Suárez Otero, El santuario galaicoromano de O Facho (O Hío, Pontevedra), Boletín Auriense XXXII, 2002, 25-52.

${ }^{28} \mathrm{G}$. Baños Rodríguez, Corpus de Inscripcións romanas de Galicia, II. Provincia de Pontevedra (Santiago 1994), esp. 27. 89.

${ }^{29}$ A. Rodríguez Colmenero, Mougás y Donón: Dos santuarios rurales galaico-romanos del litoral atlántico. El $\mathrm{Mu}$ seo de Pontevedra LI, 1999, 381-411.

${ }^{30}$ A. Tranoy, La Galice Romaine (Paris 1981).

31 I. Millán González-Pardo, Sobre las aras del santuario de Donón (Hio, Pontevedra) supuestamente dedicadas a Liber, Publicaciones del Museo Municipal Quiñones de León I (Vigo 1978)

${ }^{32}$ F. Fariña Busto y J. Suárez Otero, El santuario galaicoromano de O Facho (op. cit.), esp. 32-34.
}

mentalmente en la lectura de uno de los epígrafes más completos y en el que interpretan: Deo Lario Breo Bro San(c)to ${ }^{33}$. Lectura de la que discrepa A. Rodríguez Colmenero, quien inicialmente postula una propuesta Deo La/ri Obre/obro San(c)to ${ }^{34}$, para posteriormente inclinarse por la ya expuesta de LARI BERO BREO ${ }^{35}$.

No ha corrido la misma suerte la morfología de los monumentos, a la que sólo atendió G. Gamer, aunque de manera sucinta y referida exclusivamente al grupo de piezas descubiertas en un primer momento ${ }^{36}$. Otra breve referencia a este aspecto las encontramos en $\mathrm{A}$. Rodríguez Colmenero, quien abunda en la caracterización del conjunto, ahora con las nuevas aras incluidas ${ }^{37}$. Para un estudio más en detalle hemos de remitirnos al referido trabajo de $\mathrm{F}$. Fariña y J. Suárez, en el que realiza una propuesta de clasificación tipológica, con una interpretación de las variantes como reflejo de las distintas influencias $\mathrm{y}$ cambios que incidieron en el santuario a lo largo de su existencia ${ }^{38}$.

\section{LA EXCAVACIÓN}

La campaña de 2003 transcurrió entre el 4 y el 24 de mayo. Además de los autores del presente informe, también participaron las siguientes personas: Dra. Julia Koch (Prehistoria e Historia Antigua / Preetz), Gitte Biecker (Arquitectura/Berlín), Chr. Hartl-Reiter (Topografía/Schwerin), Monika Perkovi (Fotografía/Lyon), Juan Calvo (conductor/Madrid) y, durante un breve período de tiempo, Alfredo González (Arqueología/Madrid) y María Méndez (Arqueología/Santiago). Agradecemos a la Dirección General de Patrimonio Cultural de la Xunta de Galicia y a su Director, el Dr. Ángel Sicart Jiménez que nos hayan concedido el permiso de excavación. También deseamos mostrar nuestro agradecimiento al Director del Museo Arqueológico de Orense, el Sr. Francisco Fariña, y al Dr. Julio Carballo, Ar-

${ }^{33}$ G. Baños Rodríguez y G. Pereira Menaut, novedades y correcciones en la teonimia galaica, Avrea Saecvla 10, 1993, 37-65.

${ }^{34}$ A. Rodríguez Colmenero, Recensión a G. Baños Rodríguez, Corpus de Inscripciones Romanas de Galicia. II. Provincia de Pontevedra. Santiago: Consello da Cultura Galega, 1994, Gallaecia 14/15, 1996, 635-641.

${ }^{35}$ A. Rodríguez Colmenero, Mougás y Donón: Dos santuarios rurales galaico-romanos (op. cit.)

${ }^{36} \mathrm{G}$. Gamer, Formen römischer Altäre auf der Hispanischen Halbinsel, Madrider Beiträge 12 (Mainz 1989), esp. 136.

${ }^{37}$ A. Rodríguez Colmenero, Escultura en relieve y bulto redondo, in Galicia. Arte, vol. I (A Coruña 1993), 373-476.

${ }^{38} \mathrm{~F}$. Fariña Busto y J. Suárez Otero, El santuario galaicoromano de O Facho (op. cit.), esp. 36-38. 
queólogo Provincial de Pontevedra, por su enérgica ayuda e inestimable apoyo en todo momento.

Agradecemos el múltiple apoyo logístico al alcalde de Cangas de Morrazo, el Ilmo. Sr. Juan Enrique Sotelo Vilar, y a sus colaboradores, D. Pío Millán y D. J. Israel Ermelo, por el tesón que demostraron en su trabajo y por la diligencia con la que fueron capaces de superar todo tipo de dificultades técnicas, sin olvidar la colaboración de D. Juan Carlos Enríquez de la Fundación Comarcal do Morrazo. Por último, desearíamos dar las gracias a la Comunidad de Montes de la parroquia de S. Andrés do Hio y a los habitantes de los pueblos vecinos, por su colaboración y apoyo desinteresados.

\section{A. Los cortes $I$ y II}

Antes de empezar con los trabajos de excavación, la cima se encontraba cubierta de zarzales y maleza de la altura de una persona, concretamente con tojo (Láms. 1-3). Las excavaciones organizadas aún no habían tenido lugar ${ }^{39}$, de manera que no disponíamos de informaciones previas al respecto. Por ese motivo se procedió a despejar el terreno (de vegetación) en una zona en la que hacía unas décadas habían sido encontrados algunos altares en la superficie $^{40}$ y cuyo emplazamiento comprende la parte sur y sudoeste de la montaña entre la cumbre estrecha y amesetada y el espolón de una roca situada algo más abajo (Fig. 1, Lám. 2). Se procedió a realizar dos cortes en ángulo recto, cortes I y II (Fig. 2). Los cortes resultaron muy largos, por lo que se subdividieron en secciones (Ia-b y IIa-d) definidas a partir de características orográficas (es decir, por niveles de terreno, Fig. 3) con el fin de obtener una mejor visión de conjunto. Los cortes se orientaron en torno a los restos de un muro curvo, que se podía distinguir sobre la superficie del terreno y de la que más tarde descubrimos que formaba parte de una construcción oval (Lám. 4c) (véase la construcción oval en el pie de página). El corte I se dispuso de forma paralela a la pendiente abarcando la construcción oval en su mayor parte. El corte II, que queda en la línea de caída de la pendiente también se orientó hacia esa construcción. De esta manera se consigue una orientación aproximada del NE al SO para el corte I y de NO a SE para el II.

\footnotetext{
${ }^{39}$ Sobre las excavaciones realizadas hasta la fecha, con carácter individual y puntual, v. sección II. Yacimiento e historia de la investigación.

${ }^{40}$ v. sección. correspondiente en cap. II: Yacimiento e historia de la investigación.
}

Una vez despejado el terreno de vegetación (Lám. 2b) pudimos observar unas superficies planas en el terreno, de ubicación y tamaño irregulares, que fueron enumeradas en sentido descendente (terrazas 1-5, Fig. 3). Estas terrazas pueden distinguirse fácilmente a partir de los saltos de nivel en el terreno.

\section{Corte I}

Este corte se encuentra a ambos lados del punto de inflexión orográfica formado por el terreno comprendido entre la meseta de la cima y el espolón de más abajo (Lám. 2). Ya en ese mismo punto de inflexión se encuentra la construcción oval que comentamos con anterioridad (Lám. 4, especialmente 4c.). Las medidas son de $4 \mathrm{~m}$ de anchura y $31 \mathrm{~m} \mathrm{de}$ longitud (Figs. 2. 3. 5-7).

Desde toda la superficie del corte Ia es posible observar un derrumbe de piedras que bien podría proceder de la construcción oval (Lám. 5a). A juzgar por el número de rocas y por la longitud del derumbe, sería posible afirmar que las paredes de la construcción estarían formadas por piedras hasta arriba del todo. El tipo de construcción es típico de la arquitectura castreña tardía ${ }^{41}$. En el derrumbe (que no se llegó a tocar durante la campaña de excavación) se encontró un altar (inv. a60) y en la parte oriental del final de la sección una piedra de molino (inv. I-j-2003) y tres altares (inv. a49, a51, a52 tabla 5a). Destacan por no poseer ninguna escritura. El altar a 49 está incompleto ya que la cara anterior, es decir, la superficie de escritura sólo está pulida hasta la mitad, mientras que la otra mitad se encuentra todavía en estado bruto apenas picado (Lám. 5b).

En la superficie del desprendimiento y en la parte colindante con ella se hallan dos muros orientados norte-sur (Ma1 y Ma2, Fig. 2). El muro más occidental Ma2 es de dos caras y cuenta con un grosor de unos $40 \mathrm{~cm}$. Está compuesto por fragmentos de piedra del tamaño de una cabeza e incluso mayores, así como por bloques de piedra sin labrar. Sigue sin estar clara la procedencia de este muro, al contrario que con el muro Ma1 (más al oeste y que linda con la frontera norte del corte I), del que sabemos que era un muro de aterrazamiento debido a que está formado por una única cara.

${ }^{41}$ Véase, e.g., F. López Cuevillas, La civilización céltica en Galicia (1953) 121 y sigs.; Chr. Hawkes, The Castro culture of the peninsular north-west: fact and inference, en: $\mathrm{Pa}$ pers in Iberian Archeology, editado por T.F.C. Blagg-R.F.J. Jones-S. J. Keay (1984) 187 y sigs. [=British Archaeological Reports, International Series 193 (i)]. 

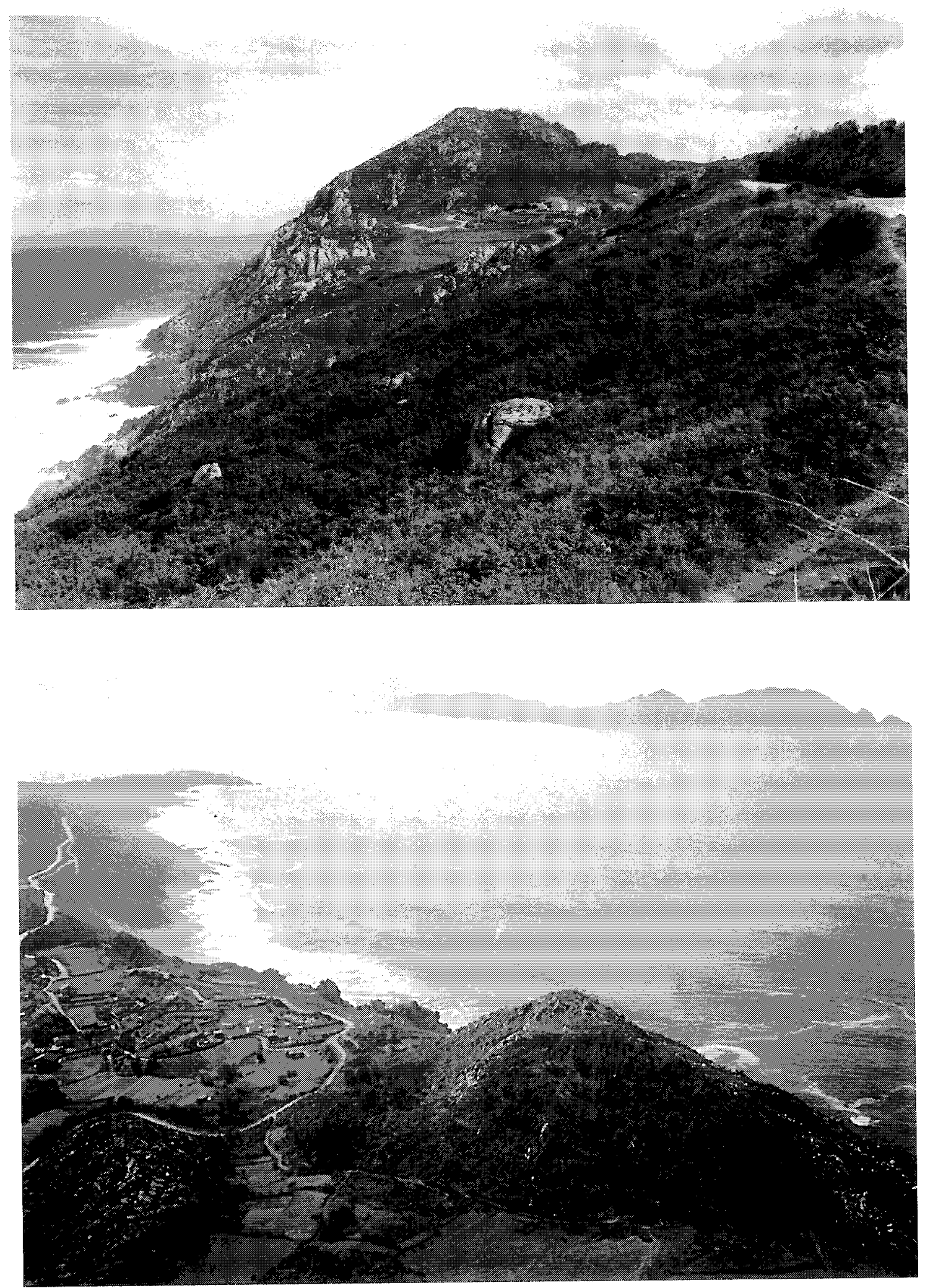

Lám. 1a. Monte Facho desde el suroeste, b Monte Facho desde el este (toma aérea). 

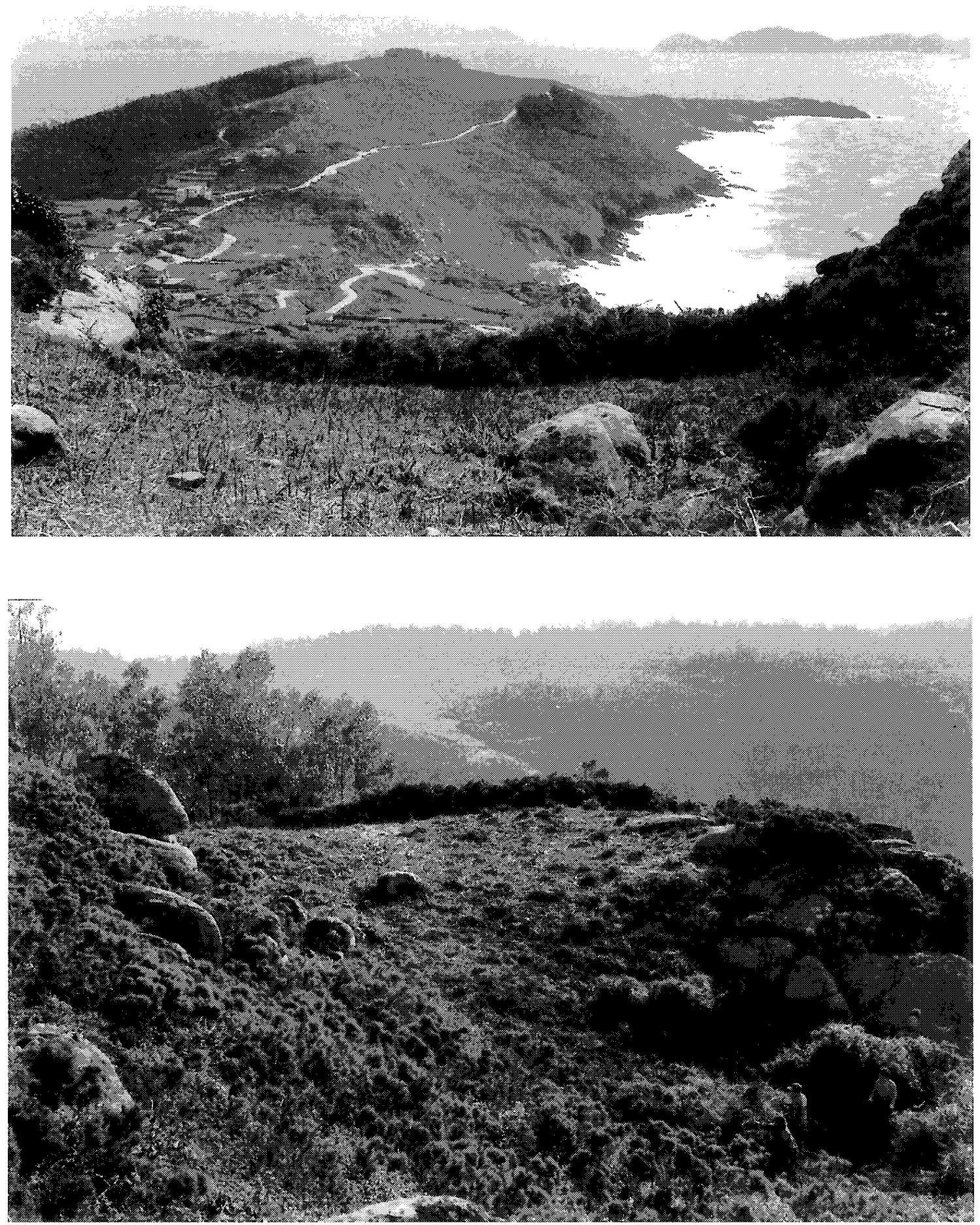

Lám. 2a. Vista desde el yacimiento (nivel 3) en el Monte Facho hacia el suroeste, al fondo el archipiélago de las Islas Cíes, b vista del Monte Facho sobre el nivel 3 hacia el sureste. 

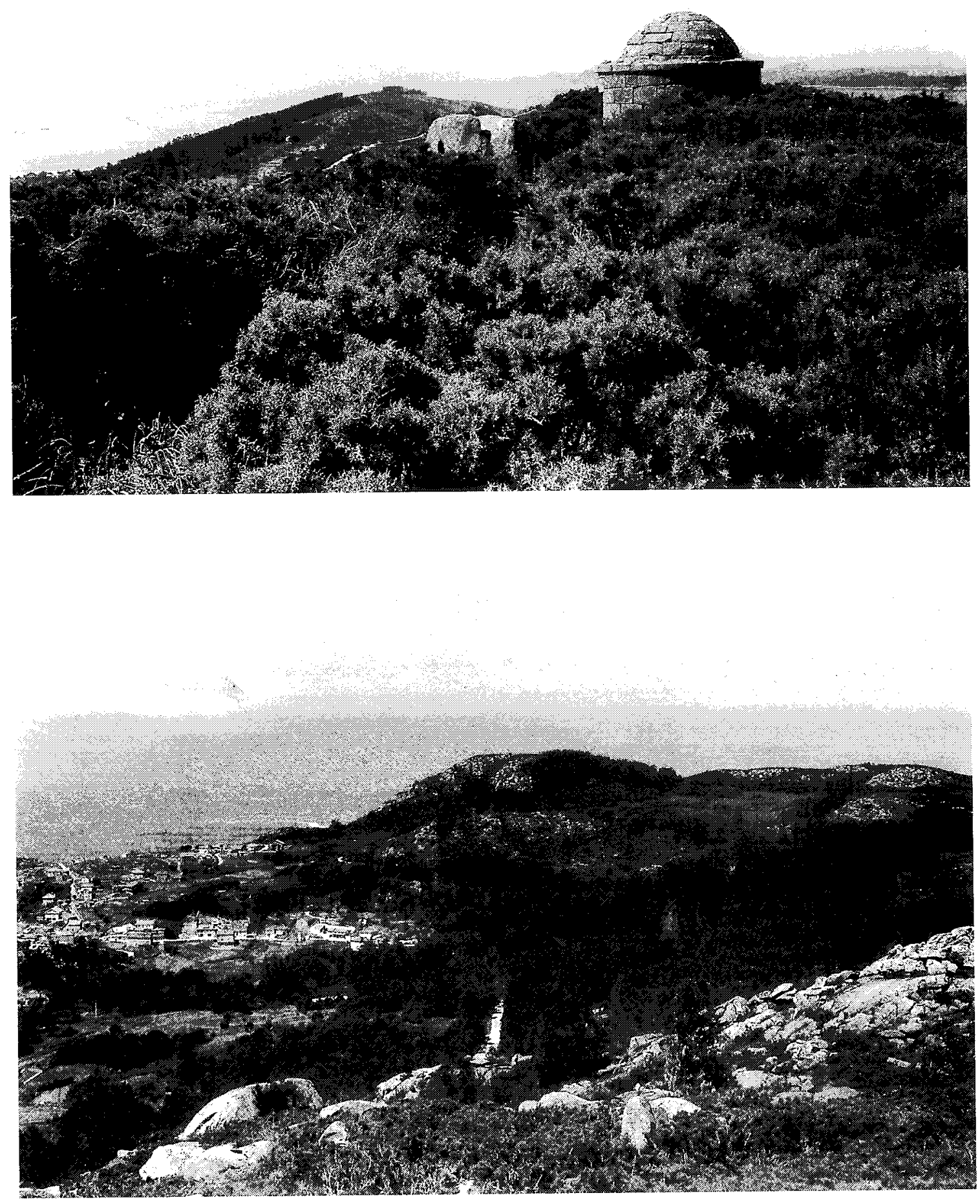

Lám. 3a. Cumbre del Monte Facho con la torre redonda a la que debe su nombre (Facho $=$ faro). b, Monte Facho desde el este. 

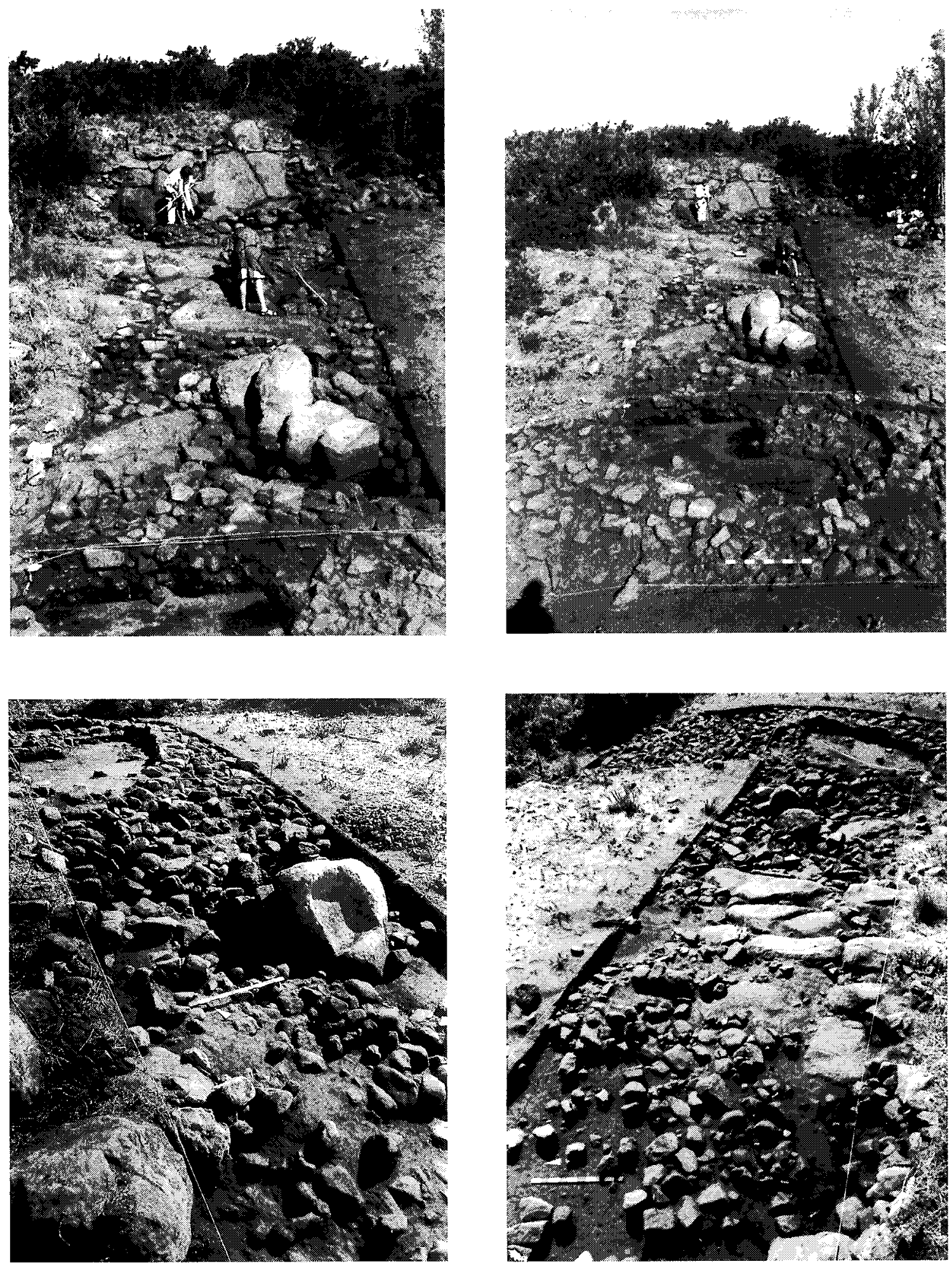

Lám. 4. Los cortes I y II, a corte II hacia el noroeste, b corte I hacia el nordeste, c corte II hacia el sureste. 


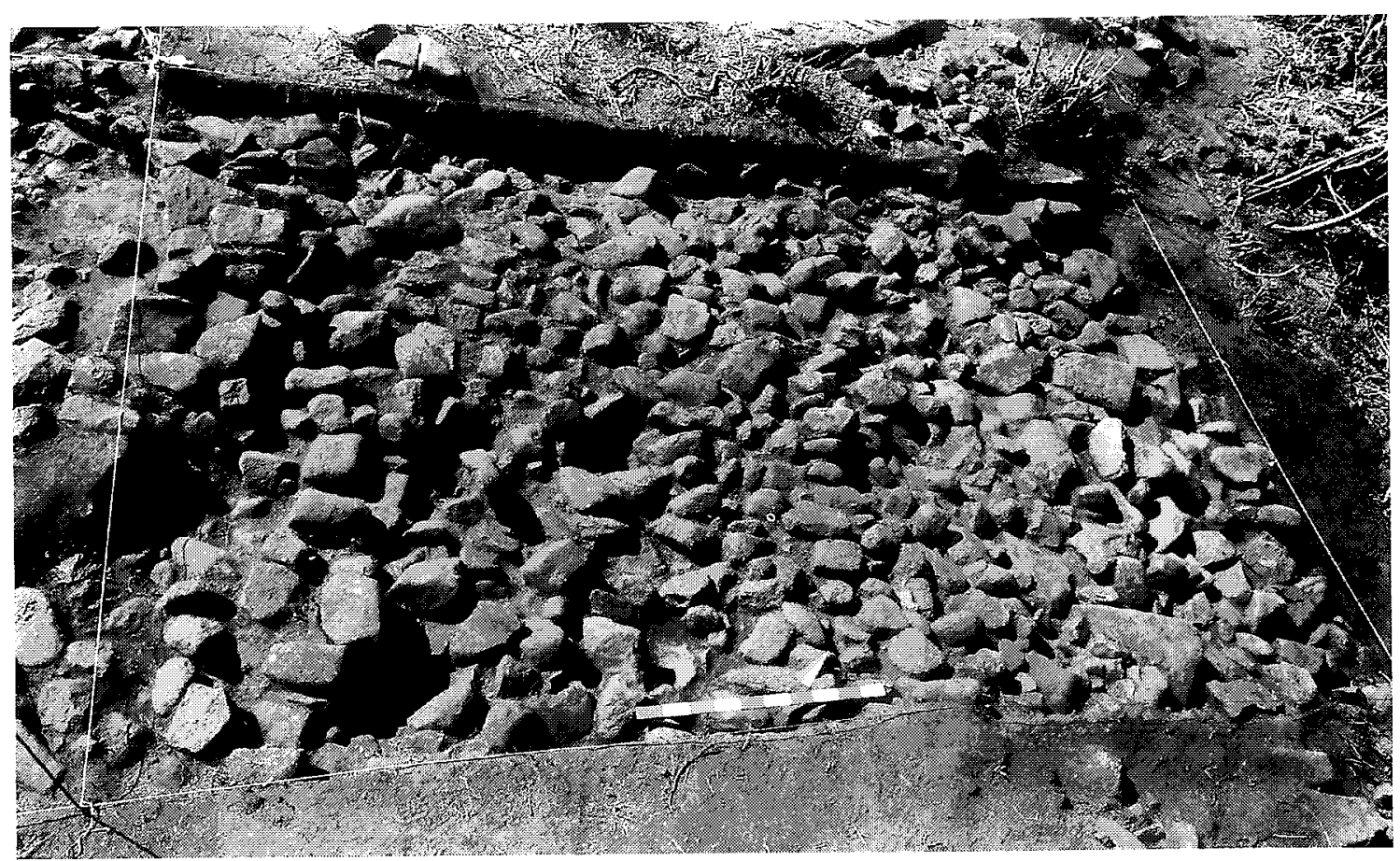

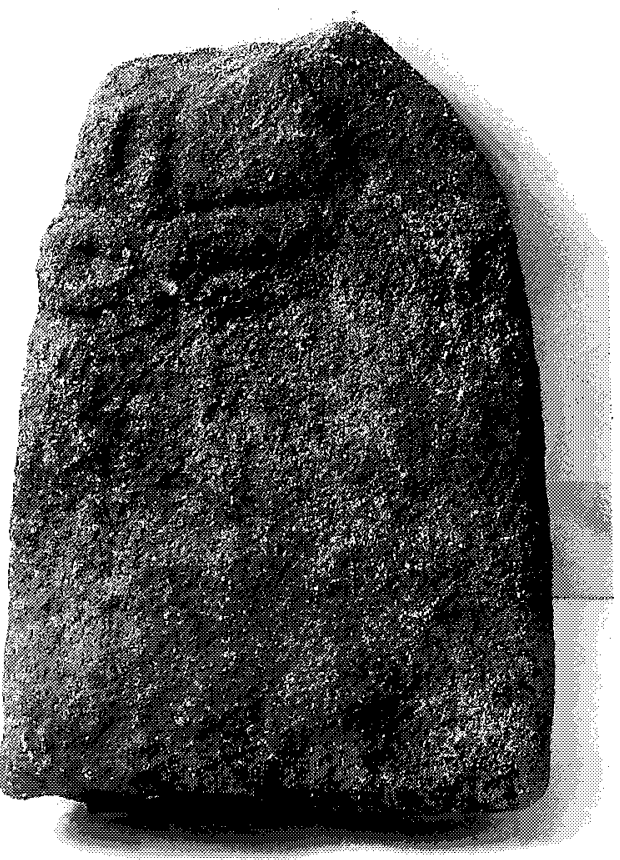

洅

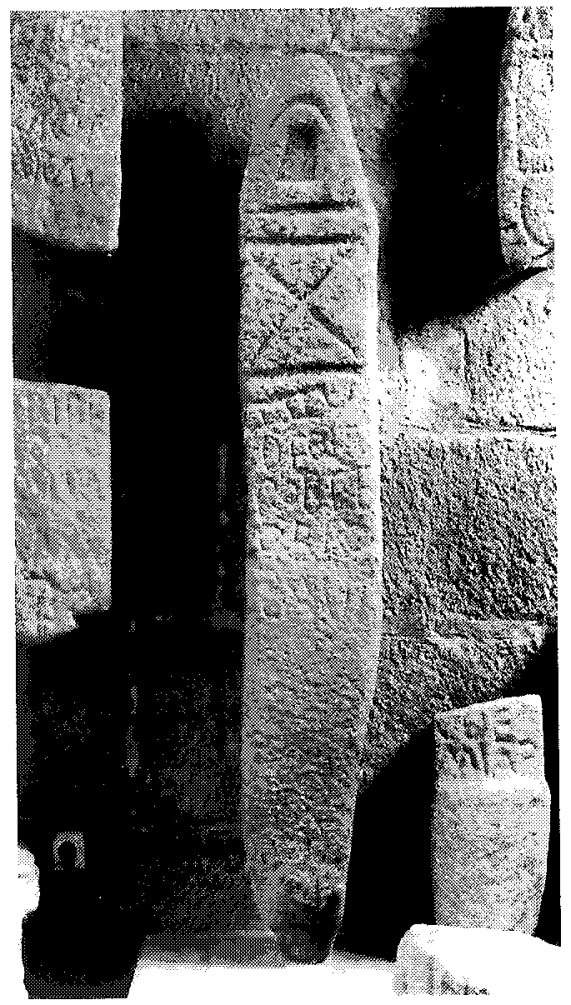

Lám 5. a corte Ia hacia NE, b altar votivo no concluido a49, c altar votivo del Monte Facho en torno al Museo de Pontevedra. 

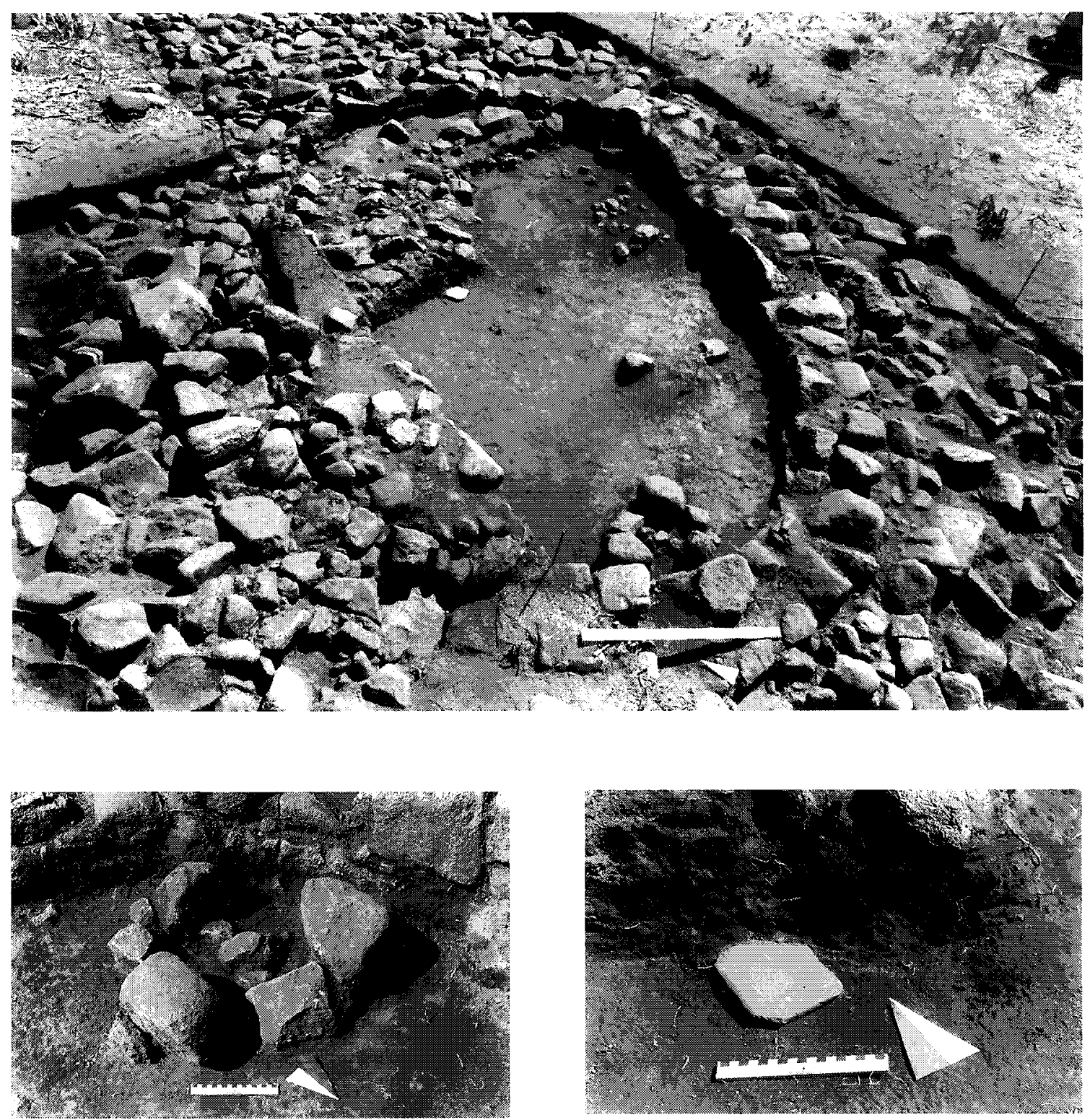

Lám. 6. a construcción oval desde el oeste, b ubicación 1, c piedra de afilar en el estado en el que se halló.

La construcción oval de la sección Ib se encuentra en el punto más alto de la depresión orográfica. Se trata del nivel 3 (Fig. 2. 3.) Algunos segmentos aislados de los muros con forma curvilínea podían verse en la superficie y estaban cubiertos sólo en parte por la capa de hierba. Tal como mostraron las excavaciones, aún se conservan dos capas de piedra de los muros externos (Lám. 6a). Los muros son de dos caras (Fig. 5). No se determinó la existencia de muros transversales que dividieran el recinto interior, por lo que se trata de una casa de una sola estancia. La capa de piedra inferior está compues- ta por piedras menudas del tamaño de un puño y la capa superior está formada principalmente por piedras del tamaño de una cabeza o incluso mayores. El material utilizado procede exclusivamente de bloques de piedra sin labrar. Los bloques de piedra sin labrar de la capa superior se distinguen por el hecho de que las piedras usadas entre las dos caras son más o menos triangulares y están siempre dispuestas de tal manera que su lado más largo mira hacia el lado exterior o, en otros casos, interior de la construcción oval, de manera que las piedras colindantes llegan a tocarse por los extre- 


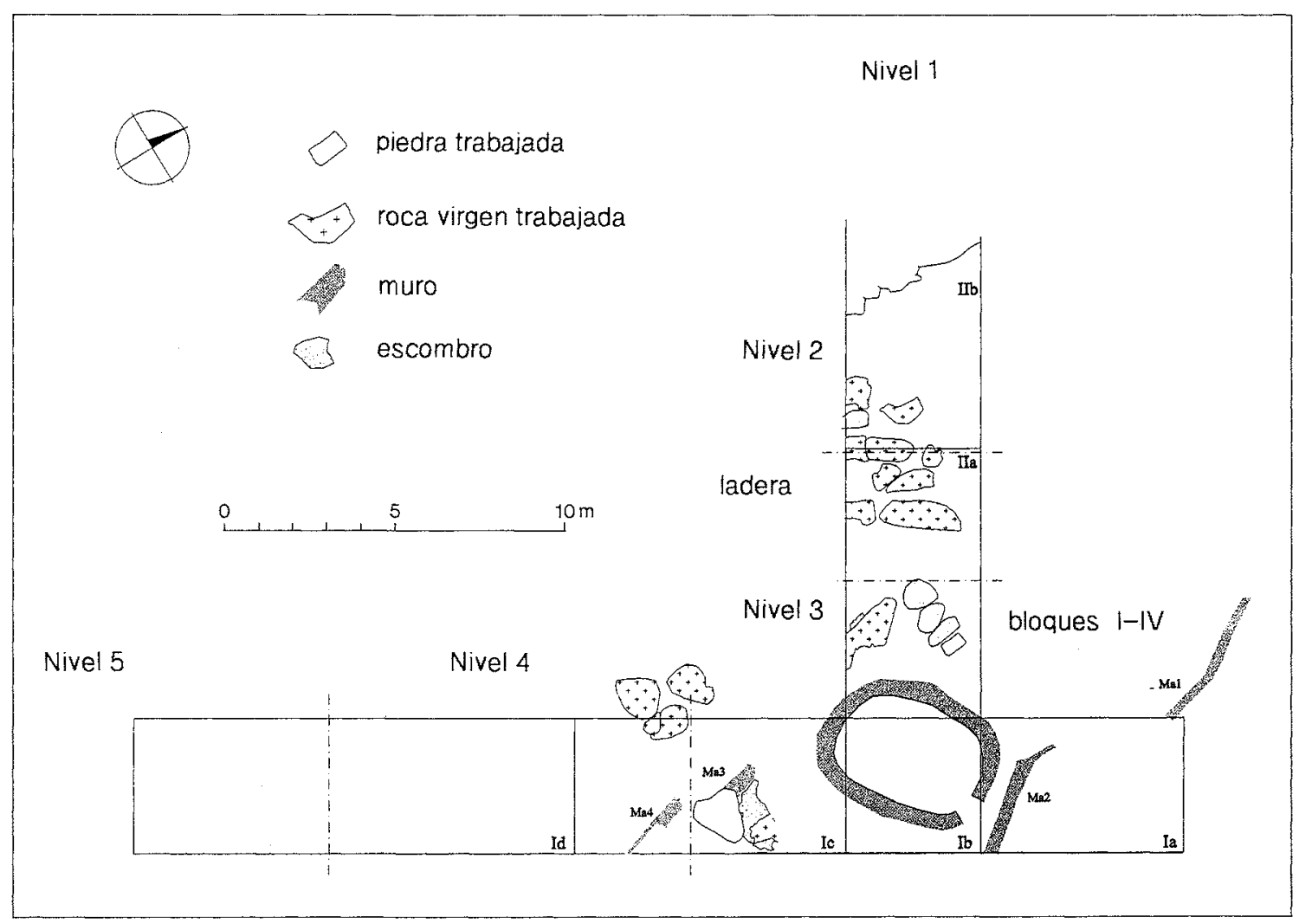

Fig. 2. Monte do Facho. Cortes I y II. E 1:250.

mos ${ }^{42}$. Este tipo de colocación hace que en los extremos de las piedras vayan apareciendo cuñas con tierra en su interior. Parece importante el hecho de que las piedras no presenten una forma curva como el edificio mismo, sino que conservaran los cantos rectos del corte inicial; lo que significa que no fueron redondeadas ex professo para su disposición en la construcción oval. Una de las diferencias entre las capas del muro es que la capa exterior contiene un mayor número de piedras de mayor tamaño que su homónima del interior. Los muros tienen un grosor de unos $50 \mathrm{~cm}$, algo habitual en la arquitectura castreña $^{43}$. El edificio oval alcanza una longitud máxima de 5,5 m (SO-NE) por fuera, y de $4,5 \mathrm{~m}$ por dentro.

En la parte correspondiente al interior del edificio se procedió a excavar unos $50 \mathrm{~cm}$ hasta llegar al primer horizonte de nivel de suelo que se encon-

42 Sobre la construcción mural en la arquitectura castreña v. F. López Cuevillas op.cit. 127 y sigs.; A. Romero Masiá, El hábitat castreño. Asentamientos y arquitectura de los castros del N. O. Peninsular (1976) 76 y sigs.

${ }^{43}$ Ibid. 75. tró ${ }^{44}$. El perfil norte (Fig. 6) que se tomó a lo largo del límite con el corte II muestra la siguiente disposición de capas:

Capa $l$ - hierba con humus gris suelto y con derrumbe en su interior.

Capa 2 - suelo con humus negro y fértil, con raíces y con abundante derrumbe de piedras de gran tamaño.

Capa 3 - tierra marrón con piedras más pequenas; esta capa no se encuentra horizontalmente en la superficie sino que está ligeramente hundida en la mitad del edificio, originando una forma de hondonada llana en el plano.

Capa 4 - horizonte de barro de un color marrón claro amarillento que, en algunas áreas, especialmente a lo largo del muro de la casa oval, muestra indicios de haber sido alisado. Teniendo en cuenta que en el Monte do Facho no es normal que haya barro, dicho material debió de ser transportado desde otro lugar. Se trata sin duda del suelo de un edificio.

${ }^{44}$ Quizás se encuentren nuevos horizontes de nivel de suelo por debajo, si bien, de momento, no es posible afirmar nada al respecto. 
Nivel 1

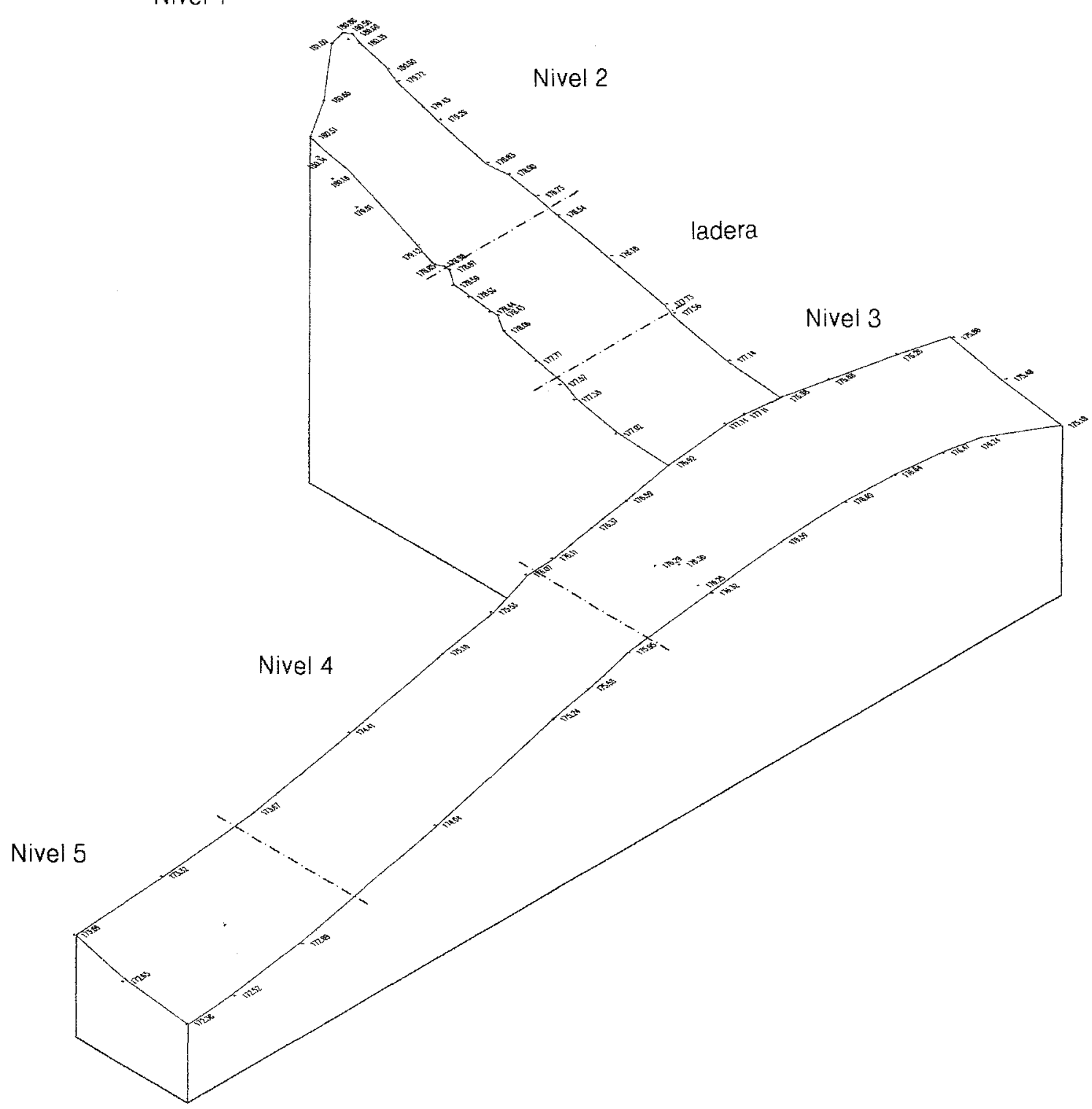

Fig. 3. Monte do Facho. Representación espacial de Ios cortes I y II.

Hay posibles pequeñas estructuras ( 1 1 y $\mathrm{S} 2$ ) en dos puntos de la casa oval, ambos cerca de los muros. La primera, al oeste, (Lám. 6b) está compuesta por dos piedras del tamaño de una cabeza y otras dos del tamaño de una mano. Al estar entrecruzadas forman más o menos un cuadrado (aprox. $58 \times 53$ $\mathrm{cm})$. En su interior se encuentran tres piedras colocadas en una fila y del tamaño de un puño. Las piedras del exterior que componen esta fila están formadas por los dos tipos de piedras del tamaño de una mano que comentábamos al principio. Debido a la manera uniforme en como están dispuestas, pare- ce ser que se trata de una construcción intencionada, aunque seguimos sin saber a ciencia cierta para qué estaría concebida. Todos los componentes de esta construcción se encuentran en la zona de tierra de color marrón claro (capa 3), sobre el horizonte de nivel de suelo (capa 4), sin estar pues en su interior. Desde un punto de vista cronológico, pertenecen entonces a la fase de utilidad del horizonte de nivel de suelo y no a su fase de construcción.

La situación es muy similar en la estructura S2 más al oeste, que también está incluida en la capa de tierra marrón (capa 3). Por lo tanto, ambas ubicacio- 


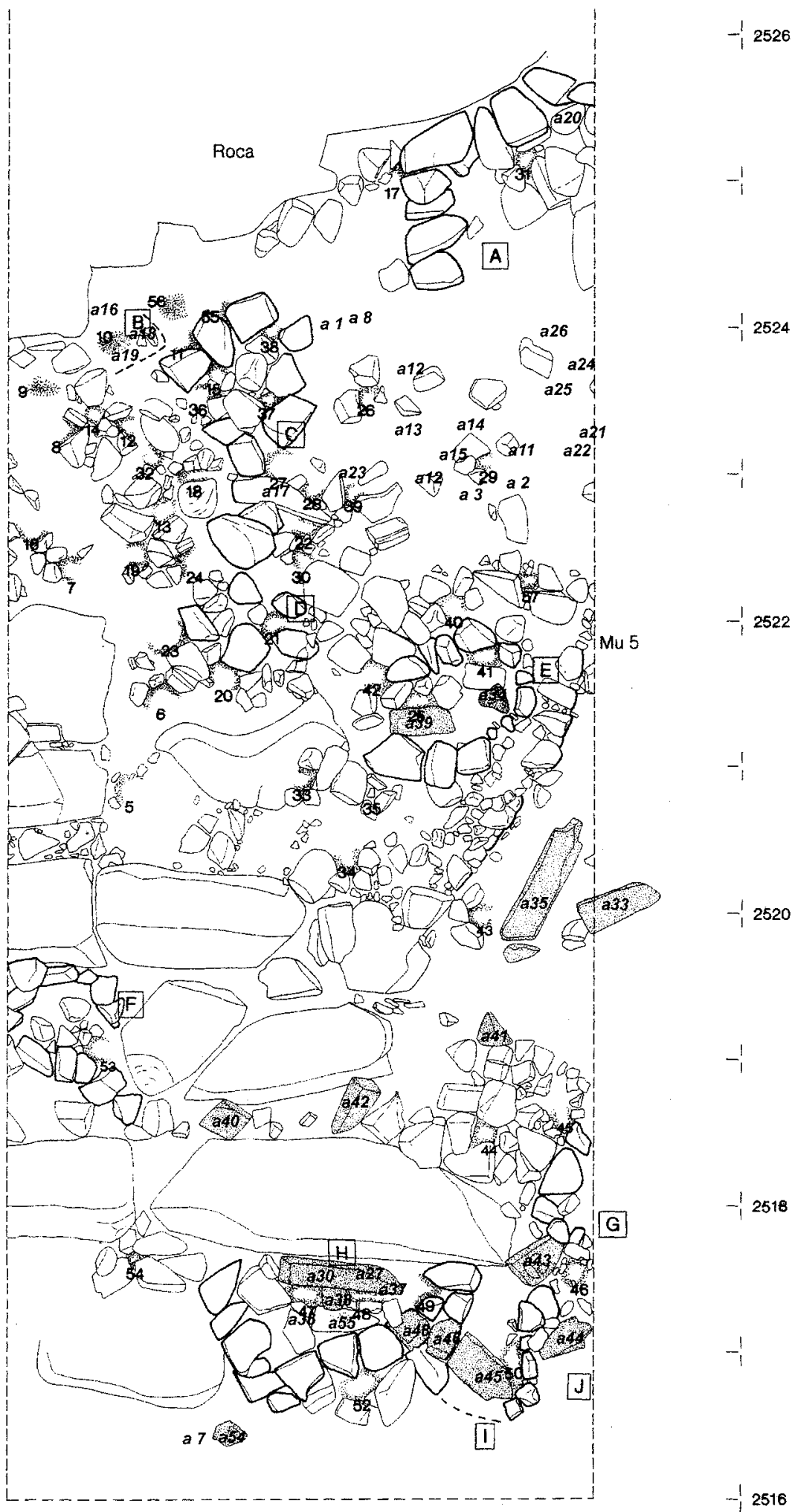

Fig. 4. Monte do Facho. Corte Ilb. Plano de piedras. E 1:50. 


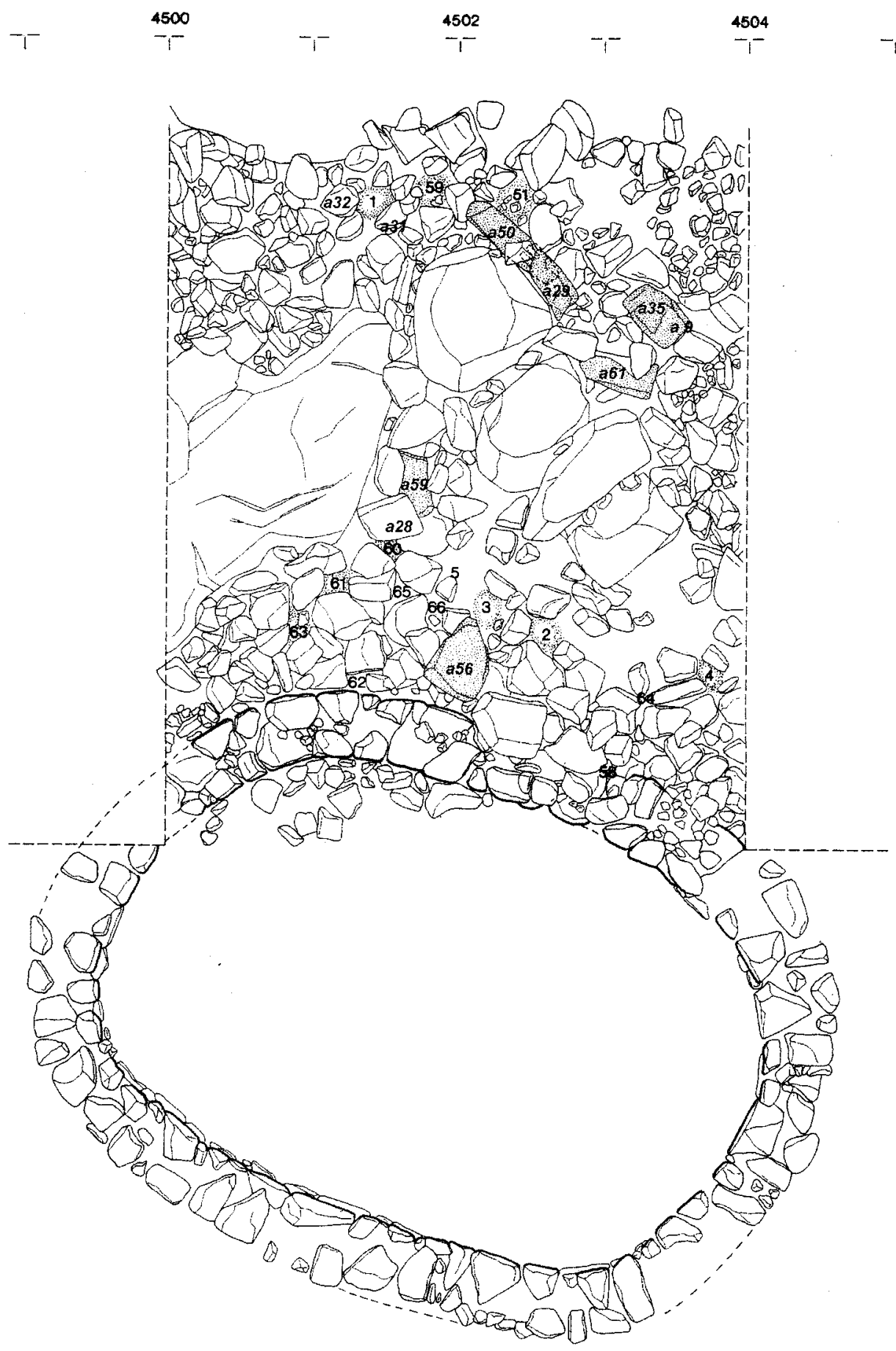

$-1$

$-\frac{1}{1} 2516$

$-2514$

$-1$

$-12512$

$-12510$

$-1$

$-$

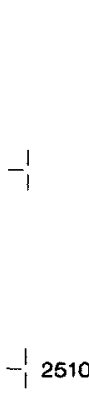

$-1$

Fig. 5. Monte do Facho. Corte IIa con la construcción oval. Plano de piedras. E 1:50. 


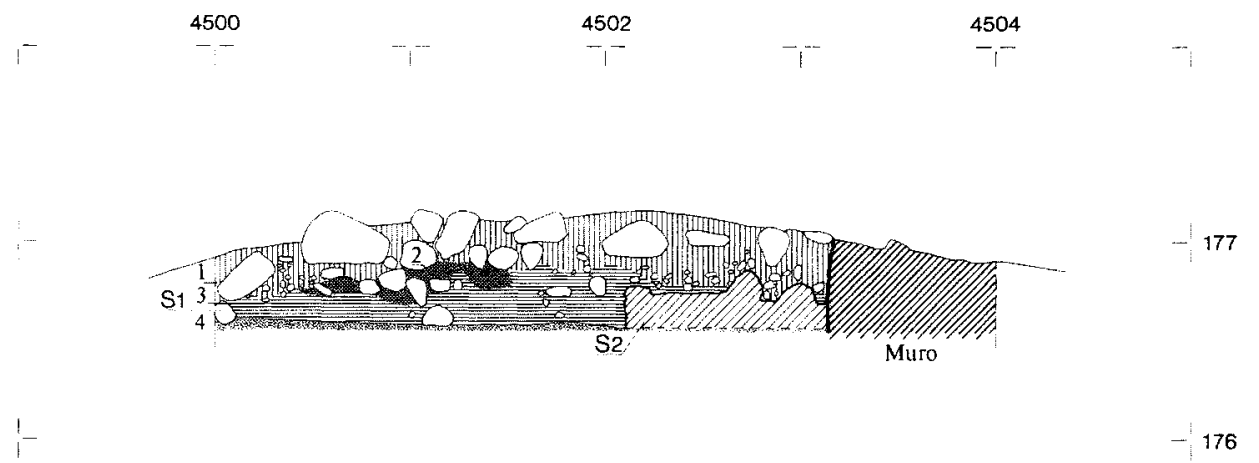

Fig. 6. Monte do Facho. Corte IIa. Perfil norte a través de la construcción oval. E 1:50.

nes son anteriores a la capa 3 y pertenecen a la misma fase de uso del horizonte de nivel de suelo. Faltan indicios para suponer la existencia de más fases de uso. El final de esta fase de uso viene dado por la datación de la capa 3. El hecho de que su superficie presente una forma ondulada y no alisada horizontalmente indica que no se trata ya de un suelo de la casa oval, sino que expresa la fase más temprana de su abandono. La superficie con ondulaciones irregulares del suelo probablemente sea producto del efecto erosionador del viento y la lluvia. Lo que significa que la casa oval fue abandonada después de su uso y a partir de ese punto empezaría a quedar en ruinas de manera paulatina. Prueba de ello es el hecho de que las piedras que formaban la casa oval cayeron al mismo tiempo que se iban conformando las tres capas 1, 2 y 3 (Fig. 6), e integrándose en ellas.

La estructura 2 tiene una forma redondeada-ovalada (con una extensión de unos $100 \mathrm{~cm}$ norte-sur y $60 \mathrm{~cm}$ este-oeste) y, durante las tareas de excavación, no destacó excesivamente por la calidad de la construcción. Sí en cambio a raíz de la observación estratigráfica descrita (Lám. 6a). En esta ubicación se encontraron cenizas y partículas de carbón de madera en algunos puntos y, si bien podría considerarse un uso ocasional como hogar, en este momento sería preferible dejar abiertas otras posibilidades.

Las observaciones estratigráficas descritas permiten distinguir tres fases:

Fase 3. Abandono y ruina del edificio (capas 1 , 2 y 3)

Fase 2. Uso del horizonte de nivel de suelo (capa 4)

Fase 1. Creación del horizonte de nivel de suelo (capa 4)

Los hallazgos, especialmente las monedas, aportan información sobre la exacta ubicación cronológica en el tiempo: un marco temporal más preciso dentro de los siglos III y IV d.C. para las capas 1 a 3 .
Únicamente en la capa 4 no apareció ninguna mone$\mathrm{da}^{45}$, aunque cabe destacar que en esa misma capa se encontró un fragmento de bronce en el suelo, así como una piedra de afilar (Lám. 6c). El resto de material hallado abarca desde una época castreña relativamente antigua hasta inicios de la Galaico-romana (s. v a.C. hasta s. II d.C.), con un especial peso de la Fase tardía de la cultura castreña (ca. s. i a.C.s. I d.C.).

Durante los trabajos de excavación en el interior de la casa oval se encontraron trozos de barro cocido excepto en la capa 1 (Fig. 6. 12b, lám. 6b), que debido al color rosado adquirido no podrían formar parte del suelo mencionado anteriormente, ya que éste estaba formado por barro amarillento-marrón claro y estaba intacto en ese punto. Podemos descartar que fueran restos de muros de barro por dos motivos. En primer lugar los muros del edificio parecen haber estado formados en su totalidad por piedra, tal y como se deduce del gran derrumbe en el corte 1 . En segundo lugar se encontraron muy pocos trozos de barro como para suponer que los muros eran de dicho material, ya que, de haber sido así, se habría debido encontrar barro (diluido o en pedazos) en mayor cantidad. A ello hay que añadir que los pedazos de barro no presentaban en ningún momento huellas de paja ni de ningún otro material utilizado en la arquitectura castreña para la construcción de muros de barro ${ }^{46}$. Por tales motivos, es probable que los pedazos formaran parte del enfoscado ${ }^{47}$. A par-

${ }^{45}$ v. III. Las excavaciones. Otros hallazgos.

${ }^{46}$ López Cuevillas op.cit. 122 con referencias a hallazgos del castro de Palmou en Deza y del castro de San Mamede en Paradela; Romero op.cit. 52 con más ejemplos.

${ }^{47}$ El enfoscado mural es un atributo técnico y, por consiguiente, atemporal. Aparece a menudo en la arquitectura circular y oval de la Hispania central, las pruebas van desde la Edad de Bronce hasta la Época romana, véase a modo de resumen ibid. 122 y sigs.; A. García y Bellido, Revista de Guimarães $81,1971,25$ y siguientes. con ejemplos de la Edad de Bronce de Orce (prov. Granada) y romanos de Monte Berno- 


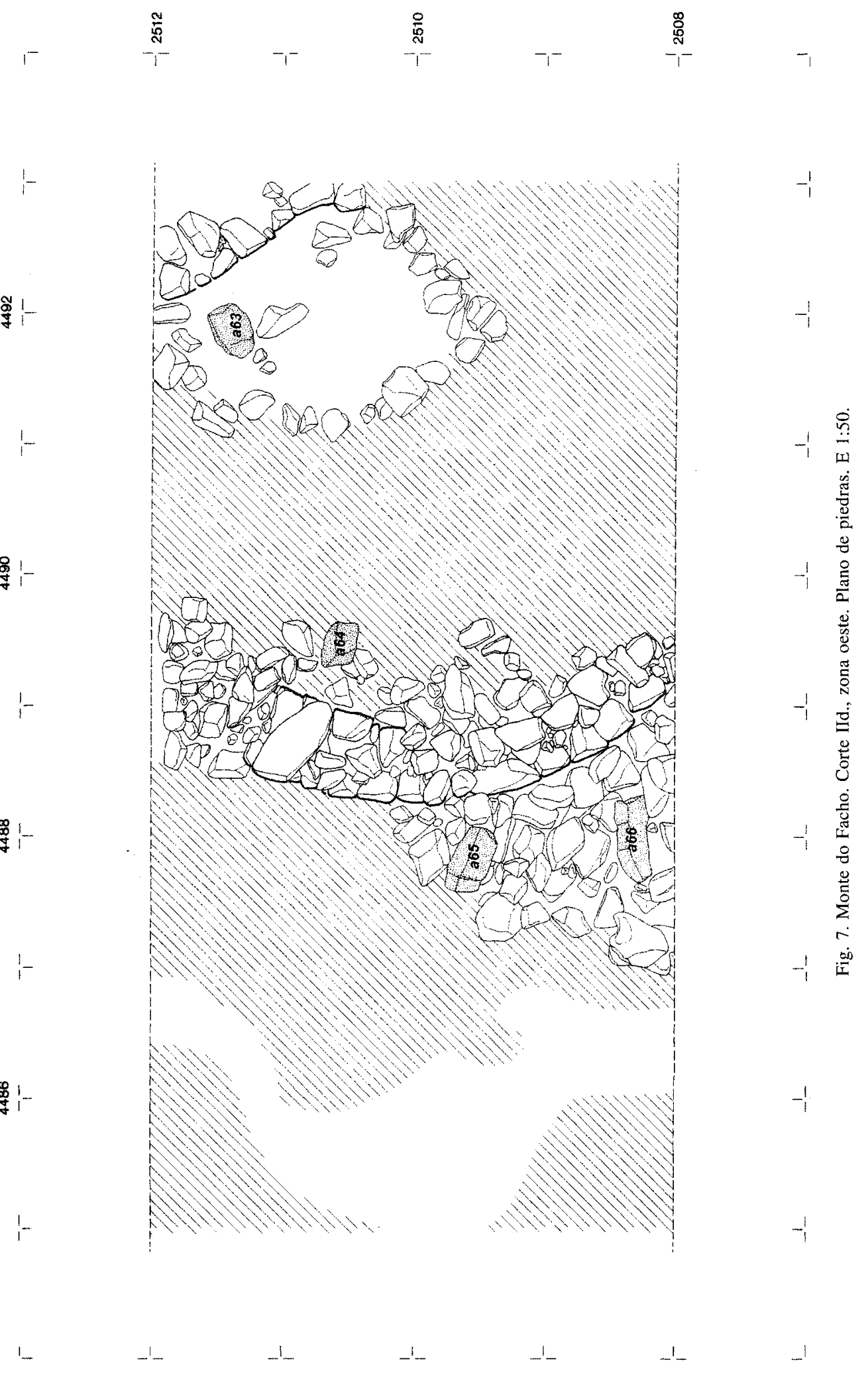


tir del estado de los hallazgos en tres de las cuatro capas observadas (v. abajo Fig. 12b) resulta un nuevo argumento para el lento proceso de ruinización que se dedujo anteriormente: los pedazos de barro tuvieron que ir cayendo desde los muros al nivel del suelo correspondiente. Por otra parte, es posible que el tejado estuviera compuesto de paja ${ }^{48}$, puesto que no se encontró ningún fragmento antiguo de teja ${ }^{49}$.

En la superficie del corte Ic aparece una curiosa piedra con evidencias de haber sido trabajada (Fig. 2, lám. 4b. 7a). Se trata de un bloque de granito, material existente en el lugar, de unos $1,9 \mathrm{~m}$ de largo, 1,4 m de ancho y $1 \mathrm{~m}$ de alto, cuya posición parece evidenciar que está volcado ${ }^{50}$. En la cara superior, la que a partir de la posición horizontal originaria pasó a adoptar una posición torcida (ángulo aprox. $45^{\circ}$ ), la piedra ha sido ahuecada hasta adoptar una forma de cuenco, con huellas evidentes de haber sido trabajada son evidentes, siendo descartable la erosión como causa. Teniendo en cuenta que esa piedra se encuentra en un santuario (véase abajo), es probable que se trate de una piedra de sacrificio (lacus). Tal como muestran las huellas correspondientes, fue partida mediante cuñas y fue seguramente durante ese proceso cuando fue volcada.

Al volcarse, el lacus quedó en parte sobre un muro orientado al norte (Ma3). El muro Ma3 es de dos caras, tiene unos $50 \mathrm{~cm}$ de grosor y está compuesto por bloques de granito del tamaño de una cabeza y menores (Lám. 7a). El granito es el típico de la región: de grano grueso y muy brillante. Entre el Ma3, el lacus y la roca se encontró un montón de escombros, que desenterramos hasta llegar al borde inferior del lacus. Se trata de una pequeña superficie de unos $1,4 \times 1 \mathrm{~m}$ que contenía muchos pedazos de cerámica y piedras del tamaño de un puño, de

rio (prov. Palencia). En la arquitectura castreña del noroeste hispánico, el enfoscado con barro no era nada frecuente, $v$. Romero, op. cit. 78 .

${ }^{48}$ Se trata de un hallazgo típico de la arquitectura castreña, v. López Cuevillas op.cit. 123; Romero, op. cit. 50.

49 Todas las tejas halladas en el yacimiento son recientes y podrían haber formado parte de viviendas edificadas en la cima de la montaña - en la que se conservan restos de muro que encajarían- en el transcurso de la construcción de la atalaya en el siglo XVII.

${ }^{\text {so }} \mathrm{Se}$ obtuvieron restos orgánicos a partir de un orificio que había salido a la luz en la pared del lacus mismo. Fueron enviados al Dr. Neef del departamento de Eurasia del Instituto Arqueológico Alemán en Berlín, a quien agradecemos las informaciones proporcionadas a raíz del análisis. Parece ser que se trata de una madera no carbonizada, aunque en tal mal estado que resultó imposible llegar ninguna otra conclusión. Estaba prácticamente desmenuzada. Según palabras del Dr. Neef, el material no está carbonizado, aunque mezclado con raíces recientes. Separarlas resultaría muy difícil, ya que cualquier impureza modificaría el resultado de la datación y se obtendría una fecha demasiado reciente. formas generalmente puntiagudas. Todo ello en un suelo de arena y barro. Los pedazos de cerámica son hasta ahora prácticamente los únicos de una época castreña relativamente antigua: Fase Media, siglos IV-II a.C. Los cascajos no prosiguen al oeste y sur del lacus. Por lo tanto, es evidente que se trata de un hallazgo puntual (Fig. 2). Una explicación plausible es que se trata de los cimientos para el cambio de posición del lacus que resultaron revueltos a causa de la busca de tesoros. Si hubiera sido éste el caso, podríamos fijar un terminus post quem en el s. IV-II a.C.

Al sudoeste del lacus hay otro muro (Ma4) que encaja, tanto en la técnica como en la anchura, con el muro descrito anteriormente, sobre el que, recordemos, descansa el lacus. La orientación de ambos muros es, además, idéntica, por lo que podemos suponer una relación entre ellos. Si bien las excavaciones no han podido aportar pruebas definitivas sobre la existencia de tal relación, pues el muro se halla destruido en el extremo final norte en cuestión. En el caso de haber formado parte de un mismo muro, en ese punto debería haber existido un resalte, ya que ambos muros no siguen una línea recta (Fig. 2).

En conjunto, el corte Ic muestra claramente menos derrumbe de piedras (Lám. 4b) que el corte Ia (Lám. 5a), de lo que se deduce que la mayor parte de la masa de piedras de la casa oval cayó principalmente sobre el corte Ia, es decir, hacia el sudoeste.

Al retirar la capa de hierba del corte Id salieron a la luz nuevos altares (inv. a58,a57,a63, a64, a65 und $a 66$ ), bajo los cuales encontramos huellas en el terreno de al menos dos casas más, bien circulares u ovales (Fig. 7). De una de ellas se pudo determinar la puerta de entrada. En el extremo sudoeste del corte apareció un suelo muy parecido al de la casa oval, construido con barro amarillento que, como describimos anteriormente, tuvo que ser traído expresamente desde otro lugar.

\section{Corte II}

Con una extensión de $4 \mathrm{~m}$ de ancho y $14 \mathrm{~m}$ de largo el corte sobre el nivel 3 se extiende hasta alcanzar el nivel 2 (Fig. 4.5, lám. 4a). Las secciones a $\mathrm{y} b$ están delimitadas por la frontera entre la superficie plana (corte IIb) y la pendiente (corte IIa) (Fig. 2.3). Aquí vemos bloques de roca dispuestos de manera escalonada y con superficies gastadas (Lám. 4a.c). Se trata de bloques de roca alargados (L 150$250 \mathrm{~cm}$, An $60-70 \mathrm{~cm}$ ), formados por el granito de grano grueso y con alto contenido de mica que se encuentra en todo el terreno, que sobresalen hasta 

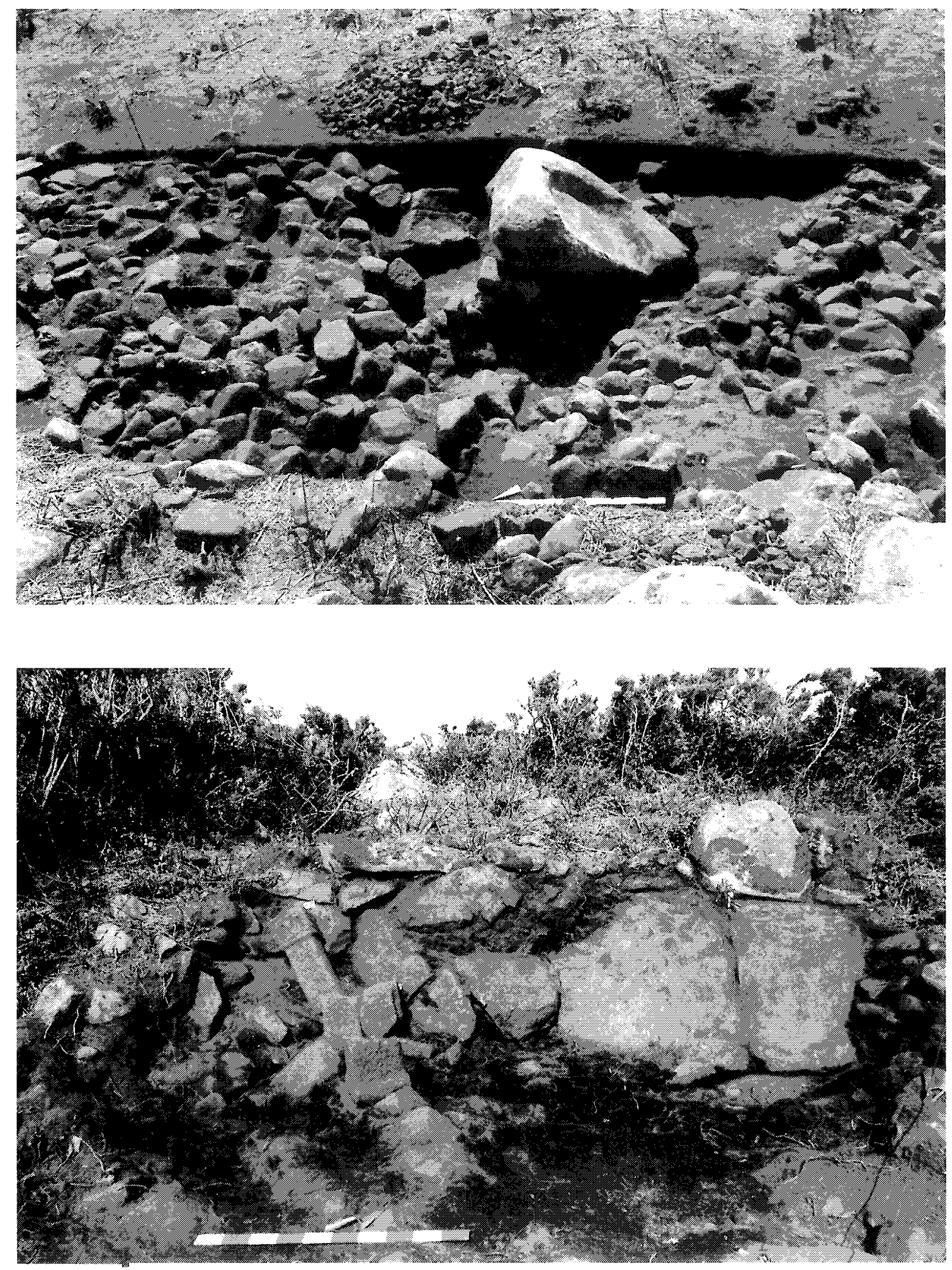

Lám. 7. a locus de lado, b muro de piedra en el corte Ilb. 
medio metro del suelo, formando escalones por el lado de la ladera. En todos ellos se pueden observar huellas de haber sufrido desgaste, con grandes diferencias entre sí. Son especialmente evidentes en los bloques de roca del corte IIa, en los que encontramos huellas del desgaste en los cantos superiores, tanto en el lado de la ladera como en el de la cima. Según nos comentaron los habitantes del pueblo, allí antes había un camino que llevaba hasta la meseta en lo alto de la cumbre. Lo que explicaría las huellas del desgaste, que asimismo podrían tener su origen en la Antiguiedad, pues toda esa zona había sido utilizado en dicha época.

El corte linda en su parte noroccidental con un muro de granito de la altura de una persona formado por dos bloques de roca. Éste origina un salto en el terreno que separa la terraza 1 de la 2 (Fig. 2.3 tabla $7 \mathrm{~b}$ ). Sobre esa pared de roca se encuentra un muro formado en parte por bloques que ya era visible en el terreno con anterioridad a las excavaciones. Prosigue hacia el SO. En este punto (del SO) el muro está sostenido por una colección de piedras singulares, éstas a su vez compuestas por bloques de piedra sin labrar algo mayores que una cabeza, de los que resulta difícil determinar su función, debido a que las piedras de la horizontal dan la impresión de haber resbalado o de haber sido cambiadas de sitio, si bien son capaces de aguantar en esa posición inestable. Es posible que se trate de un muro desmoronado. Parece como si los bloques se hubieran acuñado en su posición de caída o de inclinación de tal manera que son capaces de aguantar los restos del muro sobre ellos. Este conjunto de piedras requiere ser examinado más a fondo.

En el lado de la ladera justo delante de este muro caído se encontró el altar al6 in situ (Lám. 7b). Su base se inclinó y cayó junto con la cabeza cúbica contra el muro derrumbado. Teniendo en cuenta que en ese momento el muro ya se habría derrumbado, resulta un terminus ante quem que puede fijarse mediante la datación del altar al6.

En el transcurso de las excavaciones el muro de roca fue despejado hasta el horizonte de nivel de suelo correspondiente al pie del mismo. La roca muestra huellas de desgaste por todos lados, de manera que la superficie lisa actual, ligeramente inclinada y que, por consiguiente, parece que esté casi en posición vertical, fue creada ex professo.

Con anterioridad al inicio de las excavaciones toda la zona de la sección IIb hasta los bloques de roca colindantes fue invadido por un derrumbe de bloques de piedra sin labrar, del tamaño de una cabeza y mayores, cuyo recorrido pasaba por delante del muro de piedra y se alargaba en dirección su- roeste (Lám. $7 b$ ). Se trata de piedras sin labrar del granito ya visto antes: gris, de grano grueso y con un elevado contenido en mica. El derrumbe se vuelve más plano al ir descendiendo en cota, por lo que tuvo que ser ésa la dirección del mismo. Una vez retiradas la capa de hierba y las piedras del derrumbe que la cubrían, toda una serie de altares salió a la luz (Lám. 8a). El hallazgo se repitió en la sección IIa, en la que sólo fue necesario retirar la capa de hierba (Fig. 5, Lám. 8bc). La tierra que se hallaba bajo la capa de hierba estaba compuesta por un suelo de humus negro y denso de la misma consistencia y calidad que la del corte I (Fig. 6, capa 2). También contenía piedras del derrumbe. El suelo de humus negro presentaba continuamente partículas de madera quemada no necesariamente pertenecientes a la época antigua, ya que, desde hace algunos años, el Monte do Facho ha sufrido numerosos incendios en la época estival ${ }^{51}$. Junto a algunos hallazgos de la época actual como tapaderas de latas y objetos por el estilo encontrados en la superficie, cabe destacar otros hallazgos recientes y de fácil datación encontrados en la capa negra, así como tres pedazos de vidrio pertenecientes a la época de la garita ubicada en la cima del monte (s. XVIII) ${ }^{52}$. Todos ellos fueron encontrados justo en el pie del muro de roca. Al lado, dispersos por todo el corte y en la parte superior de la capa de tierra negra, se encontraron pedazos sin decorar procedentes de la mencionada ocupación con fines militares del monte que se produjo durante el s. XVIII y primera mitad del s. XIX.

En la parte oeste del corte IIb se procedió a despejar un muro (Ma5) orientado hacia el noroeste (Fig. 4, Lám. 4c). Es de dos caras, está compuesto por bloques de granito sin labrar, presenta una forma curva, de manera que se abre hacia el oeste. Mide exactamente $2,5 \mathrm{~m}$ de largo, mientras que la anchura, a medida que se acerca al lado de la ladera, va aumentando de 30 a $45 \mathrm{~cm}$. La cara del noreste está formada por piedras de aproximadamente el

${ }^{51}$ Parte del detritus con buena consistencia fue analizado en el Consejo de Ciencias de la sede del Instituto Alemán de Arqueología por el Dr. R.Neef, quien lo clasificó como fresno común o de hoja estrecha (Fraxinus excelsior/angustifolia). Este árbol crece principalmente en suelo húmedo, un tipo de suelo que abunda en el noroeste de España (notificación R. Neef; véase asimismo Enciclopedia Universal Ilustrada Europeo-Americana 24, 1973 (1978) 1255 s. v. fresno). Con el fin de realizar una datación con C14, la muestra fue entregada a un laboratorio. Durante la elaboración del presente informa aún no contamos con los resultados obtenidos por dicho laboratorio. El detritus, en este caso a base de carbón vegetal, proviene de la capa negra ubicada entre la ubicación $\mathrm{n}^{\circ} 29$ y el borde de corte norte (Fig. 4)

${ }^{52}$ Comunicación oral de F. Fariña/Orense. 

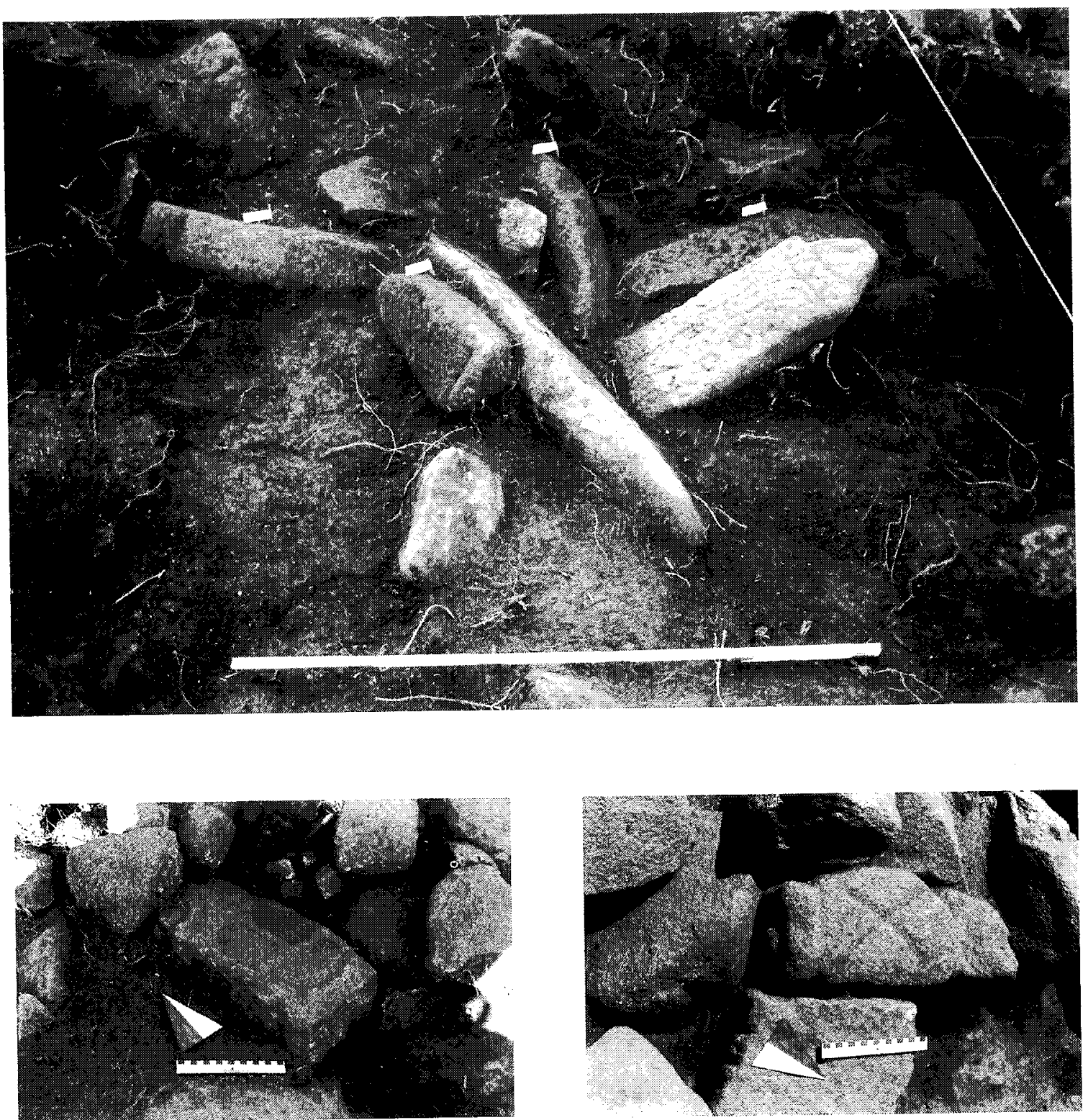

Lám. 8. a altares en estado original en corte IIb, bc altares en estado original en corte IIa.

tamaño de una cabeza, mientras que las de la cara interior del suroeste son más pequeñas, más o menos como un puño. El material aglomerante utilizado es mortero hecho a base de tierra. Al final del lado de la cima el muro no acaba de forma irregular. Al contrario: está edificado contra una piedra colocada transversalmente que, al ser suficientemente larga, abarca toda la anchura del muro (tizón). Parece que en este punto el muro sufre una interrupción, lo que indicaría la existencia de una puerta o salida. En el lado de la ladera, la cara exterior del muro acaba en un gran bloque de piedra, que a su vez limita con los bloques de roca descritos anteriormente. La cara exterior está levemente curvada. La del interior, en cambio, muestra una curvatura más pronunciada. Parece ser que las piedras de esta cara, en la parte de dicho bloque de piedra, están puestas formando un ángulo abierto en dirección a los bloques de roca ${ }^{53}$. Es imaginable una reconstrucción en la que el muro

${ }^{53}$ El hallazgo todavía no puede ser juzgado de manera definitiva ya que la excavación posterior a la liberación hasta un nivel de aproximadamente unos $20 \mathrm{~cm}$ por debajo de la corona (conservada) del muro no siguió siendo excavada hasta alcanzar una mayor profundidad. 

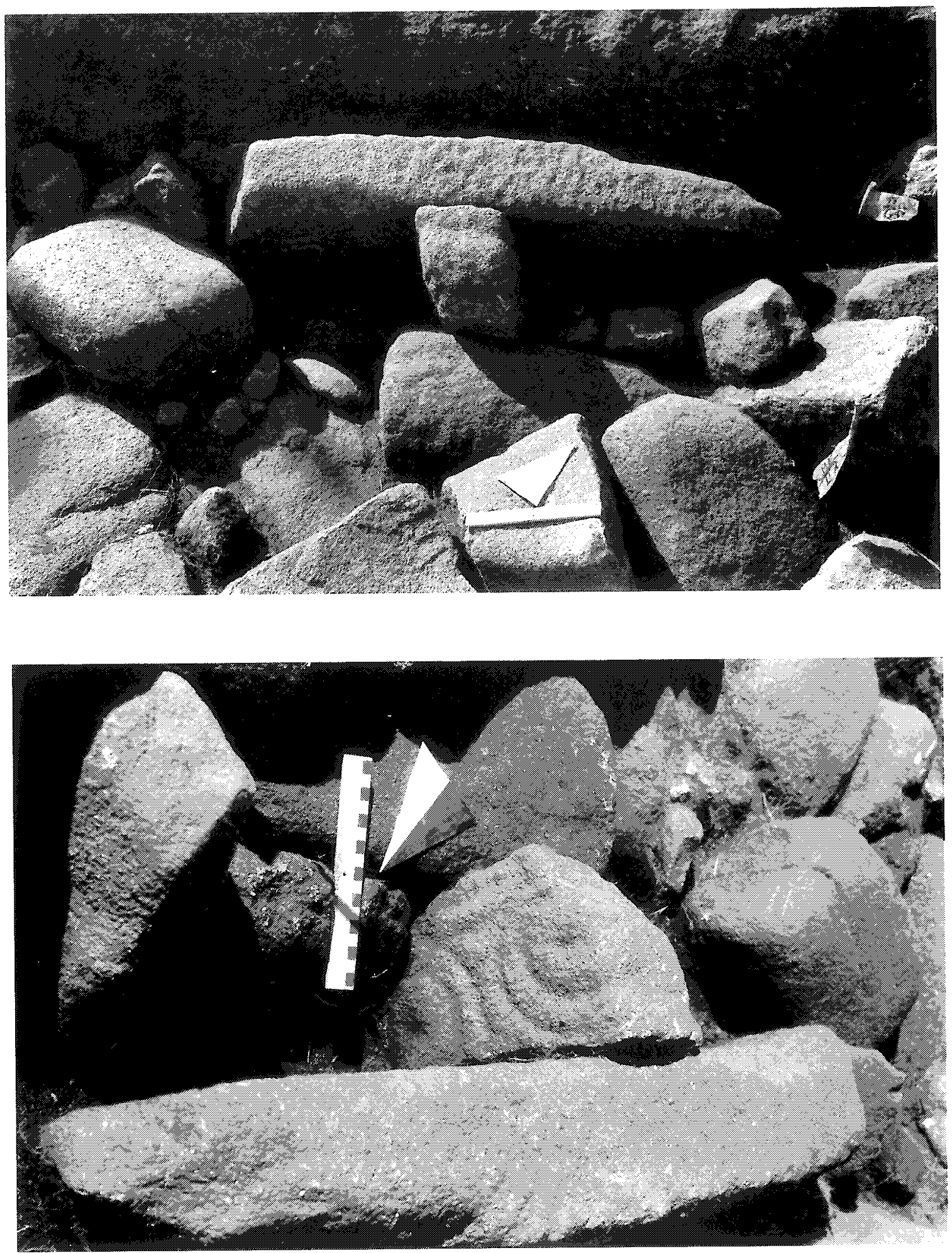

Lám. 9. reutilización de altares. 

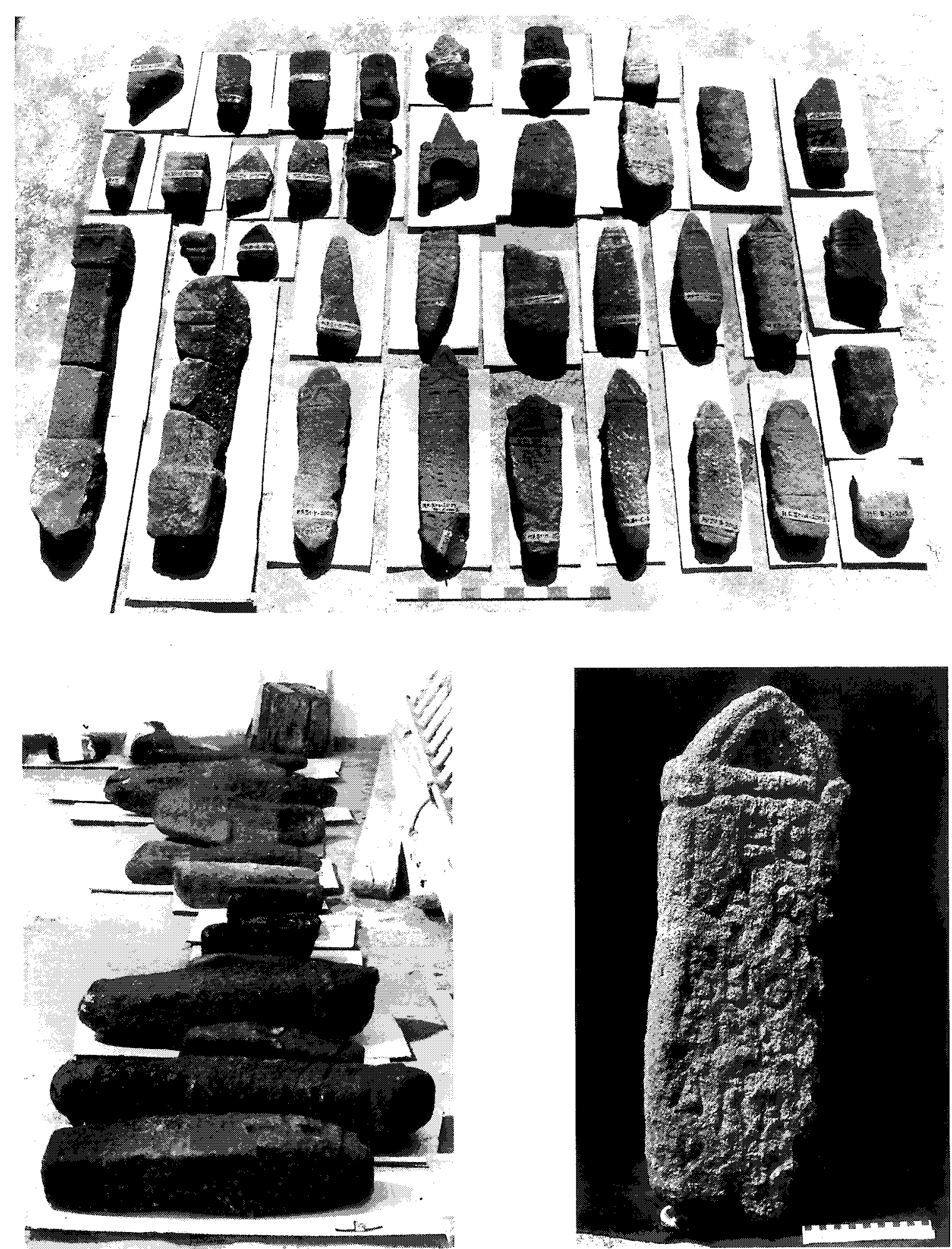

Lám. 10. ab una gran parte de los nuevos altares votivos encontrados d, c altar votivo all. 
prosiguiera más allá de los bloques de roca. A pesar de que no se observaron indicios de huecos en los bloques de roca, sería posible que las huellas del desgaste de los bloques de roca tuvieran algo que ver con la construcción del muro. En este momento sería preferible no pronunciarse definitivamente sobre cuál sería realmente la función del muro. Sin embargo, sí que podríamos descartar algunas funciones concretas. No puede tratarse de un muro de terraza: primero, porque el muro es de dos caras y, segundo, porque no discurre de forma paralela a la pendiente. También cabe descartar un uso profano, teniendo en cuenta los hallazgos encontrados hasta ahora en la sección IIb.

\section{B. Hallazgos y resultados: Los altares votivos, las ubicaciones, los recintos}

En el transcurso de la campaña se encontraron 57 altares en el yacimiento, la mayoría (40 piezas) en la zona del corte II, concretamente 22 en la sección IIb, (Fig. 4.5, lám. 10ab) ${ }^{54}$. En el Monte do Facho ya se habían hallado cuarenta y dos altares con anterioridad ${ }^{55}$, por lo que, a priori, podía preverse la existencia de algún que otro altar más. Aun así, resultó sorprendente el gran número de hallazgos de ese tipo, altares - arae según las inscripcionesdedicados al dios Berobreo. Por eso consideramos pertinente la denominación de altar votivo ${ }^{56}$.

Los altares votivos destacan por el magnífico buen estado de conservación. Una parte importante (17 piezas) está intacta, incluso los que no están enteros presentan unos fragmentos restantes de gran tamaño, a menudo aparece un único punto de fractura, y en algunos casos se encontraron fragmentos de los que encajaban muy cerca el uno del otro, por lo que ya al poco tiempo de haber comenzado las excavaciones, empezamos a sospechar que los altares, de haber sido desplazados, no podían haber sido movidos de sitio muy lejos y que probablemente estaban situados en el mismo lugar. Surgió la certeza ya cuando encontramos muchos de los altares en posición inclinada (Lám. 8a). Dado que se encuentran bajo el derrumbe del que hablábamos más arriba ${ }^{57}$, no pertenecen a la masa de piedras derrumbadas que los cubren.

El altar a16, que fue hallado en su lugar, aportó el primer indicio inequívoco sobre el emplazamien-

\footnotetext{
${ }^{54}$ En el presente informe, los altares están indicados en cursiva, siguen una numeración continua y van precedidos de una $a$, e.g.: $a 23$.

55 v. Historia de la investigación.

${ }^{56}$ v. cap. IV Epigrafía de los altares.

57 v. Los cortes II y II.
}

to original (Lám. 7b). Tal como se mostró, su pie en forma de hincón ${ }^{58}$ se había introducido en la tierra. Para ello se había excavado un hoyo cuyo tamaño era tan sólo un poco mayor que las dimensiones del pie, pero que en profundidad alcanzaba el horizonte marrón amarillento subyacente, dejando una pequeña oquedad de forma redonda-ovalada y coloración oscura en la superficie de ese nivel (Fig. 4, n. ${ }^{\circ} 10$, tabla 11a). La mitad inferior de la base de piedra estaba en su posición original, mientras que la mitad superior estaba separada por fractura y había caído contra el muro desmoronado (Lám. 7b). El punto de fractura se encuentra aproximadamente a media altura del altar (Lám. 12abc), por lo que los recortes debieron de suceder una vez el muro ya se había desmoronado. La conclusión surge a partir de otra reflexión: pues si el altar ya hubiera estado asentado, podría suponerse que cuando el muro se desmoronó también el altar hubiera sufrido las consecuencias, ya que la distancia entre ambos es muy reducida: unos $20 \mathrm{~cm}$. Sin embargo, en tal caso hubiera caído hacia el este y no - como realmente sucedió - hacia el oeste, contra el muro desmoronado.

Justo en el noreste de la parte inferior del altar a16 se encontró un fragmento de otro altar (a19) colocado como pieza reutilizada de manera paralela a la pendiente (Fig. 4). De ahí se originó un ángulo recto entre al6 y al9. En la parte oeste de delante había el fragmento de otro altar (al8) - también una pieza reutilizada. Tal como se vio con posterioridad, los fragmentos a18 y a19 pertenecen a un mismo altar, el cual, junto con otro fragmento más (a17) encontrado unos pocos metros más abajo (Fig. 4), se conserva completo ${ }^{59}$. Los fragmentos al8 y a19 estaban desplazados de manera ordenada, con sus lados superiores alineados horizontalmente.

Una vez despejado el desmoronamiento de piedras y excavada la capa negra, apareció en la superficie de la sección IIb una serie de piedras cuyos tamaños oscilaban entre el de una mano y una cabeza, y que a primera vista no parecían seguir ningún tipo de orden (plano de piedras Fig. 4). Aunque tal como se demostró más tarde, muchas de ellas seguían un orden intencionado. Cada agrupación de piedras (pocas) abarcaba una pequeña superficie, en su totalidad o sólo una parte de la misma. Entre las piedras de mayor tamaño aparecen a menudo otras más pequeñas en posición vertical. Aquí empleamos el término «ubicación» para nombrar el conjunto formado por pequeñas su-

\footnotetext{
${ }^{58}$ Referente al término «pie en forma de hincón», introducido en otro contexto, v. autor MM 44, 2003, 131 (grupo 7). 134.

${ }^{59}$ El altar, conservado en su totalidad, puede verse en la tabla 10a, fila de abajo, segundo por la izquierda.
} 

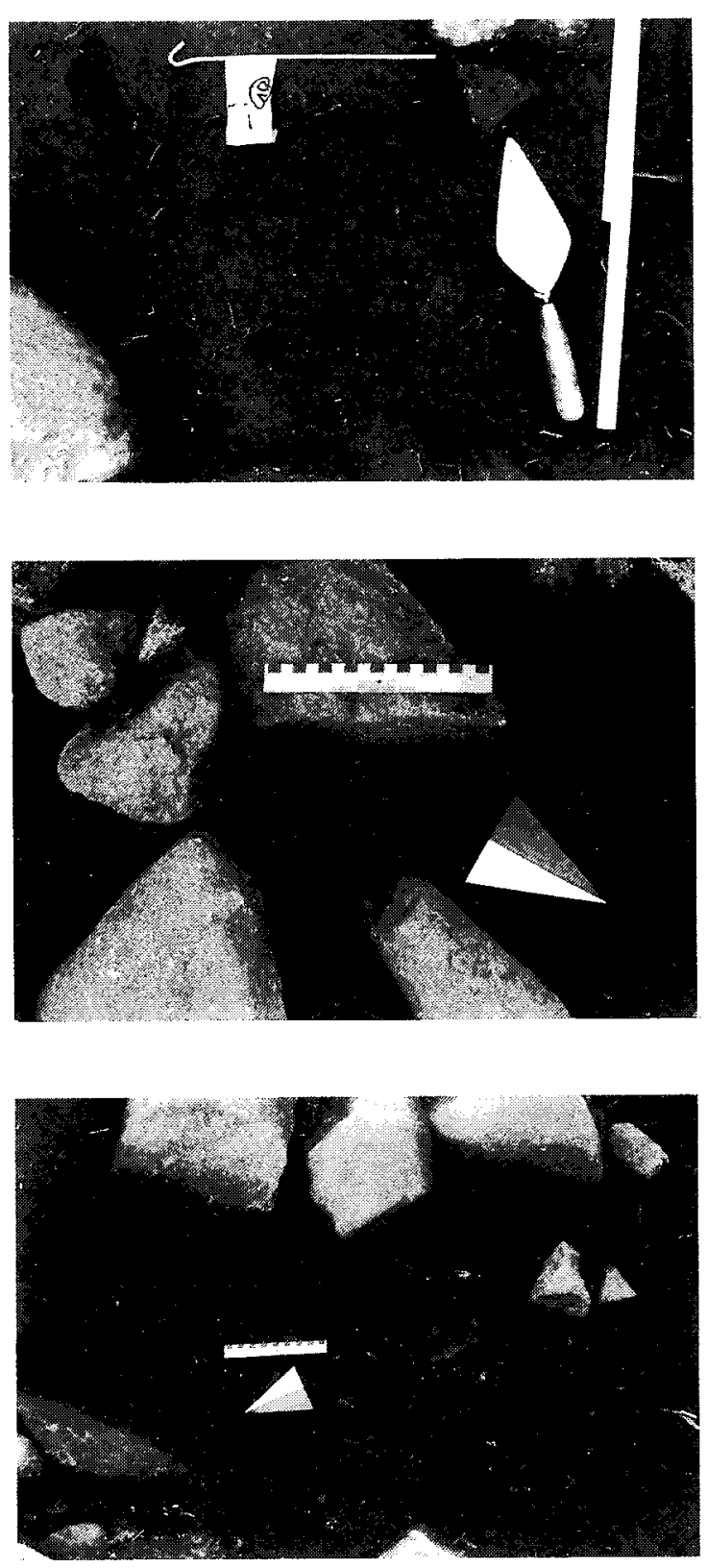

Lám. 11. a coloración de la tierra como indicio dejado por el altar $a 16$, b coloración de la tierra y ubicación de piedras Nr. 39.

perficies con las piedras que las rodean, término en el que profundizaremos más adelante ${ }^{60}$.

Finalmente se observó una cambio de color en un terreno que rodeaban piedras ordenadas de manera que formaban círculos entre sí (ubicación nº 39, Fig. 4, Lám. 11b). Del suelo formado por tierra marrón

${ }^{60}$ Las ubicaciones siguen una numeración continua $\left(\mathrm{n}^{\circ} 1\right.$ 66) y están resumidas en la tabla de la Fig. 10. oscuro destacaba muy marcadamente una superficie trapezoide de tierra más bien negra. Al lado se encontraba un altar votivo volcado $(a 23)^{61}$, conservado a la perfección (Lám. 13ab), motivo por el cual no pudo haber sido desplazado y, por lo tanto, seguramente pertenecería a esa ubicación. Es posible que se encontrara en el centro de dicha ubicación. Es probable que hubiera sido enterrado y que, con ayuda de las piedras existentes y otras piedras de menor tamaño de las que faltan, hubiera sido acuñado o volcado. Un argumento igualmente válido para establecer la conexión entre ubicación y altar votivo lo aportan la ubicación $n^{\circ} 43$ y el altar votivo $a 35$, encontrado justo al lado de la ubicación y que también se ha conservado perfectamente (Fig. 4).

Cabe añadir otras observaciones al respecto: $\mathrm{Se}$ encontraron pedazos de recipientes, en su mayor parte ánforas (ubicaciones n. ${ }^{\circ} 17.29 .31$ ) o vasos de vidrio (ubicaciones $n .^{\circ} 15.58$ ), aunque también piedras pequeñas (ubicaciones $\mathrm{n}^{\circ} 21.28 .35 .41 .46$ ), éstas a su vez en el centro de algunas de las ubicaciones. Tanto los pedazos como las piedras se encuentran por lo general en una posición horizontal. En la ubicación n. ${ }^{\circ} 17$ se encontró, además, el mango de bronce de un cuchillo.

Habida cuenta de todas estas observaciones, parece que la explicación es la siguiente: los pedazos y piedras, al estar situados en el centro de las ubicaciones, estuvieran señalizando el altar votivo, y sobre esas señalizaciones cabría reconstruir dicho altar. Para los pedazos, la denominación «pie» o bien «fragmento que sirve de base» sería la más acertada.

Si bien parece ser que el uso de piedras y pedazos de ánfora respondería principalmente a motivos técnicos, en cierto modo para construir un fundamento bajo el altar ${ }^{62}$, éste no sería el caso con los pedazos de vidrio ni con el mango de cuchillo. Los recipientes son pequeños y finos, el grosor de los pedazos es relativamente reducido, el cristal, por lo tanto, muy frágil. No podrían tener una explicación técnica. Parece más probable suponer que los recipientes de vidrio formaban parte del ritual llevado a cabo durante la colocación de los altares — quizás se hubiera realizado previamente una libación con el agua de un recipiente, luego éste hubiera sido depuesto en la ubicación y finalmente se hubiera colocado el altar encima. A favor de esta hipótesis habla el hecho de que en la ubicación $n .^{\circ} 15$ se conserva una cantidad bastante grande de pedazos de vidrio y,

${ }^{61}$ El plano de piedras (Fig. 4) y la foto (Lám. 11b) muestran los hallazgos una vez descubierto el altar.

${ }^{62}$ En el caso de la ubicación $n^{\circ} 37$, la piedra que sirve de base fue incluso acuñada expresamente, v. Fig 4 y tabla resumen Fig. 10. 

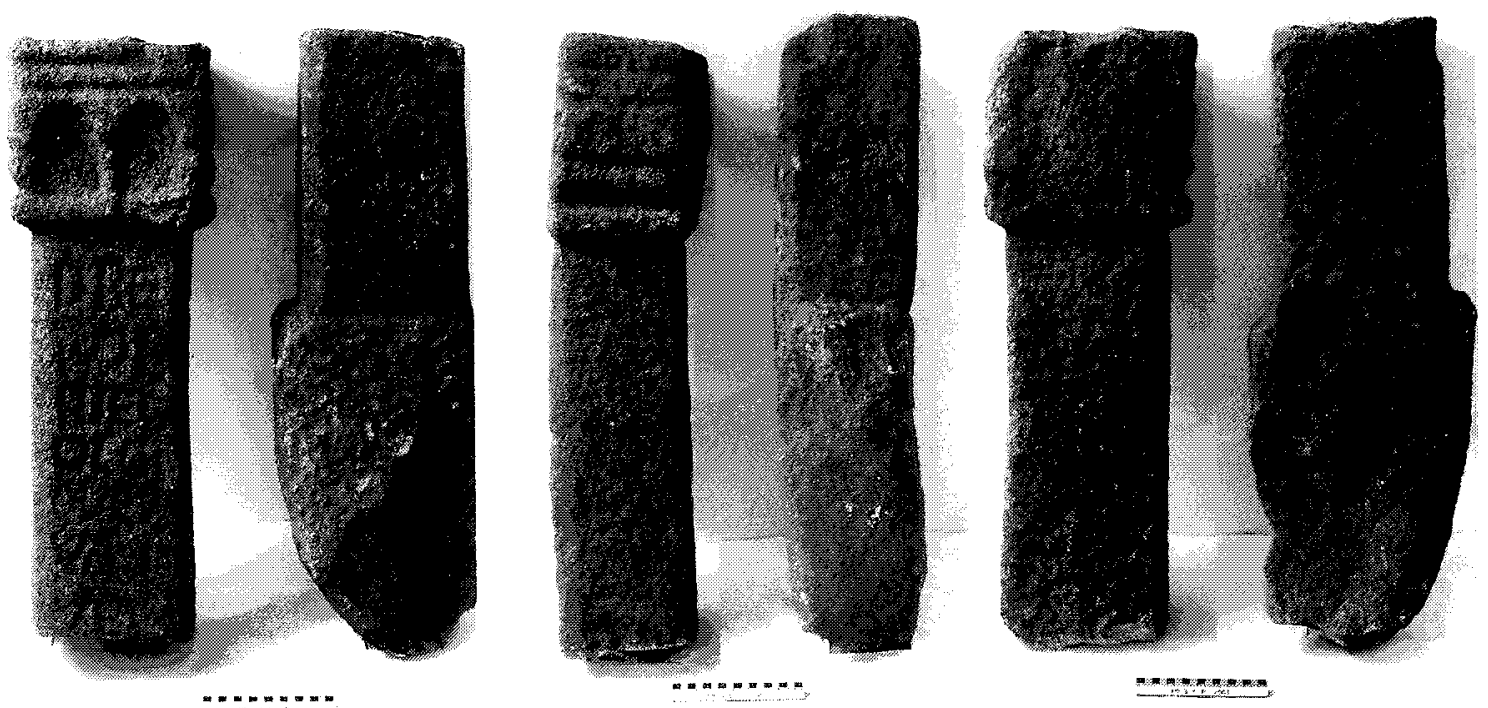

Lám. 12. abc altar votivo a16, de frente, de lado, por detrás.

por ende, el recipiente de vidrio fue colocado ahí intacto o bien en pedazos. Es posible que la reconstrucción y la restauración de los recipientes nos

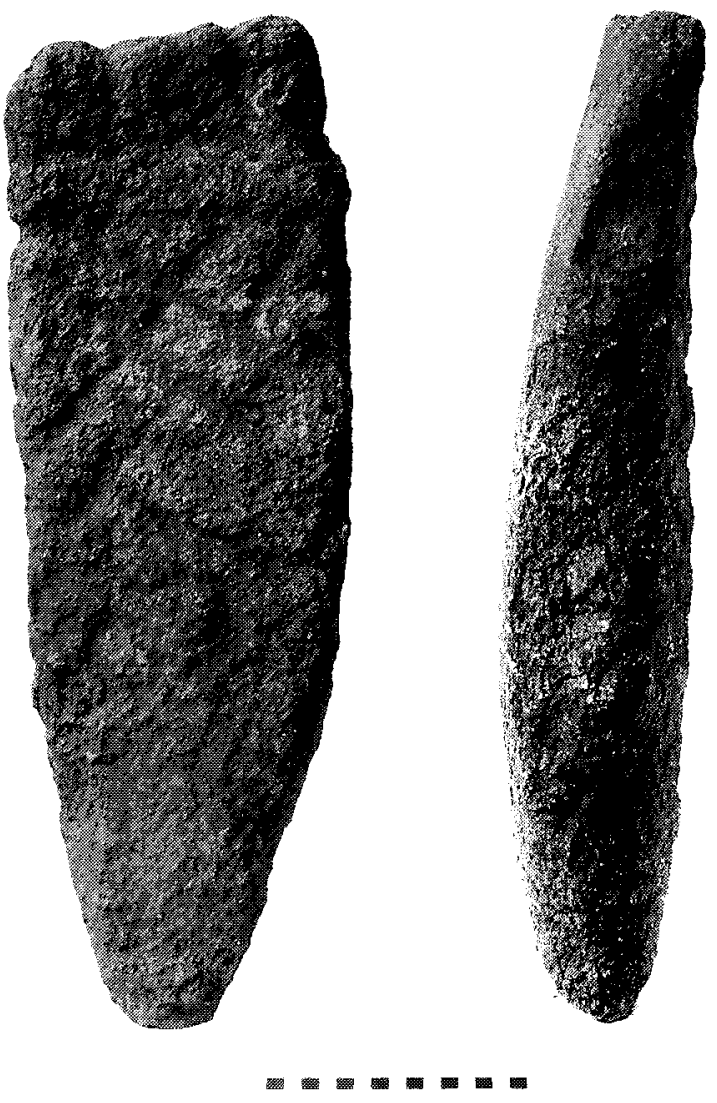

Lám. 13. ab altar votivo $a 23$, de frente, de lado, c. muestre finalmente que no fue depositado un único recipiente, sino un puñado de pedazos procedentes de recipientes distintos ${ }^{63}$. Aunque sólo fuera por los motivos de tipo técnico ya descritos, que son convincentes, no parece que la conclusión sea necesariamente que las piedras y los fragmentos de pies de ánforas, que sirven de base, estuvieran igualmente relacionados con algún tipo de culto. Para realizar afirmaciones que vayan más allá faltan argumentos. De los pies de ánforas y ánforas no se llegaron a encontrar restos mayores que un único pedazo de cada uno, pero en ningún caso un fragmento de mayor tamaño ni mucho menos toda una pieza entera. Del hecho que algunos de los altares fueron colocados encima de rocas cercanas de la zona, también se desprende que se buscaba un subsuelo compacto. Esto se deduce no sólo a partir de las ubicaciones encontradas en ese mismo lugar, sino a partir del hecho de que la roca fue trabajada pertinentemente para colocar el altar sobre ella (ubicación n. ${ }^{\circ} 33.53$. 60, Fig. 4. 5, v. también la tabla de la Fig. 10).

Parece interesante observar que en las ubicaciones se usaron piedras de un tono rojo claro, adquirido con la ayuda del fuego. Para éstas resulta imposible encontrar una explicación concluyente (ubicación n. ${ }^{\circ}$ 22. 27. 28. v. tabla Fig. 10). Al encontrarse sólo en unas pocas ubicaciones, resulta

${ }^{63}$ Entre el final de las excavaciones y la redacción del presente informa han transcurrido escasos meses, por lo que todavía no ha sido posible la reconstrucción y restauración de los recipientes de vidrio. Por ese mismo motivo no se ha podido decir nada sobre el estado de conservación de los recipientes en el momento en el que fueron depositados en la ubicación. 
evidente que las quemaduras no pudieron haber sido originadas por los incendios forestales, ya que, de ser así, todas las piedras de la zona presentarían marcas del incendio. Es posible, pues, que las piedras ya hubieran pasado por el fuego antes de ser reutilizadas en las ubicaciones. Aunque también cabe pensar en la posibilidad de que tuvieran algo que ver con algún tipo de ritual, como durante la ceremonia de libación, en la que el fuego también hubiera desempeñado algún papel. En ese caso, el uso del fuego en las ubicaciones no hubiera sido lo habitual, sino más bien algo excepcional. También puede considerarse una excepción el mango de bronce procedente de un cuchillo, encontrado en la ubicación $n .^{\circ} 17$, sobre todo si tenemos en cuenta que no ha sido posible determinar con exactitud su datación en la Antigüedad.

A partir de lo visto, todo apunta a que los altares votivos estaban en las ubicaciones. Si tenemos en cuenta que, según el ejemplo del altar $a 16$, los altares votivos también fueron fijados siendo introducidos en hoyos, los cuales a su vez en el transcurso de las excavaciones fueron reconocidos por la coloración del suelo, podemos aplicar el término por igual a estos últimos. Así pues, el término «ubicación» hace referencia al lugar en el que el altar votivo fue colocado, independientemente de la manera cómo esté fijado al terreno. Puede estarlo de dos maneras: bien introduciéndolo en el suelo, quedando como testimonio las coloraciones oscuras de la tierra, o bien acuñándolo o soportándolo con la ayuda de las piedras que se encontraron en las ubicaciones y que estaban colocadas de manera homóloga. Las cuales, por ese motivo, cumplen una función técnica. Tal como muestra la tabla resumen Fig. 10 sobre las ubicaciones y sus características, predomina el segundo tipo de fijación.

En ambos casos las partes inferiores, es decir, los pies de los altares están conformados ad hoc: Los altares que debían ser enterrados poseen un pie de forma prismática o similar (e.g. altar a16, Lám. 12); los que debían ser acuñados presentan un pie más o menos contraído sin forma especial (e.g. a23, Lám. 13ab). Algunas piezas destacan por carecer de pie diferenciado, es decir, que su parte inferior no acaba en forma cónica, sino en forma recta (e.g. Lám. 10a, tercera fila desde arriba, cuarto altar de la derecha).

Por lo general, ambos tipos de fijación son utilizados en la forma descrita. Sin embargo, en dos casos aparecen contaminaciones: las ubicaciones $n^{\circ} 8$ y 39 están enmarcadas por piedras y al mismo tiempo presentan coloraciones en la tierra, aunque claramente menores (en ningún caso el diámetro supera los de $10 \mathrm{~cm}$ ) que las coloraciones restantes, la ma- yoría de las cuales mide unos $20 \mathrm{~cm}$. Lo que significa que los altares no sólo fueron acuñados en estas dos ubicaciones, sino que también sus pies fueron introducidos un buen trozo en la tierra. Ésta puede ser por lo general una medida de tipo técnico, ya que de esta manera se consigue una mayor estabilidad. Aunque también podrían entrar en juego otros motivos particulares. Es posible que la inscripción fuera especialmente larga o con unas letras muy grandes cubriendo toda la superficie frontal del altar hasta llegar, incluso, a la parte que debía ser colocada bajo tierra (ejemplo altar a11, Lám. 10c). Así, para que el ara fuera legible en su totalidad es probable que sólo se utilizara una pequeña parte del pie del altar para anclarlo, necesitando entonces, además de ser enterrado, el refuerzo de su acuñación mediante piedras ${ }^{64}$.

Tal como muestra el plano de piedras Fig. 4 y 5 , no todas las piedras pueden asignarse a una ubicación. Sin embargo, una parte considerable de ellas fue colocada intencionalmente, tal como muestra su propia posición en el terreno y, otras veces, el orden alineado en el que se encuentran las piedras. Por lo general, formando un círculo, aunque también, mediante la formación de esquinas y cantos estas piedras abarcan superficies de un tamaño considerablemente mayor que las superficies de las ubicaciones, las cuales, una o más, se encuentran en el interior de esos círculos de piedras, participando, además, en la conformación de los mismos; esto último implica que las ubicaciones no están en el centro, sino en la periferia de estas estructuras de mayor tamaño. Esta situación parece afectar únicamente en aquellas ubicaciones formadas por círculos de piedras, pues hasta la fecha no se han observado ubicaciones de coloraciones en la tierra en este mismo contexto.

De todo ello se deduce que, en el caso de estos círculos de piedras, de mayor tamaño, no puede tratarse de ubicaciones. Por lo tanto, aquí reciben la denominación de «recintos». Su función primordial no es de tipo técnico. Se observó un total de diez recintos $(\mathrm{A}-\mathrm{J})^{65}$. Todos ellos se encuentran en el corte II, en la sección IIa y IIb, es decir, en la zona de la terraza 2 y de la pendiente al final (Fig. 2-4). Una muestra clara de ello es el hallazgo en los alrededores de la ubicación $n^{\circ} 31$ en la esquina norte del

${ }^{64}$ Una cuestión relacionada con este problema es la relativa al nivel de la superficie del terreno en la Antigüedad, la cual no pudo ser aclarada en esta campaña debido a falta de suficientes hallazgos.

${ }^{65}$ Cuestionable es el hallazgo en torno a la ubicación $n^{\circ}$ 20. Si bien no existe nada que pudiera indicar la existencia de un recinto, la roca en dirección a la bajada de la pendiente podría ser interpretada en ese sentido, ya que su superficie está trabajada. 


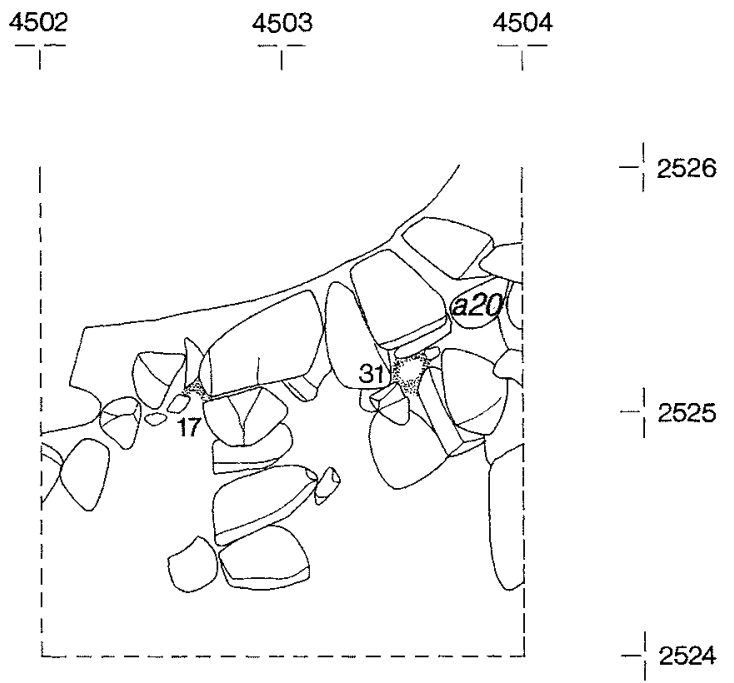

Fig. 8. Recinto en torno a la ubicación $n^{\circ} 31$ (detalle del plano de piedras Fig. 4)

plano Fig. 4, donde se encontró el fragmento de al$\operatorname{tar}$ a20. La Fig. 8 muestra dicho hallazgo.

En la parte oeste delante de la pared de roca se encuentra una fila de piedras que gira en ángulo casi recto continuando en dirección sur. Este lado del ángulo está compuesto de piedras cuyas caras externas están alineadas. Entre la última piedra del lado sur del ángulo y la ubicación en sí, la fila se interrumpe de manera que se forma una especie de apertura en el recinto, que podría corresponder al acceso a la ubicación. Se trata de un hallazgo ejemplar.

Respecto a la relación entre ubicación y recinto, cabe destacar que ni cada ubicación tiene un recinto ni, tal como muestra la tabla, cada recinto abarca una única ubicación. La siguiente tabla informa sobre la distribución de las ubicaciones respecto a los recintos, así como sobre los altares votivos hallados en su interior o en los confines inmediatos, siempre

\begin{tabular}{|c|c|c|}
\hline Recinto & Ubicación & Altares votivos \\
\hline A & $N^{\circ} 31$ & $a 20$ \\
\hline B & $\mathrm{N}^{\circ} 10$ & $a / 6$ \\
\hline C & $\mathrm{N}^{\circ} 15, \mathrm{~N}^{\circ} 36, \mathrm{~N}^{\circ} 37, \mathrm{~N}^{\circ} 38$ & \\
\hline D & $\mathrm{N}^{\circ} 21$ & \\
\hline E & $\mathrm{N}^{\circ} 25, \mathrm{~N}^{\circ} 41$ & $a 34, a 39$ \\
\hline F & $\mathrm{N}^{\circ} 53$ & \\
\hline G & no excavada & \\
\hline H & $\mathrm{N}^{\circ} 47, \mathrm{~N}^{\circ} 48, \mathrm{~N}^{\circ} 49$ & \\
\hline I & $\mathrm{N}^{0} 50$ & \\
\hline J & no excavada & \\
\hline
\end{tabular}

Fig. 9. Tabla resumen. Distribución de las ubicaciones respecto a los recintos. que no hayan sido piezas reutilizadas (sobre éstos, $\mathrm{v}$. tabla 10).

Tal como muestra la tabla, los recintos pueden contener una, dos, tres o incluso cuatro ubicaciones, sin seguir ninguna regla concreta. En estos momentos sería muy prematuro llegar a una conclusión sobre cuáles serían los motivos de esa distribución.

A excepción de a16, los altares votivos corresponden a piezas más o menos fragmentadas. A partir del estado en el que se encuentran es por tanto imposible poder establecer una conexión sin más entre el altar votivo y el recinto. Hasta el momento, sólo es posible para el altar al6, hallado en su lugar. Resulta complicado llegar a una conclusión sobre qué función tenían en este caso los fragmentos de altar a 18 y al9 que son piezas reutilizadas. Dada su dislocación y aparente colocación intencional podría tratarse de partes de recintos o ubicaciones. En estos casos, las piezas reutilizadas se encuentran a menudo como parte integrante de los recintos (v. tabla resumen Fig. 10) y siempre se trata de partes de altares reaprovechadas.

Debido a su forma cúbica, los altares reutilizados al8 y $a 19$ no se prestan a ser acuñados. En teoría, incluso podrían haber servido para sostener el altar a16. Si bien sería bastante improbable ya que el altar se inclinó sin que el pie hubiera sido desplazado mucho a raíz de la presión. Al contrario, cuando se encontró, el pie del altar se encontraba en posición perfectamente vertical respecto al suelo. A partir de lo cual se deduce que estaba anclado en el terreno, de manera estable y sin desplazarse. Así pues, no es posible reconocer una cierta función técnica de los altares reutilizados al8 y a19, descartándose entonces la explicación de que pudiera tratarse de una ubicación, por lo que nos inclinamos por la idea del recinto.

Respecto a la relación entre ubicación y altar votivo, podemos remitirnos al hallazgo de la ubicación $n^{\circ} 43$ y al altar $a 34$ (Fig. 4), el cual parece no dejar lugar a dudas. La relación resulta no sólo a partir de los hallazgos encontrados en las inmediaciones, sino especialmente a partir del hecho de que el altar a35 se conserva completo $-\mathrm{y}$, por lo tanto, no podía haber sido movido muy lejos.

Todas estas observaciones respecto a las ubicaciones, los recintos y sus características están resumidas en la tabla a continuación (Fig. 10). La primera columna corresponde a las ubicaciones, que aparecen numeradas. La segunda columna hace referencia al tipo de ubicación, dependiendo de si se trata de una coloración en la tierra sin estar enmarcada por piedras («Tierra») o de una ubicación enmarcada por piedras, pero sin coloración en la tierra («Piedra»). En el caso de las pocas ubicaciones con piedras y con 


\begin{tabular}{|c|c|c|c|c|c|c|c|}
\hline \multirow{2}{*}{$\begin{array}{l}\text { Ubica- } \\
\text { ción } \mathrm{n}^{\circ}\end{array}$} & \multicolumn{2}{|c|}{ Ubicación } & \multirow{2}{*}{$\begin{array}{l}\text { Medidas interiores } \\
\text { Ubicación (P); } \\
\text { Ubicación (T) }\end{array}$} & \multicolumn{2}{|c|}{ Ubicación } & \multirow{2}{*}{$\begin{array}{l}\text { Altares como } \\
\text { piezas } \\
\text { reutilizadas en } \\
\text { las ubicaciones } \\
\text { o recintos }\end{array}$} & \multirow[t]{2}{*}{ Observaciones en torno a la ubicación } \\
\hline & Tierra & Piedra & & Sí & & & \\
\hline 1 & & $\bullet$ & $S:<28 \mathrm{x}<30 \mathrm{~cm}$ & & - & altares $a 31, a 32$ & \\
\hline 2 & & - & $\mathrm{S}:<24 \times 26 \mathrm{~cm}$ & & - & & \\
\hline 3 & & - & $\mathrm{S}:<24 \mathrm{x}<30 \mathrm{~cm}$ & & - & altar $a 56$ & \\
\hline 4 & & $\cdot$ & $\mathrm{S}:<20 \mathrm{x}<14 \mathrm{~cm}$ & & - & & \\
\hline 5 & & - & $\mathrm{S}: 17 \mathrm{x}>15 \mathrm{~cm}$ & & $\bullet$ & & \\
\hline 6 & & $\cdot$ & S: $27 \mathrm{x}>14 \mathrm{~cm}$ & & - & & \\
\hline 7 & & - & $\begin{array}{l}\text { S: }>15 \mathrm{x}>8 \mathrm{~cm} \\
\text { E: v. ubicación } \mathfrak{n}^{\circ} 19\end{array}$ & $?$ & $?$ & & \\
\hline 8 & & - & $\mathrm{S}:<20 \times 13 \mathrm{~cm}$ & & - & & $\begin{array}{l}\text { Coloración redonda en la tierra en un } \\
\text { diámetro de unos } 10 \mathrm{~cm} \text {. }\end{array}$ \\
\hline 9 & • & & S: $31 \times 20 \mathrm{~cm}$ & & - & & $\begin{array}{l}\text { Coloración en la tierra. Forma elipsoide- } \\
\text { redonda. }\end{array}$ \\
\hline 10 & - & & $\begin{array}{l}\text { S: } 32 \times 19 \mathrm{~cm} \\
E:<130 \times 80 \mathrm{~cm}\end{array}$ & - & & altares $a 18, a 19$ & $\begin{array}{l}\text { Coloración en la tierra. Forma elipsoide- } \\
\text { redonda. }\end{array}$ \\
\hline 11 & - & & $\begin{array}{l}\text { S: } 22 \times 11 \mathrm{~cm} ; \\
\text { E: v. ubicación } \mathrm{n}^{\circ} 10\end{array}$ & - & & & $\begin{array}{l}\text { Coloración en la tierra. Forma que } \\
\text { recuerda a un corazón. }\end{array}$ \\
\hline 12 & & $\cdot$ & $\mathrm{S}:<12 \mathrm{x}<9 \mathrm{~cm}$ & & $\cdot$ & & \\
\hline 13 & & $\cdot$ & $\mathrm{S}:<12 \mathrm{x}<20 \mathrm{~cm}$ & & $\cdot$ & & \\
\hline 14 & & $\cdot$ & $\mathrm{S}:<15 \mathrm{x}<12 \mathrm{~cm}$ & & $\cdot$ & & Piedras para acuñar en el lugar mismo \\
\hline 15 & & - & $\begin{array}{l}\text { S: } 13 \times 9 \mathrm{~cm} \\
\text { E: } 90 \times 60 \mathrm{~cm}\end{array}$ & - & & & $\begin{array}{l}\text { Pedazos de vidrio biselados en el punto } \\
\text { del pie. }\end{array}$ \\
\hline 16 & & - & $\mathrm{S}:<29 \mathrm{x}<31 \mathrm{~cm}$ & & - & & \\
\hline 17 & & - & $\begin{array}{l}S: 17 \times<11 \mathrm{~cm} \\
E 68 \times 50 \mathrm{~cm}\end{array}$ & - & & & $\begin{array}{l}\text { Pedazos anfóricos como pedazos de la } \\
\text { base; aparecen junto a un mango de } \\
\text { bronce de un cuchillo. }\end{array}$ \\
\hline 18 & & $\cdot$ & $\mathrm{S}:<7 \mathrm{x}<32 \mathrm{~cm}$ & & $\cdot$ & & \\
\hline 19 & & - & $\begin{array}{l}\mathrm{S}:<20 \times<18 \mathrm{~cm} \\
\text { E: } 80 \times 50 \mathrm{~cm}\end{array}$ & & - & & \\
\hline 20 & & $\cdot$ & $S:<13 \mathrm{x}<20 \mathrm{~cm}$ & & $\cdot$ & & Roca trabajada como superficie de apoyo \\
\hline 21 & & - & $\begin{array}{l}\text { S: } 25 \times 18 \mathrm{~cm} \\
\text { E: } 70 \times 30 \mathrm{~cm}\end{array}$ & $?$ & & & Piedra que sirve de base $13 \times 15 \mathrm{~cm}$ \\
\hline 22 & & $\cdot$ & $\mathrm{S}:<11 \mathrm{x}<13 \mathrm{~cm}$ & & $\bullet$ & & Piedras enrojecidas por el fuego. \\
\hline 23 & & - & S: $28 \mathrm{x}<24 \mathrm{~cm}$ & $\bullet$ & & & \\
\hline 24 & & $\cdot$ & $\mathrm{S}:<23 \mathrm{x}<25 \mathrm{~cm}$ & - & & & \\
\hline 25 & & - & $\begin{array}{l}\mathrm{S}:<10 \times<16 \mathrm{~cm} ; \\
\text { E: } 80 \times 80 \mathrm{~cm}\end{array}$ & - & & altar $a 39$ & \\
\hline 26 & & - & $S:<10 \mathrm{x}<22 \mathrm{~cm}$ & & - & & \\
\hline 27 & & $\cdot$ & $S:<19 x<14 \mathrm{~cm}$ & & $\bullet$ & & Piedras enrojecidas por el fuego. \\
\hline 28 & & - & $\mathrm{S}:<15 \mathrm{x}<15 \mathrm{~cm}$ & & - & & $\begin{array}{l}\text { Piedras enrojecidas por el fuego. Piedra } \\
\text { que sirve de base }\end{array}$ \\
\hline 29 & & $\bullet$ & $\mathrm{S}:<12 \times<8 \mathrm{~cm}$ & & $\cdot$ & & Fragmento que sirve de base \\
\hline
\end{tabular}




\begin{tabular}{|c|c|c|c|c|c|c|c|}
\hline \multirow{2}{*}{$\begin{array}{l}\text { Ubica- } \\
\text { ción } \mathrm{n}^{\circ}\end{array}$} & \multicolumn{2}{|c|}{ Ubicación } & \multirow{2}{*}{$\begin{array}{l}\text { Medidas interiores } \\
\text { Ubicación (P); } \\
\text { Ubicación (T) }\end{array}$} & \multicolumn{2}{|c|}{ Ubicación } & \multirow{2}{*}{$\begin{array}{l}\text { Altares como } \\
\text { piezas } \\
\text { reutilizadas en } \\
\text { las ubicaciones } \\
\text { o recintos } \\
\end{array}$} & \multirow[t]{2}{*}{ Observaciones en torno a la ubicación } \\
\hline & Tierra & Piedra & & & & & \\
\hline 30 & & $\cdot$ & $\mathrm{S}:<18 \mathrm{x}<15 \mathrm{~cm}$ & & $\cdot$ & & \\
\hline 31 & & $\cdot$ & $\mathrm{S}:<19 \mathrm{x}<9 \mathrm{~cm}$ & $\cdot$ & & altar $a 20$ & Fragmento anfórico que sirve de base \\
\hline 32 & & $\bullet$ & $\mathrm{S}:<10 \mathrm{x}<20 \mathrm{~cm}$ & & $\cdot$ & & Piedras para acuñar en el lugar mismo \\
\hline 33 & & $\bullet$ & $\mathrm{S}:<13 \mathrm{x}<18 \mathrm{~cm}$ & & - & & Se apoya en una roca trabajada \\
\hline 34 & & - & $\begin{array}{l}\text { S: }<17 \times<17 \mathrm{~cm} \\
\text { E: } 83 \times 40 \mathrm{~cm}\end{array}$ & - & & & \\
\hline 35 & & - & $\begin{array}{l}S:<10 \times<6 \mathrm{~cm} \\
E: 60 \times 53 \mathrm{~cm}\end{array}$ & - & & & Piedra que sirve de base \\
\hline 36 & & $\bullet$ & $\begin{array}{l}\mathrm{S}:<18 \times 12 \mathrm{~cm} \\
\text { E: v. ubicación } \mathrm{n}^{\circ} 15\end{array}$ & - & & & \\
\hline 37 & & - & $\begin{array}{l}\mathrm{S}:<11 \times<14 \mathrm{~cm} ; \\
\text { E: v. ubicación } \mathrm{n}^{\circ} 15\end{array}$ & - & & & Piedra acuñada que sirve de base \\
\hline 38 & & - & $\begin{array}{l}\mathrm{S}:<13 \mathrm{x}<10 \mathrm{~cm} \\
\text { E: v. ubicación } \mathrm{n}^{\circ} 15\end{array}$ & & - & & \\
\hline 39 & & - & $\begin{array}{l}\text { S: }<14 \mathrm{x}<17 \mathrm{~cm} \\
\text { E: v. ubicación } \mathrm{n}^{\circ} 22\end{array}$ & - & - & & $\begin{array}{l}\text { Coloración redonda en la tierra en un } \\
\text { diámetro de unos } 10 \mathrm{~cm} \text {. }\end{array}$ \\
\hline 40 & & - & $\mathrm{S}:<20 \mathrm{x}<22 \mathrm{~cm}$ & 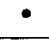 & & & \\
\hline 41 & & • & $\begin{array}{l}\text { S: }<29 \mathrm{x}<24 \mathrm{~cm} \\
\text { E: v. ubicación } \mathrm{n}^{\circ} 25\end{array}$ & • & & altar $a 34$ & Piedra grande que sirve de base \\
\hline 42 & & - & $\mathrm{S}: 61 \times 42 \mathrm{~cm}$ & & $\bullet$ & & Piedra que sirve de base $17 \times 12 \mathrm{~cm}$ \\
\hline 43 & & • & $\begin{array}{l}S:<30 \times>19 \mathrm{~cm} ; \\
\text { E: } 100 \times 55\end{array}$ & - & & & Probablemente pertenezca al altar $a 35$ \\
\hline 44 & & - & $\begin{array}{l}S:<13 \times<19 \mathrm{~cm} ; \\
\text { E: } 70 \times 10\end{array}$ & • & & altar $a 42$ & \\
\hline 45 & & - & $\begin{array}{l}S:<20 \times>20 \mathrm{~cm} \\
E: 64 \times 36 \mathrm{~cm}\end{array}$ & • & & altar $a 41$ & \\
\hline 46 & & - & $\begin{array}{l}\text { S: }>24 \mathrm{x}<19 \mathrm{~cm} \\
\text { E: } 50 \mathrm{x}>30 \mathrm{~cm}\end{array}$ & • & & altares $a 43, a 44$, & Pies \\
\hline 47 & & - & $\begin{array}{l}\text { S: } 14 \times 10 \mathrm{~cm} ; \\
\text { E: } 150 \times 80\end{array}$ & - & & $\begin{array}{l}\text { altares } a 30, a 36, \\
a 38, a 55\end{array}$ & Recinto junto con las ubicaciones 48 y 49 \\
\hline 48 & & - & $\begin{array}{l}\text { S: }<22 \mathrm{x}<8 \mathrm{~cm} ; \\
\text { E: v. ubicación } \mathrm{n}^{\circ} 47\end{array}$ & - & & $\begin{array}{l}\text { altar } a 27, a 30, \\
a 37, a 38, a 55\end{array}$ & Recinto junto con las ubicaciones 47 y 49 \\
\hline 49 & & - & $\begin{array}{l}\text { S: }<33 \mathrm{x}<20 \mathrm{~cm} \\
\text { E: v. ubicación } \mathrm{n}^{\circ} 47\end{array}$ & - & & altar $a 48$ & Recinto junto con las ubicaciones 47 y 48 \\
\hline 50 & & - & $\begin{array}{l}\mathrm{S}:<24 \mathrm{x}<20 \mathrm{~cm} \\
\text { E: } 80 \times 50 \mathrm{~cm}\end{array}$ & - & & altar $a 45, a 46$ & \\
\hline 51 & & - & $\begin{array}{l}\mathrm{S}:<18 \times<18 \mathrm{~cm} ; \\
\text { E: } 37 \times 26 \mathrm{~cm}\end{array}$ & - & & altar $a .50$ & \\
\hline 52 & & - & $\begin{array}{l}\text { S: }<15 \times<17 \mathrm{~cm} ; \\
\text { E: } 25 \times 11 \mathrm{~cm}\end{array}$ & $\bullet$ & & & \\
\hline 53 & & - & $\begin{array}{l}\text { S: }<22 \times<26 \mathrm{~cm} \\
E: 130 \times 40 \mathrm{~cm}\end{array}$ & - & & & Roca trabajada como superficie de apoyo \\
\hline
\end{tabular}




\begin{tabular}{|c|c|c|c|c|c|c|c|}
\hline \multirow{2}{*}{$\begin{array}{l}\text { Ubica- } \\
\text { ción } n^{\circ}\end{array}$} & \multicolumn{2}{|c|}{ Ubicación } & \multirow{2}{*}{$\begin{array}{l}\text { Medidas interiores } \\
\text { Ubicación (P); } \\
\text { Ubicación }(T)\end{array}$} & \multicolumn{2}{|c|}{ Ubicación } & \multirow{2}{*}{$\begin{array}{l}\text { Altares como } \\
\text { piezas } \\
\text { reutilizadas en } \\
\text { las ubicaciones } \\
\text { o recintos } \\
\end{array}$} & \multirow[t]{2}{*}{ Observaciones en torno a la ubicación } \\
\hline & Tierra & Piedra & & Sí & & & \\
\hline 54 & & $\bullet$ & $S: 14 \mathrm{x}>10 \mathrm{~cm}$ & & . & & \\
\hline 55 & $\bullet$ & & S: $57 \times 10 \mathrm{~cm}$ & & - & & \\
\hline 56 & - & & S: $14 \times 9 \mathrm{~cm}$ & & $\bullet$ & altares $a 18, a 19$ & \\
\hline 57 & & $\cdot$ & $\mathrm{S}: 15 \times 14 \mathrm{~cm}$ & - & & & \\
\hline 58 & & $\bullet$ & S: $16 \mathrm{x}>9 \mathrm{~cm}$ & $\bullet$ & & & Fragmentos de vidrio en la base \\
\hline 59 & & $\bullet$ & S: $10 x>18 \mathrm{~cm}$ & & $\bullet$ & & Pie \\
\hline 60 & & - & $\mathrm{S}: 11 \mathrm{x}>18 \mathrm{~cm}$ & & $\bullet$ & altares $a 28, a 59$ & Roca trabajada como superficie de apoyo \\
\hline 61 & & $\bullet$ & S: $17 \times 14 \mathrm{~cm}$ & & $\cdot$ & & \\
\hline 62 & & $\cdot$ & S: $13 \times 10 \mathrm{~cm}$ & & - & & \\
\hline 63 & & $\bullet$ & S: $15 \times 17 \mathrm{~cm}$ & & $\bullet$ & & \\
\hline 64 & & $\cdot$ & S: $20 \times 10 \mathrm{~cm}$ & & $\cdot$ & & \\
\hline 65 & & $\bullet$ & S: $20 \times 20 \mathrm{~cm}$ & & $\bullet$ & & \\
\hline 66 & & $\bullet$ & $\mathrm{S}: 10 \times 15 \mathrm{~cm}$ & & - & & \\
\hline
\end{tabular}

Fig. 10. Cuadro sinóptico con las ubicaciones correspondientes a los altares votivos.

coloración en la tierra, se ha añadido el comentario sobre la coloración en una columna al final de la tabla a la derecha. La tercera columna contiene las medidas interiores de ubicaciones y recintos, si bien debido al tipo de hallazgo y sus características, por regla general los operadores de comparación han tenido que indicarse como mayor y menor; por este motivo las medidas no pueden considerarse valores exactos, sino que deben entenderse en todo caso como indicadores de una escala de dimensiones. La cuarta columna refleja la existencia de recintos, y la quinta los altares reutilizados en las ubicaciones y en los recintos.

\section{Los bloques I-IV}

En la sección IIa del corte 3, un poco más arriba de la construcción oval, se encuentran cuatro grandes bloques de roca de granito del que se encuentra por la zona (Fig. 2.5, tabla 4a). Se encuentran apilados en una fila y los tres bloques de más al este se tocan, habiendo entre ellos piedras más pequeñas. La orientación es aproximadamente Oeste-Este. En todos los bloques pueden observarse señales de haber sido trabajados. Los dos bloques de la parte este (bloques I y II) son de mayor tamaño y presentan una forma redondeada, mientras que los bloques III y IV, en cambio, destacan por sus formas puntiagudas.

El bloque I (superficie aprox. $100 \times 60 \mathrm{~cm}$ ) sobresale unos $60 \mathrm{~cm}$ del suelo. La superficie que da a la ladera presenta unas abolladuras muy toscas, mientras que sus bordes están recortados. Cabe pensar que originariamente formara el lado inferior del bloque y que, por lo tanto, éste se encuentre volcado con respecto a su posición original. En este caso, cabe pensar que la superficie que mira a la cima del monte sería la originaria. En virtud del tamaño, quizás el bloque I pueda ser considerado como un basamento de algo que desconocemos.

Debido a las similitudes de forma respecto a esta construcción, podría ser que el bloque II (Al $120 \times$ An $70 \times \mathrm{L} 40 \mathrm{~cm}$ ) perteneciera de algún modo a la misma. Visto desde el lado de la ladera, el bloque se asemeja a uno de los tipos de altares votivos, concretamente porque su parte inferior tiene forma de pala o de hincón, porque dispone de una superficie alisada claramente delimitada — que en los altares votivos servía para realizar en ella alguna inscripción-, y también porque tiene una parte superior sobrepuesta de forma semicircular. Todas las caras visibles del bloque han sido trabajadas. Debido a que la cara norte presenta un alisado de mayor calidad, podríamos considerar aquí que la cara norte es la cara anterior y la cara sur la posterior. Esta diferenciación es evidente debido a que en la cara norte, bajo la parte superior, se encuentra una superficie alisada y enmarcada (An $40 \times \mathrm{Al} 30 \mathrm{~cm}$ ), que en cambio no aparece en la cara sur. El resto de caras no están trabajadas.

El bloque III (L $150 \times$ An $47 \times \mathrm{Al} 28 \mathrm{~cm}$ ) tiene una apariencia amorfa, en la cara superior presenta 


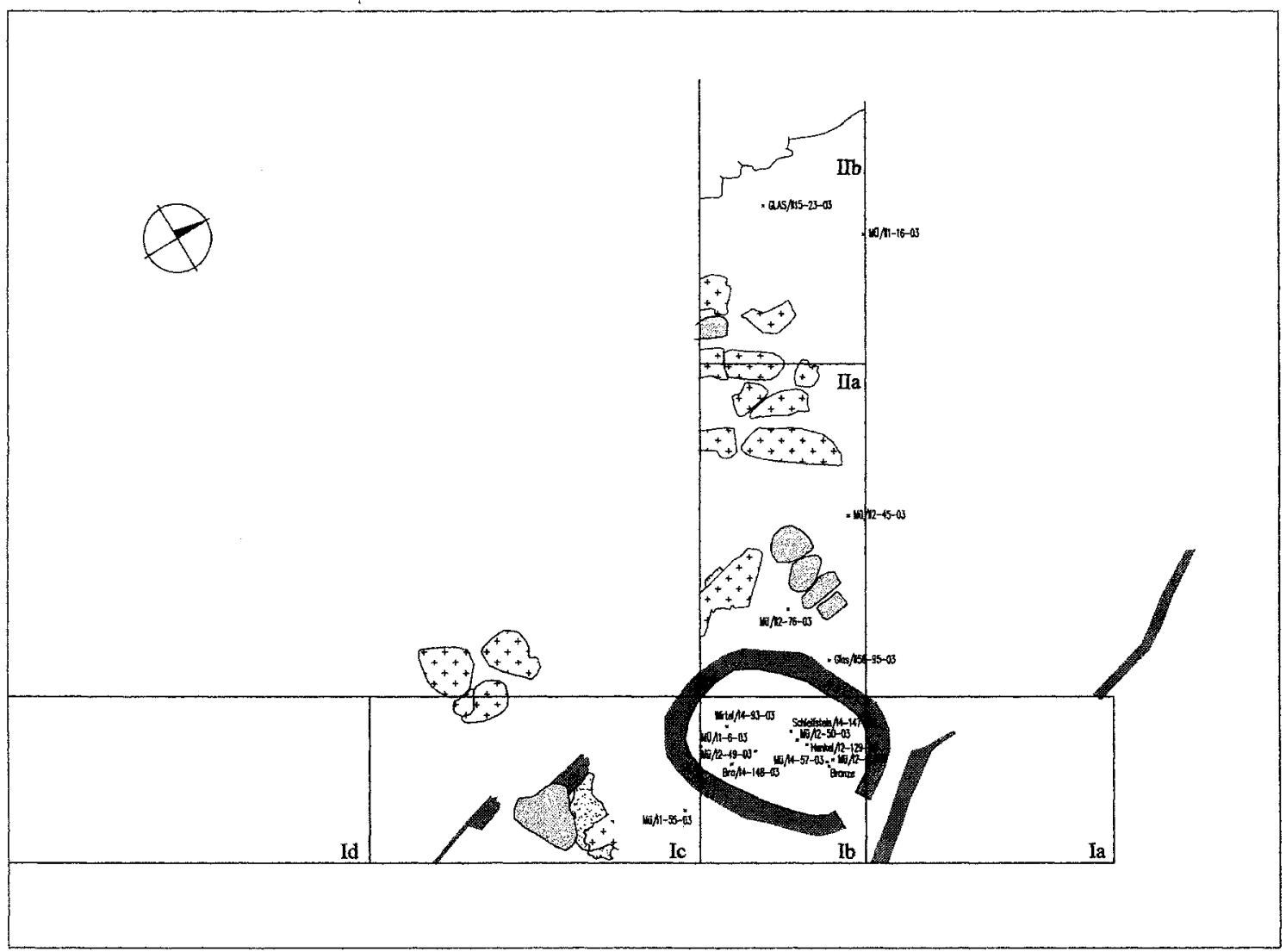

Fig. 11. Monte do Facho. Distribución de los hallazgos pequeños.

una superficie de cuarzo áspera, resultado de una fractura natural, quizás, posterior a la realización y posible uso de esta piedra.

Es evidente que el bloque IV (L $60 \times$ An $32 \times \mathrm{Al}$ $40 \mathrm{~cm}$ ) se encuentra en una posición de lado, tal como se dedujo a partir de los diferentes niveles de elaboración y alisado. A partir de ahí, la cara sur puede ser considerada como la cara superior, ya que está mejor trabajada, y la cara norte como la inferior. La superficie de la cara sur está vaciada de forma irregular y en ella se ven huellas de picado.

Resulta difícil interpretar este hallazgo. Si bien los bloques están uno al lado de otro y en fila, lo que muestra que fueron llevados a adoptar esa posición, cabe decir que han sido reutilizados, tal como se desprende de las observaciones en torno a las diferentes superficies trabajadas, las cuales muestran haber estado cumpliendo una función anterior. Un indicio sobre esta apreciación lo muestra el bloque II con sus formas parecidas a las de los altares votivos y con su superficie frontal especialmente elaborada. Al ser reutilizados, no es posible reconocer a qué habían estado destinados en un principio, incluso parece ser que se intente evitarlo, ya que ninguno de los bloques está colocado como lo estaría originalmente; muy al contrario, están volcados totalmente o de lado.

\section{Otros hallazgos}

La Fig. 11 aporta información sobre la distribución de los hallazgos pequeños acotados. Se trata principalmente de vidrio, monedas, utensilios de piedra y de metal, concretamente de bronce. La imagen aparentemente irregular de la distribución mediante la concentración de hallazgos en las secciones IIa y IIb, así como Ib, tiene su base en que las excavaciones estaban especialmente dirigidas a ese fin y que las secciones al margen Ia, Ic y Id no fueron excavadas en absoluto o sólo muy por encima.

De los hallazgos de vidrio, que hemos de considerar relativamente abundantes, sólo han sido acotados aquellos pedazos que salieron a la luz en las 


\begin{tabular}{|l|l|c|l|}
\hline \multicolumn{1}{|c|}{ Hallazgo acotado } & \multicolumn{1}{|c|}{ No inv. } & Capa & \multicolumn{1}{c|}{ Datación } \\
\hline Moneda & II-6-03 & 1 & Constantino I 399 d.C. \\
\hline Moneda & I2-49-03 & 2 & $330-348$ d. C. \\
\hline Moneda & $12-50-03$ & 2 & Constancio Cloro 302-303 d.C. \\
\hline Moneda & I2-31-03 & 2 & \\
\hline Asa de ánfora & I2-129-03 & 2 & \\
\hline Moneda & I4-57-03 & 3 & Claudio II Gótico 268-270 d. C. \\
\hline Tortera & I4-93-03 & 3 & \\
\hline Piedra de afilar & I4-147-03 & 4 & \\
\hline Fragmento de bronce & I4-148-03 & 4 & \\
\hline
\end{tabular}

Fig. 12a. Tabla resumen. Correspondencia estratigráfica de los hallazgos acotados procedentes del interior de la construcción oval con las capas 1 a 4 (v. Fig. 6).

\begin{tabular}{|c|c|c|}
\hline Hallazgo & $N^{\circ}$ inv. & Capa \\
\hline Fragmento de muela & II4-20-03 & 1 \\
\hline Perlas de azabache & II $4-72-03$ & 1 \\
\hline Fragmento arquitectónico? & I2-g-03 & 1 \\
\hline Ancla de piedra? & I-h-03 & 1 \\
\hline Trozos de barro ( 4 un.) & $12-70-03$ & 2 \\
\hline Pedazos de vidrio (7 unidades) & $12-69-03$ & 2 \\
\hline Trozos de barro (4 un.) & $12-54-03$ & 2 \\
\hline Trozos de barro ( 17 un.) & $12-53-03$ & 2 \\
\hline Trozos de barro (12 un.) & $12-52-03$ & 2 \\
\hline Trozos de vidrio (4 un.) & $\mathrm{I} 2-51-03$ & 2 \\
\hline Fragmentos de moleta ( 2 un.) & $12-48-03$ & 2 \\
\hline $\begin{array}{l}\text { Fragmento de moleta (muela } \\
\text { corredera) }\end{array}$ & $12-33-03$ & 2 \\
\hline Trozo de vidrio ( 1 un.) & $12-32.03$ & 2 \\
\hline Fragmento de muela & I4-87-03 & Paso de la 2 a la 3. \\
\hline Trozos de barro (13 un.) & I4-86-03 & Paso de la 2 a la 3. \\
\hline Trozos de vidrio (5 un.) & $14-85-03$ & Paso de la 2 a la 3. \\
\hline $\begin{array}{l}\text { Fragmento de hierro (Cabeza de } \\
\text { clavo?) }\end{array}$ & I4-84-03 & Paso de la 2 a la 3. \\
\hline Trozos de barro ( 3 un.) & $12-88-03$ & 3 \\
\hline Trozos de barro ( 2 un.) & $14-60-03$ & 3 \\
\hline Fragmento de muela & $14-59-03$ & 3 \\
\hline Trozos de vidrio ( 2 un.) & 14-58-03 & 3 \\
\hline Trozo de vidrio ( 1 un.) & $12 / 4-119-03$ & Paso de la 3 a la 4. \\
\hline Fragmentos de muela & $12 / 4-120-03$ & Paso de la 3 a la 4. \\
\hline Trozos de barto ( 8 un.) & $14-115-03$ & 4 \\
\hline
\end{tabular}

Fig. 12b. Tabla resumen. Correspondencia estratigráfica de los hallazgos no acotados procedentes del interior de la construcción oval con las capas 1 a 4 (v. Fig. 6). 
ubicaciones ${ }^{66}$. Ciertamente, los pedazos de vidrio, junto con las monedas, están desperdigados por toda la zona central de excavación, es decir, en las secciones IIa, IIb y Ib.

Por otra parte, los hallazgos del interior de la construcción oval, excavada hasta el primer horizonte de nivel de suelo, dicen mucho sobre el fin para el que estaban destinados. Especialmente notables parecen ser cinco monedas, dos fragmentos de bronce y una tortera, una piedra de afilar y un asa de ánfora. El lugar exacto en la superficie en que fueron hallados puede apreciarse en la Fig. 11. La clasificación estratigráfica de estos y otros hallazgos, éstos últimos no acotados expresamente, respecto a las capas 1 a 4 (v. Fig. 6) se deduce a partir de las tablas Fig. 12a y b.

Las dataciones de las monedas procedentes de la construcción oval están registradas en la tabla Fig.12a. Tal como se muestra, el orden cronológico que siguen las monedas se corresponde muy bien con el estratigráfico, mientras que la datación del resto de hallazgos no desencaja. De todo ello cabe deducir que el momento de construcción y también el de uso de la casa oval debe corresponder a un período anterior a mediados del siglo III d.C.: la moneda MF I4-57-03 (Claudio II Gótico) procede del nivel 3 (Fig. 6) que corresponde a una primera fase de abandono del edificio. Hallazgos como la tortera, la piedra de afilar, las piedras, las muelas y moletas, o la cabeza de clavo de hierro parecen señalar, en principio, un uso profano de la casa oval. De momento, no se ha encontrado nada que pudiera apuntar a un uso religioso

\section{ERGOLOGÍA}

\section{A. Introducción}

Es pronto para poder ofrecer una valoración exhaustiva de unos materiales que configuran un conjunto que podemos considerar escaso, al menos en términos relativos, dado que, aunque se trata de una campaña inicial y en la que se profundizó muy poco en el terreno, no podemos olvidar que estamos ante épocas - castreña y galaico-romana- y un tipo de yacimiento - el castro- comúnmente ricos en el apartado ergológico; además la extensión de los trabajos no fue pequeña (vide supra). Sólo futuras campañas permitirán estudios sino definitivos sí con probabilidad de resultar significativos en cuanto al

66 Véase cap. III. Las excavaciones. Los altares votivos, las ubicaciones, los recintos. registro arqueológico. No obstante, no podríamos obviar unos contenidos que son relevantes al menos como referencia de las distintas realidades a las que nos enfrentamos y en algún caso resultan incluso significativos para una interpretación inicial de las mismas.

\section{B. Cerámicas modernas}

La componente más abundante en superficie son los restos de tejas curvas del tipo tradicionalmente usado en la zona y por tanto datación no muy antigua. Asociado a ella, tanto en superficie como entre la primera capa de derrumbe, aparecen fragmentos cerámicos hechos a torno, de relativa buena calidad, en la que podemos distinguir un tipo de escudilla carenada y de fondo realzado que aparece generalmente en contextos de los siglos XVII y XVIII, como evidencia el despoblado de Punxeiro al pie del Monte do Facho, pero también otros yacimientos gallegos tanto próximo como cercanos, o simplemente la pintura española de la época. Otros recipientes resultan algo más toscos, abundando los de mayor porte -ollas o cántaros- de superficies grises o negruzcas, con algunos ejemplos de aplicación de vedrío pero siempre aplicado a las superficies internas de los recipientes. Se trata de unas cerámicas propias de la alfarería popular gallega, que de nuevo volvemos a encontrar en Punxeiro, así como en ambientes tanto rurales como urbanos de la misma época, y que puede identificarse sin dificultad con la existencia del puesto de vigilancia costero en la cima del monte durante segunda mitad del siglo XVIII y la primera del XIX.

\section{Cerámica romana (Fig. 13)}

La cerámica romana está representada por un conjunto de cerámicas toscas hechas a torno y de carácter local que todavía no están tipificadas, pero consta su aparición en contextos tardorromanos de la zona, como es el caso de la villa de Pipín ${ }^{67}$ o el yacimiento romano existente a los pies del monte ${ }^{68}$. Dentro de éstas y en menor cantidad encontramos ejemplos de especies cerámicas mejor conocidas, como es el caso de los recipientes de engobe rojo,

${ }^{67}$ F. Fariña Busto, A. de la Peña y J. C. Sierra, Restos de una villa romana en Hio, El Museo de Pontevedra 29, 1975, $177-186$

68 Amplia ocupación romana de la rasa litoral situada al pie del monte, del que se conocen tan sólo restos superficiales que incluyen la presencia de un ara anepígrafe. 


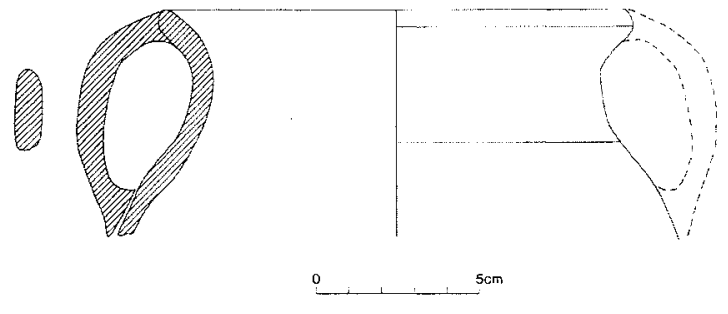

Fig. 13. Monte do Facho. Cerámica romana.

representados aquí por los fragmentos de algún plato y de jarra o similar. Son unas cerámicas de amplia vigencia en el marco de la Gallaecia, pero están especialmente ligadas a contextos de los siglos III a V. A esta misma cronología deben vincularse los escasos restos de cerámica común romana, en particular un fragmento de cuenco hemiesférico en cerámica de pastas decantadas pero poco consistentes. Mención a parte merece la relativa abundancia de unos recipientes de pequeño tamaño y paredes muy estrechas que recuerdan las producciones de «paredes finas», pero sin poder adscribirse a esa especie cerámica. Parecen producciones locales vinculadas a las mencionadas en primer lugar, pues tienen pastas y algún aspecto formal similar, $y$, por otra parte, nos consta su aparición en el yacimiento romano inmediato a $\mathrm{O}$ Facho, aunque también parecen estar presentes en contextos tardorromanos gallegos como la villae de Santomé en Ourense. Finalmente, mencionar la presencia de cerámicas comunes galaico-romanas, de carácter más tosco que las anteriores y con aparentes vinculaciones a la tradición prerromana. Resultan más difíciles de definir, pues son escasas y su estado de conservación es deficiente; además, estas producciones están aún por estudiar, a pesar de resultar muy abundantes en los contextos romanos gallegos.

Un capítulo aparte es el de las ánforas, de las que grandes fragmentos parecen servir de base a la colocación de los monumentos, mientras otros aparecen dispersos tanto en el estrato superficial, mezclados con el derrumbe pétreo, como en los sucesivos niveles alcanzados por la excavación, lo que parece indicar que estamos ante restos vinculados no a un momento en particular, sino a varios de los afectados por la excavación. Lamentablemente, la mayoría de los fragmentos recuperados hasta ahora no permiten la identificación formal del recipiente original, a lo que se suma el carácter de piezas rodadas, y por lo tanto desplazadas de su deposición original, de buena parte de dichos fragmentos. De hecho lo único que podemos constatar es la presencia de ánforas hispánicas de variada cronología, de la que podemos confirmar únicamente la presencia de algu- na forma altoimperial, como la Haltern 70, o alguna pieza tardía sin identificar.

\section{Cerámica castreña (Fig. 14)}

El conjunto cerámico castreño se manifiesta de momento escaso y ambiguo. A parte de los restos dispersos en el nivel superficial, y mezclados con los materiales antes referidos, la ergología castreña aumenta en la medida que profundizamos, circunstancia que ocurre en tres áreas de la superficie excavada.

La primera de ellas se refiere al extremo Oeste del corte 1. Aquí bajo las ubicaciones de las aras y mezclada con material romano aparecen fragmentos de cerámica castreña, aumentando en profundidad y en detrimento del anterior. La segunda corresponde a la construcción oval en la intersección de los cortes 1 y 2 , donde se vuelven a encontrar los dos horizontes, con las mismas características, sólo que aquí asociadas al nivel de derrumbe y a lo que parece ser el último episodio de uso de esa construcción. La tercera es el extremo sur del corte 2, en el que se profundizó hasta un pavimento de barro que parece volver a señalar la última ocupación del poblado de la Edad del Hierro.

Del material recogido y claramente diferenciable de la cerámica galaicorromana de tradición castreña, obtenemos la visión de un horizonte avanzado dentro de la alfarería castreña propia de las Rías $\mathrm{Ba}$ jas ${ }^{69}$. Así y a pesar de lo escaso del registro, es posible distinguir unas formas estandarizadas y con escasa decoración acogen una tipología basada en las ollas de pequeño y mediano tamaño, con o sin asas, y en menor medida los grandes recipientes con decoración plástica o las jarras «tipo Toraia»; también están presentes, aunque de momento de manera muy limitada, los recipientes de borde reforzado de tipo marítimo que hay que relacionar con las ollas «tipo Vigo». Las decoraciones todavía muy escasas se remiten a las $\mathrm{S}$ estampilladas y las líneas horizontales incisas, y alguna decoración plástica. Se trata de un conjunto muy semejante a los que ya se conocían para el yacimiento: los obtenidos de los niveles superiores del «concheiro» de la ladera Oeste o los resultantes de las excavaciones realizadas en los años setenta en el área Noroeste y dentro del recinto exterior del poblado, aunque aquí la riqueza del registro y su vinculación estricta a la ocupación castreña, permite perfilar una alfarería claramente

${ }^{69} \mathrm{M}^{\mathrm{a}}$ Josefa Rey Castiñeiras, Cerámica indígena de los castros costeros de la Galicia occidental: Rias Bajas. Valoración dentro del contexto general de la cultura castreña, Castrelos 3-4, 1987, 141-164. 


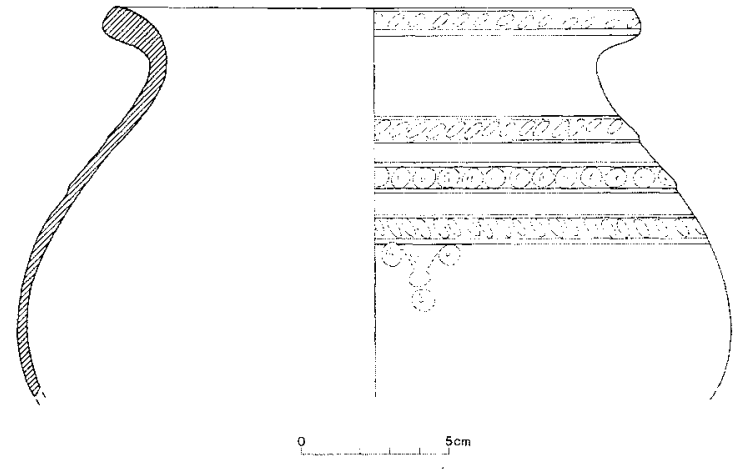

Fig. 14. Monte do Facho. Cerámica castreña.

basada en las formas propias de la Fase Media: jarras tipo Toraia, grandes recipientes de borde exvasado y ensanchado con labio plano y decoración plástica a base de cordones, los llamados recipientes tipo Vigo, al lado de ollas de perfil en $S$ y ollitas de dos asas, siendo más escasos los recipientes de borde reforzado tipo Vigo. En consecuencia, y teniendo en cuenta siempre que nos encontramos en un primer acercamiento al problema, la cerámica parece apuntar un abandono relativamente temprano para O Facho: fines del siglo I a.C., o todo más principios del siguiente, sin ser descartable un abandono incluso algo anterior.

Una impresión que se refuerza si comparamos la cerámica castreña de $O$ Facho con la última fase de ocupación de dos yacimientos similares que resultan próximos y relativamente bien conocidos, como son el Castro de Vigo ${ }^{70}$ y Santa Trega ${ }^{71}$, notamos una clara diferenciación tanto en la composición del registro cerámico indígena, como en la presencia de alfarería romana. En cuanto a la primera se echan de menos en $\mathrm{O}$ Facho, además de una más amplia presencia de los bordes reforzados de tipo marítimo, las fuentes de asas horizontales sean interiores o exteriores, o las ollas con orejetas para suspensión. Al mismo tiempo falta el amplio registro de cerámicas romanas altoimperiales que es notorio en Vigo y Santa Trega, donde evidencian una ocupación del siglo I d. C., llegando en el primer caso incluso más allá de principios del siglo II d. C. Mientras que en O Facho el contacto con lo romano sólo aparece en la presencia de algunos fragmentos de ánfora aún por definir con precisión, y que nos lleva a poco más allá del cambio de Era.

70 J. M. Hidalgo Cuñarro, Castro de Vigo. Campaña 1983, Arqueoloxía/Memorias 1 (Santiago 1985). Idem, El castro de Vigo y sus niveles de ocupación, Lucerna $2^{\mathrm{a}}$ ser., vol. II 1987. Idem

${ }_{71}$ A. de la Peña Santos, Yacimiento galaico-romano de Santa Trega. Campaña 1983, Arqueoloxía/Memorias 5 (Santiago 1986)

\section{E. Monedas (Fig. 12a)}

En lo que a la numismática se refiere se trata de pequeños bronces de época tardía con un variado estado de conservación. De aquellos que podemos identificar, nos encontramos con un «antoniniano» de Claudio II Gótico, que nos remite a la segunda mitad del siglo III, donde también podemos situar otro «antoniniano» ilegible. Sin embargo, la mayoría de las piezas parecen situarse en la primera mitad del siglo IV: pequeño bronce de Constancio Cloro, otro de Constantino y un follis de la ciudad de Roma, así como una cuarta moneda de difícil lectura, pero quizá atribuible a Faustina. Si la primera parece datar el momento previo a la última fase del santuario, las otras se inscriben en este marco cronológico y funcional, pudiendo ser relacionadas con las ofrendas o los ritos que allí se celebraban.

\section{F. Vidrios (Fig. 15)}

Otro material particularmente abundante son los vidrios. Muy fragmentados y aparentemente vinculados directamente al área de ubicación de las aras, se inscriben en algunas de las formas comunes de
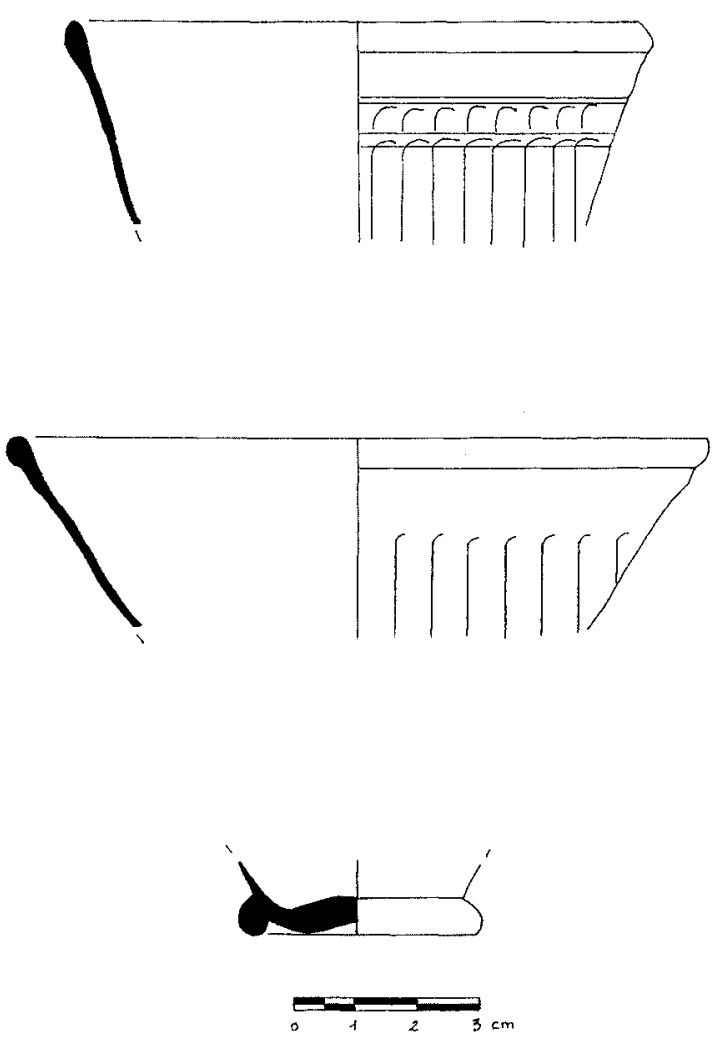

Fig. 15. Monte do Facho. Vidrio romano. 
los vidrios de época tardorromana en Galicia. Se trata de vidrios verdosos o incoloros entre los que constatamos la presencia de dos cuencos con decoración de leves depresiones verticales; o también, ya en hallazgos superficiales previos a la excavación, de los vasos acampanados Isings 106, en algunos casos con una decoración en panal de abeja. Una decoración similar fue aplicada a un pequeño cuenco o bol hallado bajo uno de los agujeros de ara, cuyo estado de fragmentación impide su identificación precisa. Existen paralelos para estos ejemplos en distintos yacimientos tardorromanos de Galicia $^{72}$, pero merece destacar la presencia de recipientes similares en la villa tardorromana de Toraia (Vigo), justo al otro lado de la ría de Vigo ${ }^{73}$.

\section{Otros}

Algunos restos metálicos en deficiente estado de conservación nos permiten apenas constatar la presencia de unas tijeras en bronce vinculables al conjunto de materiales tardorromanos. Algún hierro parece corresponder tanto a esa época, aunque resultan difíciles de identificar, como a otras más recientes, caso de una herradura de factura moderna.

En piedra tenemos que reseñar la presencia de un cristal de cuarzo que aunque en estado natural, es claramente ajeno a la geología de la zona. Más comunes los fragmentos de molinos planos realizados en granito local, que hay que atribuir, como en el caso de una «fusayola» de pizarra, al poblado castreño subyacente.

\section{EPIGRAFÍA DE LOS ALTARES}

Durante la campaña llevada a cabo en el Monte do Facho, descrita en el presente informe, se hallaron 57 altares votivos con forma de estela y partes de altares votivos en los cortes I-II, en su mayor parte con inscripciones en latín y en menor proporción sin epígrafe alguno ${ }^{74}$. Estos hallazgos aumentan a casi 100 la cifra formada por aquellos altares votivos encontrados con anterioridad en el Monte do Facho y aledaños y los altares votivos o fragmentos de tales llevados a los museos de Pontevedra y

\footnotetext{
${ }^{72}$ M. Susto Rodríguez, O vidro provincial galaicorromano (Ourense 2001).

${ }^{73} \mathrm{~J}$. M. Hidalgo Cuñarro, Últimas excavaciones de urgencia en Vigo: Castros y yacimientos romanos, Castelos 3-4, 1987, 191-216, esp. 196-197.

${ }_{74}$ v. cap. III. Los cortes I y II.
}

Vigo ${ }^{75}$. Es bien seguro que esta cifra aumentará a medida que vayamos continuando con las excavaciones.

La mayor parte de las inscripciones leídas hasta el momento la componen consagraciones al dios Lar Berobreus, de bien seguro local y únicamente conocido en esa zona. Esta denominación aparece en casi todos los altares votivos, salvo escasas excepciones. Hasta la fecha, Berobreo no había aparecido en la epigrafía latina de la Península Ibérica. En el material epigráfico hallado no son nombrados otros dioses, ni célticos ni los del panteón romano-helénico.

Es evidente que el santuario del Monte do Facho -que en la actualidad ha sido analizado de manera sistemática y cuya existencia prerromana ya era reconocible, aunque por ahora no es posible afirmarlo con un cien por cien de certeza ${ }^{76}$ - puede interpretarse como un lararium utilizado por la población (o de un cierto grupo de personas dentro de la misma) procedente del castro cercano en tiempos de romanización avanzada. Se trata del primer lararium con estas características, i.e., con tanta exclusividad y cantidad de inscripciones estrechamente relacionadas entre sí, conocido hasta ahora en la Península Ibérica.

Coincidiendo con las reflexiones generales formuladas por F. Beltrán Lloris en 1988, veo aquí un culto local dedicado al amo del lugar (¿de la colina?) por parte de la población que allí habitaba (o por parte de ella), todo ello con los típicos adornos romanos. Se confirma la tesis de G. Wissowa, según la cual los lares también eran grupos de dioses de un lugar o de un pueblo. Una bella confirmación al respecto la aporta la inscripción CLL II 804 = Dessau, ILS 3639 (diis Laribus Gapeticorum gentilitatis) hallada en La Oliva, en la Lusitania vetónica. Es probable que el castro del Monte do Facho también estuviera habitado por una gentilitas similar. Podría ser que el adoptar la denominación romana tuviera algo que ver con una representación local anterior de esa deidad (lo que implicaría un acto de romanización intencionado). Ahí también concuerda el término «deus» que precede al propio nombre del dios, una costumbre también muy extendida en la Germania romana (agradezco a la Dra. Ute Schillinger el haberme aportado esta información), que podría ser interpretada como una manera de someter a un dios local a la interpretatio romana. Aquí podría observarse un modo parecido de proceder; Rodríguez

${ }^{75}$ Millán González-Pardo $(1978,18)$ informa sobre eliminación y daños intencionados en «piedras parecidas» por parte de un capellán. Al final del presente capítulo se encuentra una lista de bibliografía abreviada.

${ }^{76}$ v. cap. II. Las excavaciones. Otros hallazgos. Cerámica. 
Colmenero ${ }^{77}$ hace referencia a observaciones paralelas de $\mathrm{E}$. Thèvenot.

Los altares votivos que actualmente están en los museos de Pontevedra ${ }^{78}$ y Vigo, y que se encontraron en la superficie o como piezas, fueron tratados en la investigación de G. Gamer sobre las diferentes formas de altares romano-hispánicos, así como en diversos estudios epigráficos (Millán; Tranoy; Bouza Brey; Baños Rodríguez, Olivares Pedreño, entre otros), mas sin llegar nunca a una conclusión definitiva en torno a su interpretación. Rodríguez Colmenero consiguió fijar el dativo DEO LARI BERO BREO en 1997, basándose en el material existente en ese momento. J. C. Búa Carballo llegó a interpretar correctamente por lo menos una parte de las inscripciones y a identificar el «nombre» y los términos Berobreus, deus y lar en su tesis doctoral, presentada en la Universidad de Salamanca en el 2000, «Estudio lingüístico de la teonimia lusitano-gallega « (Búa 2000, 104 y passim).

Búa (op. cit.) interpreta Berobreo como un «topónimo compuesto de *bero- de significado desconocido (v. Berisi) $+*$ bri , colina, castro», aunque también hace referencia a otras interpretaciones que podrían interpretar Breus como un nombre de persona. Cabe observar que todas estas explicaciones derivan del material encontrado antes de 2003.

Las inscripciones encontradas más recientemente aportan argumentos a favor de la hipótesis de que podría tratarse del nombre de un dios llamado Lar y de un ON o VN utilizado de forma adjetival, lo que significa que el dios es llamado Lar y que Berobreus representa un epíteto local o étnico ${ }^{79}$. El hecho de que la denominación no aparezca en ningún otro sitio reforzaría tal hipótesis

Todo esto recuerda al VN berón (el indicio más importante corresponde a Estrabón 3, 4, 12) y otros con raíces célticas citadas por Holder. Más adelante nos pronunciaremos sobre esto en base al estado de la totalidad del material; una cosa está clara: las investigaciones en torno al origen lingüístico de Berobreo y variantes como Berobriaecus (?) en el contexto de nombres de dioses como e.g. Bandue Veigebreaego y otros no serán pan comido en ningún

\footnotetext{
77 Rodríguez Colmenero 1997, Nota 54.

${ }_{78}$ Sobre la historia de las investigaciones más o menos sistemáticas en la zona del Monte Facho que comenzaron en los años sesenta, v. Rodríguez Colmenero 1997, 387 y sigs., así como la aportación a la historia de las investigaciones en el preinforme con ese mismo título. Las «Inscripciones Romanas de Galicia. III Museo de Pontevedra», editadas por J. Filgueira Valverde y A d'Ors, Santiago de Compostela 1955, contienen únicamente una inscripción del castro Liboreiro «entre Cangas y Adán» (núm. 29).

${ }^{79}$ Sobre composiciones de nombres similares, comp. Unterman 1985, 350 y sigs.; Albertos Firmat 1977, 21
}

momento y requerirán conocimientos lingüísticos específicos ${ }^{80}$

Por lo que respecta al deus Lar, el del Monte do Facho se incluye en la multitud de yacimientos que llevan por nombre estos numina de difícil comprensión, y casi multifuncionales ${ }^{81}$. La inscripción romana VI 646 describe a Silvanus como Lar agrestis. El deus Lar Berobreus deberíamos imaginárnoslo como una divinidad protectora muy general del $\mathrm{Fa}$ cho o del castro y de sus habitantes.

Llama la atención que en el formulario de las consagraciones, con sus pocas variantes, sólo una parte mínima de las inscripciones de Donón contengan los nombres de los donantes; las consagraciones transcurren casi en su totalidad de manera anónima ${ }^{82}$ y pluralmente a través de un donante, quien se presenta a sí mismo en primera persona del singular. Lo entiendo como posible prueba de la existencia de una sociedad cerrada de los donantes en la pequeña zona del castro. Dichos donantes se conocerían muy bien entre sí, de tal manera que no considerarían necesario plasmar ningún tipo de diferenciación al respecto. De todos modos, podría ser que un grupo de piedras colocadas en un lugar concreto diera cuenta de la pertenencia al grupo del donante. Otra interpretación cercana a la consagración del grupo en tanto que sociedad colonizadora queda descartada por el formulario, ya que los donantes tal y como mencionamos anteriormente, se expresan mayormente en singular. También deberíamos contemplar la posibilidad de que el formulario usual (donante en primera persona del singular, sin mencionar el nombre) corresponda a una representación moderna y corriente de un diálogo directo entre el donante y la divinidad. A mi saber, las consagraciones «anónimas» aparecen en la Antigüedad, pero, por regla general, son definidas de manera indirecta, bien mediante el locus privatus de la representación o bien de algún otro modo. No obstante, no deberíamos dejar de contemplar esa posibilidad.

A partir de los hallazgos con los que contamos hasta ahora, también llama la atención la inexisten-

\footnotetext{
${ }^{80}$ Trabajos previos al respecto se encuentran en Albertos Firmat, 1975, del mismo autor 1977; Unterman, op. cit. 351 y sigs.; 353 y sigs. En una conferencia pronunciada con ocasión del coloquio «Interpretatio romana» en Sintra, cuyas actas aún no han sido publicadas, Untermann trató el tema nuevamente, bajo el título «Los teónimos del noreste peninsular y la gramática de la lengua indígena de la misma región». Agradezco a J. Untermann haber sido tan amable de dejarme el manuscrito.

81 Más aportaciones de la Península Ibérica en Albertos Firmat, op. cit. 59; Untermann 1985, 361.

${ }^{82}$ En Baños Rodríguez, 1994, 51 y sigs., aparece una $A e$ burina(?) que pro sua filia [po]suit el altar. Más adelante aparece una Coemia(?) como posible donante.
} 
cia de indicios cristianos. Esto partiendo de la base de que la datación habitual de los altares votivos en relación con el material ya conocido, que fija su origen en los siglos III y IV d.C., sea correcta. Personalmente, tengo mis dudas en este sentido, puesto que el material se escapa de la categorización tanto relativa como estrictamente cronológica: una forma de escritura «buena», que pudiera relacionarse con los tiempos imperiales, aparece junto a escritos «bárbaros» que deberían ser datados más tarde, pero que podrían ser contemporáneos con los primeros y haber sido creados por manos no profesionales. En contra de esta hipótesis habla la sociedad remarcadamente «cerrada» del castro, en el que difícilmente existiría más de un taller al mismo tiempo. Es probable que una investigación profunda al respecto, que incluya especialmente las cabezas de los altares, pueda aportar conclusiones sobre este punto. Estas cabezas de altares merecen ser objeto de una profunda investigación, partiendo de la base de Garner (1989, 50 y passim), tanto en lo relativo a las -pocas- variantes como respecto a su lenguaje de símbolos derivado de la arquitectura sagrada.

Parece como si a menudo se tratara de versiones bidimensionales de otros altares tridimensionales procedentes de otras zonas de la región más «ricas» y más «evolucionadas» desde un punto de vista cultural, como e.g. Lucus Augusti, aunque también en otros sitios en los que se observaran modelos a seguir».

El material de los altares votivos del Monte do Facho es uniforme, estando formado exclusivamente por el granito existente en la región, si bien éste presenta diferencias de tipo geológico: a parte de roca dura hay material quebradizo con inclusiones duras de cuarzo, gneis y mica. Estas estelas/placas tienden a romperse a lo largo de las venas de cuarzo. Es de suponer que esas roturas sucedieron en parte en la Antigüedad; y cabe pensar que se ocasionarían más roturas en otras fases de derrumbe en el lugar ${ }^{83}$.

A partir del material encontrado durante la campaña desearía presentar un hallazgo (altar a11, tabla $10 \mathrm{c}$ ), típico tanto por su forma, como por su contenido y su formulario.

Se trata de un altar votivo de granito marrón con un pie con forma cónica escindido irregularmente. Según Gamer $(1989,131$ y sigs.), este tipo de granito, si bien con diferentes grosores, está extendido por toda la Hispania. La inscripción probablemente, aunque no es seguro, se mantuvo en su totalidad. Las medidas del altar son: máx. 73,5 cm al., máx.

\footnotetext{
${ }^{83}$ v. cap. III: Las excavaciones. Los bloques I-IV.
}

$24,5 \mathrm{~cm}$ an. y $15 \mathrm{~cm}$ la. La cabeza tiene dos bultos en los laterales y un bulto que la separa de la superficie de la inscripción (frontón, dos pulvini cilíndri$\cos$ ) y tiene una altura de $14 \mathrm{~cm}$. La profundidad del triángulo interior es de $1.5-2 \mathrm{~cm}$. El diámetro de ambos pulvini es de $5 \mathrm{~cm}$. Su parte cilíndrica está trabajada por completo, cosa que nos hace suponer que, como mínimo, sus laterales quedaban a vista después de la colocación del altar. Las tres caras de piedra están alisadas toscamente; la cara posterior más toscamente que las laterales y la anterior. La placa de la inscripción está enmarcada en la parte superior y en los laterales, siendo el marco de un grosor entre 3 y $4 \mathrm{~cm}$. La altura de las letras está entre los 6,5 y los $3,5 \mathrm{~cm}$; no sigue ningún sistema reconocible y parece ser fruto de la casualidad. Las letras tienen una profundidad de entre 0,1 y $0,5 \mathrm{~cm}$.

$\begin{array}{ll}1 & \text { DEO } \\ 2 & \text { LARI } \\ 3 & \text { BERO } \\ 4 & \text { BREO } \\ 5 & \text { ARA(m) } \\ 6 & \text { POSV[.] }\end{array}$

Las cuatro primeras líneas pueden leerse a la perfección. En la quinta línea habría espacio para una letra más o bien para una ligadura, aunque no ha sido posible llegar a reconocer ninguna de las dos posibilidades a partir de los métodos de análisis de los que disponemos. La sexta línea está borrada detrás de POS /II/. Con mucha imaginación, podríamos llegar a ver, quizás, un POSV///. Surgen entonces dos posibles variantes: ara pos (sita) y $\operatorname{ara}(\mathrm{m})$ posv[i].

Si me inclino por la segunda de las variantes, el motivo sería el siguiente: tales analogías en un formulario dentro de un contexto epigráfico del Facho son algo frecuente $y$, por otro lado, olvidar letras al final de una palabra o cometer errores gramaticales en un pueblo romanizado sólo en parte es algo más corriente que el «ara pos(ita)», abstracto, si bien correcto desde un punto de vista gramatical, y que, a mi parecer, resulta demasiado complicado para el contexto en el que se encuentra. En lo concerniente a la datación, cabe proceder con sumo cuidado. Según los informes de excavación de ambos colegas, la datación resultante de la capa 1 está en el s. III/IV d.C. Al mismo tiempo podemos suponer que el lugar cumplía la función de santuario desde el s. III/IV d.C. Saber cuándo se añadió el formulario en latín en los altares es algo que resulta difícil de reconocer a partir de la sucesión arqueológica de las capas, pues a menudo resultaba complicado determinar con 
exactitud dónde acababa una y dónde comenzaba la siguiente. Confiamos lograr una ubicación temporal a partir de ir comparando el material en su totalidad. Tengo una primera impresión de que nada hablaría en contra de adjudicar una ubicación en el s. II d.C. a las inscripciones más antiguas conocidas hasta el momento, una conclusión basada en el mejor tipo de escritura hallada, si bien sujeta a las restricciones mencionadas anteriormente. También el hecho de que los altares hubieran sido reutilizados como piezas de sujeción para ubicaciones de piedras hace suponer una cierta diacronía, si bien no está claro si las donaciones de individuos ya difuntos o de familias extinguidas o de que ya no vivieran en el poblado habían perdido su utilidad al haber sido abandonadas, o si existían otros motivos para destruir los altares votivos y reutilizar sus restos como material de construcción.

Seguir con las excavaciones podría modificar esta idea, ya que hay piedras en ambos lados del corte II, las cuales no necesariamente tienen que pertenecer al mismo marco temporal que el encontrado hasta ahora, sino que podrían ser más antiguas o también más recientes.

Llegar a una datación fiable dependerá en gran medida de la exploración - planificada - del propio castro. En este contexto, el argumento de Rodríguez Colmenero (op. cit. 391), según el cual la prohibición, en 392 d.C., de Teodosio I referente al culto para lares y penates implicaría un terminus post quem non para la construcción de los altares votivos, resulta poco convincente, ya que queda por saber si, cuándo y hasta qué punto tales órdenes y prohibiciones llegaron a este lugar tan remoto. En el material epigráfico de Donón que se conoce hasta la fecha no ha sido posible hallar ningún indicio que apuntara a un contacto con el cristianismo. Este hecho tampoco es del todo relevante para realizar una datación, puesto que no sabemos cuándo se impuso el cristianismo en el oeste gallego, de manera definitiva y con carácter obligatorio.

\section{LA FORMA DE LOS ALTARES}

\section{A. Aproximación a la tipología}

Sin pretender una valoración tipológica exhaustiva que queda para futuras campañas, hemos de tratar la aportación que en el ámbito de la morfología de las aras ha supuesto la primera intervención arqueológica en el Santuario de O Facho, máxime si tenemos en cuenta que estas constituyen el grueso de los hallazgos obtenidos. En el hasta ahora único intento de clasificación tipológica de este amplio conjunto de aras, y por tanto más allá de la caracterización global como aras-poste de G. Gamer ${ }^{84} \mathrm{o}$ de los añadidos a esa caracterización de A. Rodríguez Colmenero ${ }^{85}$, se establecía una subdivisión formal en cuatro grupos de aras ${ }^{86}$.

Un primer grupo lo componían aras de forma típicamente romana, con el pié marcado, cuerpo prismático de menor grosor y cabecera amplia, con molduras sencillas y coronada por pulvini y focus. El segundo grupo estaba formado por aras con el pié marcado, pero el cuerpo y la cabeza no se diferencian sólo por su volumen, sino por la molduración profusa y variada de esta última, en la que destaca el focus asentado sobre una base piramidal o prismática, con los rollos o cilindros laterales en la base a la manera de los pulvini. El tercer grupo englobaba piezas que semejan placas para poner adosadas a una pared, debido a su escaso grosor y a que sólo está trabajado su parte delantera, recordando la visión frontal de un ara con el focus y los pulvini, con la reiteración propia de la plástica provincial. Finalmente, un cuarto grupo se refería a piezas que presentaban cuerpo prismático, muy alargado y poco cuidado en factura, terminado en una cabeza piramidal, señalada por la decoración y, en su remate, por un pequeño focus.

Las piezas aparecidas en esta primera campaña aportan importantes novedades, pues a su mayor número, superior a todas las conocidas anteriormente, se une la mayor presencia de piezas completas - hasta diecisiete, frente a las cuatro anteriores-, pero sobre todo la contextualización de las mismas. A pesar de todo ello, se adecuan en principio a esa clasificación previa, aunque aportan nuevos matices a la misma y expresa una mayor presencia del grupo IV, lo que traerá aparejada una mayor diversidad formal dentro del mismo. Además, aparecen formas que requieren un tratamiento particularizado abriendo nuevas posibilidades tipológicas.

Así, relacionada con el primer grupo tenemos una pequeña pieza ( $a 66)$ conservada en su integri$\mathrm{dad}$, aunque con un marcado desgaste de sus superficies - ha perdido prácticamente el epígrafe - y en un contexto de derrumbe prácticamente superficial que evidencia un importante desplazamiento postdeposicional. No lejos de ésta y en parecidas condicio-

\footnotetext{
${ }^{84}$ G. Gamer, Formen römischer Altäre auf der Hispanischen Halbinsel, Madrider Beiträge 12 (Mainz 1989).

${ }_{85}$ A. Rodríguez Colmenero, Escultura en relieve y bulto redondo, in Galicia.Arte, vol I (A Coruña 1993), 373-476.

${ }^{86} \mathrm{~F}$. Fariña Busto y J. Suárez Otero, El santuario galaicoromano de O Facho (O Hío, Pontevedra), Boletín Auriense XXXII, 2002, 25-52.
} 
nes nos encontramos con una de las piezas más singulares del santuario ( $a 57)$ : un ara realizada en granito de excelente calidad, bien trabajada en todas sus caras, con un frontón triangular y pulvini en el remate y un cuerpo ocupado por una hornacina $y$ decorado con un motivo en «S» en relieve. Esta pieza expresa la existencia de variantes en este primer grupo, más allá de la diferencia de matiz en la definición de los rasgos típicos, pero también la presencia de modelos ajenos al contexto galaico, e incluso peninsular, dado que no conocemos en esos ámbitos ningún paralelo para esta pieza. El tercer ejemplar recuperado (a17-19) vuelve a insistir en esas diferencias, pues, además de su gran tamaño, presenta una cabeza moldurada y rematada en un frontón triangular en cada lado, así como un pié cúbico bien diferenciado. Una pieza que tiene un paralelo en el otro lado de la ría de Vigo: ara a Mercurio hallada en la playa de Panxón ${ }^{87}$.

En el segundo grupo, dentro de una aparente escasez, nos encontramos con los formas típicas. Remates cuadrangulares con decoración de arcos y motivos geométricos simples, esculpidos o grabados en las paredes laterales y parte superior de la cabeza de las piezas (v.gr. a7). La pieza más destacable, un ara fragmentada y hallada in situ (a16), presenta una cabeza bien diferenciada del resto del ara y con unos rasgos propios de primer grupo, aunque con una morfología y decoración del segundo. Estaríamos ante una pieza concebida en el proceso de creación de las formas propias del Santuario, acentuando incluso una sus principales características: una acusada altura y relativa estrechez. Esta ara-pilar se acerca al 1,90 m. de la pieza portuguesá de Lisouro (Paredes de Coura, Minho) ${ }^{88}$, sobrepasando a las mayores piezas hasta ahora conocidas para $O$ Facho, como los 1, 70 del ara a17-19, o los 1,67 del ara $\mathrm{n}^{\circ} 1$ del CIRG II ${ }^{89}$. Dentro de este tipo de cabeza prismática, encontramos también ejemplos de una de sus variantes ya constatadas, como es la de aquellas piezas que destacan por su estrechez, con $20 \mathrm{~cm}$ o menos de ancho y un grosor similar, como en la a46 de esta campaña.

Al lado de las de cabeza prismática, existen también ejemplos del tipo caracterizado por su remate triángular, en el que se ubica un pequeño focus, y que suelen ofrecer una amplia superficie decorada

${ }^{87} \mathrm{G}$. Baños Rodríguez, Corpus de Inscripcións romanas de Galicia, II. Provincia de Pontevedra (Santiago 1994), esp. 325 .

${ }^{88} \mathrm{G}$. Gamer, Formen römischer Altäre (op. cit.).

${ }^{89} \mathrm{G}$. Baños Rodríguez, Corpus de Inscripcións romanas de Galicia, II. (Op. cit.), esp. 27.

${ }^{90} \mathrm{G}$. Pereira Menaut (dir.), Corpus de inscripcións romanas de Galicia I. Provincia de A Coruña (Santiago 1991), esp. 197.
(V.gr. la a47). Como variante de estas podemos señalar las que podría ser llamadas aras-placas, pues si en las anteriores disminuían en anchura, éstas lo hacen en grosor, como muestra la a11. También como posible variante de este tipo pueden considerarse algunos ejemplares que manteniendo buena parte de las características -remate triangular, preocupación por lo ornamental y relativa buena calidad del granito-, empiezan a manifestar cambios en la concepción global de la pieza, ahora sin solución de continuidad entre la cabeza y el campo epigráfico, o entre éste y el hincón, así como también en su elaboración, algo más tosca. Ejemplos serían la $a 37$ o la compuesta por los fragmentos a30 y a38, en la que destaca el motivo de volutas obtenido sobre la parte frontal de los pulvini, como ocurre en un ejemplar mucho más tosco de Dodro (Porto do Son) ${ }^{90}$. Algunas de las piezas, como esta última, aparecen fragmentadas y reutilizadas como sostén de aras del grupo cuatro, lo que implica una anterioridad con respecto al mismo.

El antiguo grupo III parece ausente en esta campaña, salvo quizás una pequeña pieza anepígrafa (a23) que lo recuerda aunque en versión muy reducida: mantiene el carácter de placa rectangular con una cabeza bien diferenciada por la presencia de unos pulvini y un espacio para el focus bien definidos, bajo los cuales aparece un amplio espacio decorado, ahora en forma de líneas oblicuas cruzadas, que en este caso no se continua con el campo epigráfico, sino por un hincón apuntado. En realidad los nuevos hallazgos nos sitúan frente a un grupo más diverso morfológicamente de las ya mencionadas aras-placa, que ahora no serán ya siempre estrictamente rectangulares y con otras soluciones en el remate o la decoración. Unas con remate curvo y recuerdo del modelo clásico por la presencia de rollos y un «focus» apenas insinuado, otras con remate triangular y conformación irregular; en unos casos con abundancia de decoración, mientras que en otros está parece limitarse a la mera configuración de la cabeza del ara. En definitiva un modelo extraño para el que apenas existen paralelos: una pieza de Arlanza, León ${ }^{91}$, y una gran ara del santuario de Postoloboso en Ávila ${ }^{92}$, coincidencias que parecen por tanto circunstanciales y ligadas a las necesidades del espacio en el que se integrarían estas piezas. Más interés presenta la pieza $a 63$ que tiene un claro paralelo en un ejemplo del interior de la provincia de Pontevedra: S. Pedro de Ferreiroa (Agolada) ${ }^{93}$;

\footnotetext{
${ }^{91}$ G. Gamer, Formen römischer Altäre (op. cit.).

92 Idem.

${ }^{93} \mathrm{G}$. Baños Rodríguez, Corpus de Inscripcións romanas
} de Galicia, II (Op.cit.), no 85, pp. 205-6. 
aunque en este caso no pueda definirse su condición de ara o estela dado lo extraño de un epígrafe que apunta a una datación muy tardía.

El último grupo de piezas nos remite a la fragmentación que los nuevos hallazgos han motivado en la tipología del conjunto de monumentos de $\mathrm{O}$ Facho. EI más numeroso con diferencia, ofrece una diversidad que apunta incluso a su ruptura y a la necesidad de crear nuevas variantes tipológicas dentro del conjunto de aras de Monte do Facho. Algunas de estas aras siguen conservando los rasgos del grupo II, como el focus y los pulvini, en un remate triangular con similares motivos decorativos. Otro mantiene la morfología general de la pieza - delgada y alta - pero pierde los pulvini en un frontón triangular simple que tan solo en ocasiones conserva un recuerdo del focus. En cuanto a la decoración se reiteran algunos de los motivos, pero tratados de distinta manera o, simplemente, sustituidos por otros nuevos. Otras piezas manifiestan formas ya dispares que nos hablan de otras posibilidades tipológicas. Así como expresión extrema de la transformación del tipo II pueden ser entendidos los ejemplares de pequeña talla y forma de «betilo» (aI4 y a24), de cuerpo robusto e indiferenciado, que apenas recuerda el modelo original de ara, pero conserva todavía la parte superior decorada, el campo epigráfico y una parte inferior apuntada y lisa.

Finalmente, existen ejemplos que presentan dificultades de adscripción tipológica, pues aún teniendo los rasgos generales e incluso alguno de los específicos, los combinan de una manera ajena a las pautas que hemos venido exponiendo. Un último caso (a15) parece en realidad más un esqueuomorfo de ara que un ara propiamente dicha, pues se trata de una piedra de pésima calidad y sin trabajar cuya forma recuerda lejanamente a las aras de remate triangular, lo que se aprovecha para dibujar alguno de los elementos propios de aquellas: cabeza decorada y separada del campo epigráfico, ahora convertido en decorativo por una simple línea oblicua, y de nuevo la separación entre éste y una base irregular, obtenida de la configuración natural del soporte.

Una de las características de las aras recogidas es una mayor pobreza en el apartado decorativo con respecto a las que ya se conocían, además de una general reiteración de los motivos registrados en ellas. Sin embargo la decoración sigue jugando un papel importante que incide, además, en la propia caracterización tipológica de las piezas. Así, la decoración por lo general se reduce a la cabeza de unas aras que debemos recordar son en general de menores dimensiones y factura más pobre. En cuanto a los motivos se repiten las arcadas o similares, los crecientes lunares, las aspas, los zig-zags y otros motivos difíciles de definir. Decoración que puede estar obtenida mediante relieve, acentuado el carácter plástico que las molduras otorgan a algunos monumentos, o por simple grabado, líneas incisas para los motivos geométricos simples.

Existen, no obstante, algunas que rompen esa caracterización para mostrarse especialmente barrocas, al tiempo que ofrecen nuevos motivos ornamentales, por lo que requieren un tratamiento aparte. Se trata de aras de morfología ya muy alejada de la idea original, aunque permanecen estrechamente ligadas a las características más específicas del conjunto del Facho: piezas compactas, alargadas y estrechas. Pero se trata ya de piezas generalmente de menores dimensiones y carácter anepígrafo, en las que la propia decoración parece ocupar el espacio que antes correspondía al campo epigráfico, como vimos en las piezas $a 15$ y a23. El ejemplo más paradigmático es el ara a50 con una compleja y barroca cabeza, en la que los pulvini de las formas romanas se reinterpretan como motivo decorativo, multiplicándose y dando forma a esta parte del monumento, en una solución inédita que sólo tiene paralelos en una pieza dedicada a Diana de (Ourense) ${ }^{94}$. Pero en ese caso los rollos aun mantienen una disposición y configuración que recuerdan al motivo original, mientras que en este se han convertido apenas en círculos con punto central que decoran una cabeza que remata en un pequeño agujero, apenas recuerdo del focus, y contiene unos estrechos cuadrados rehundidos: uno de los motivos más frecuentes en O Facho, quizás relacionable con el de las arcadas. El campo epigráfico está ocupado por un extraño motivo obtenido por incisión, que estilística y formalmente se aparte de lo conocido en el resto del conjunto, abriendo un nuevo ámbito para la interpretación simbólica.

\section{B. Caracterización y evolución}

A la hora de interpretar esta amplia y relativamente marcada variedad a la hora de entender el «ara» hemos de tener necesariamente en cuenta los cambios que pudieron acontecer a lo largo de la vida del santuario, para la que existe un marco aún difuso en sus extremos que iría desde el abandono del poblado en la primera mitad del siglo I d. C. y el del propio santuario, que habría que ligar al proceso de cristianización de la zona en torno a los siglos IV y/

${ }_{94} \mathrm{~J}$. Lorenzo; F. Bouza y A. D'Ors, Inscripciones Romanas de Galicia. Ourense (Santiago 1968). 
o v d.C. Un argumento clave para un acercamiento a esta cuestión es la estratigrafía horizontal de los restos recuperados, en la que encontramos que las aras aparecidas dispersas a lo largo de las laderas o en el pie del monte, es decir alejadas de la que debería ser su ubicación original, corresponden mayoritariamente, sino exclusivamente, a los grupos I y II. Mientras que las piezas halladas en la cumbre del monte corresponden mayoritariamente a los grupos III y IV, o a sus nuevas variantes, circunstancia constatada en los hallazgos de J. Suárez Mariño ${ }^{95}$ que ha refrendado la propia intervención arqueológica: sólo cuatro piezas halladas en la presente campaña pueden atribuirse con seguridad a los primeros grupos. Por otra parte, las aras de los grupos I y II aparecen en un estado de conservación peor que las del III: mayor grado de fragmentación y erosión, a pesar de que la materia prima suele ser de mejor calidad; una situación que parecería directamente relacionada con ese acusado desplazamiento de los restos, pero que se constata también en aquellos que se hallaron en la propia cumbre (V.gr. a7), al lado de piezas que estaban claramente in situ (a16).

Esta última circunstancia nos habla de un segundo argumento para la diferenciación cronológica dentro del conjunto. Se trata de la estratigrafía vertical, que sólo ha podido ser conocida gracias a la excavación del lugar original de las aras y que como hemos visto presenta dificultades dada lo superficial de los hallazgos. No obstante existen dos hechos incuestionables. El primero es el uso de monumentos o fragmentos de los mismos como soporte para la colocación de otros, lo que habla de su anterioridad. Los restos que aparecieron en esas condiciones corresponden a los grupos I y II, mientras que los huecos generados responden claramente a los hincones estrechos, cortos y apuntados de los dos últimos grupos de aras. El segundo se refiere a la posición estratigráfica de los dos tipos de huecos registrados: bajo los agujeros cortos y estrechos que aparecen dispersos a lo largo de la superficie pudo detectarse la presencia de otros de mayores dimensiones, cuya forma coincide con los grandes hincones prismáticos de los primeros grupos, y que parecen quedar amortizados por una reorganización de este espacio para acoger a la última etapa de uso cultual del mismo.

La conclusión de toda esta argumentación es que lo que en algún momento se interpretó como destrucción intencional y violenta del santuario ${ }^{96}$ es en

${ }^{95}$ F. Fariña Busto y J. Suárez Otero, El santuario galaicoromano de O Facho (O Hío, Pontevedra), Boletín Auriense XXXII, 2002, 25-52.

${ }_{96}$ F. Bouza Brey; J. Ma . Álvarez Blázquez; E. Massó Bolivar, Las aras del santuario galaico-romano de Donón (Hío, realidad una prueba de que la existencia de éste, en tanto que santuario galaico-romano, manifiesta una evolución en la que parece clara la diferenciación de al menos dos etapas bien definidas. Una primera aparece de momento en forma de aras muy fragmentadas, y en buena medida rodadas pues aparecen fuera de su ubicación original, e incluso en muchas ocasiones - hallazgos de los años 60 y 70 - alejadas de la misma, pues sabemos por algunos negativos de hincones o alguna pieza conservada in situ que esta se situaba en la cima del monte y sus inmediaciones; espacio en el que también aparecen sus trozos reaprovechados para la ubicación de otras aras. Se trata de piezas de relativa buena calidad, tanto en la elección del granito como en la elaboración, en las que, al lado de algunos ejemplos de tipos típicamente romanos (grupo I), aparecen las formas que van a caracterizar a este santuario y que implican la creación de un taller propio (grupo II), con una más que probable proyección en su entorno geográfico: área sudoccidental de la Gallaecia.

Una segunda etapa parece implicar una amplia reestructuración del santuario, al tiempo que una también evidente modificación en la manera de hacer, quizá de entender, el ara como ofrenda. Ahora tenemos la ubicación precisa de unas aras que aparecen en bastantes ocasiones enteras y caídas o fragmentadas no lejos de su posición original. Se trata de piezas que aun conservando los rasgos de las anteriores van a redefinirlos alejándose de los modelos originales romanos, sobre unos granitos cada vez de menor calidad y con una elaboración menos cuidada. Las formas se diversifican acentuando la individualidad de las piezas, mientras que la epigrafía se reduce hasta su total desaparición, sustituida, aparentemente, por nuevos y complejos motivos decorativos. La especificidad de estas aras hace ahora difícil encontrarle paralelos fuera del santuario, salvo ejemplos que se caracterizan también por su propia atipicidad.

\section{RESUMEN, PRIMERAS INTERPRETA- CIONES Y VALORACIÓN}

La campaña de excavación en el Monte do Facho ha aportado un resultado sorprendente con respecto al planteamiento descrito al principio e incluso asombroso en vista de la evidencia y abundancia de los hallazgos encontrados, sobre todo de los altares

Cangas), Cuadernos de Estudios Gallegos 78, 1971, 64-81. También F. Fariña Busto y J. Suárez Otero, El santuario galaico-romano de O Facho (O Hío, Pontevedra), Boletín Auriense XXXII, 2002, 25-52. 
votivos, ubicaciones y recintos. El resultado nos anima a formular las primeras interpretaciones que, sin embargo, una vez transcurrida sólo una campaña, deben entenderse con reservas.

En primer lugar debemos constatar que la zona excavada abarca, sin duda, el santuario mismo o una parte importante del mismo. A esta zona del santuario pertenecen, a parte de las terrazas con los altares votivos (nivel 2/pendiente/nivel 3, v. Fig. 3), con toda seguridad el lacus y con menos probabilidad la zona contigua en el oeste (sección Id), puesto que su gama de hallazgos es totalmente distinta. Sin embargo, esto afecta a toda la zona del corte I en la que, hasta el momento, no se han observado ubicaciones y en la que era evidente que los pocos altares que salieron a la luz habían sido cambiados de sitio (Fig. 7). En estos momentos, sería demasiado prematuro realizar una valoración topográfica sobre la relación entre el lacus y las terrazas con los altares votivos que están situadas pendiente arriba, si bien, en conjunto, parece ser que la zona sagrada se extiende hacia el norte y el este, es decir, hacia la cumbre y el lado este de la colina no afectado por el clima y, por consiguiente, en dirección al castro de la Edad del Hierro, y no en dirección a la pendiente sureste de la Edad del Bronce (Fig. 1). A esta zona pertenecen el muro de roca trabajada que delimita el corte IIb desde el noroeste, así como los bloques I a IV en el corte IIa que en esta ubicación no corresponden a su uso original.

En el corte II se llegó a observar un total de 66 ubicaciones, esto es, un número que corresponde aproximadamente a la cantidad de altares hallados (57 piezas). La equivalencia nos demuestra una relación equilibrada entre unos y otros. Esta relación, en vista del buen estado de conservación, tanto de los altares votivos - de los cuales están completamente intactos al menos unos 17 - como de las superficies de las ubicaciones y de los recintos hallados, nos permite deducir que, si bien el santuario antiguo ha llegado hasta nuestros días en un estado de destrucción, no hubo posteriores actuaciones destructivas a gran escala, dirigidos contra los altares o contra sus emplazamientos. Como ya es sabido, en la arqueología de campo el binomio formado por el tipo de destrucción y la duración del mismo suele aportar buenos indicios para valorar sus características. Habida cuenta de que hasta ahora no han aparecido señales de cristianismo durante la excavación, y teniendo en cuenta las informaciones aportadas por la investigación, cabe excluir la posibilidad de que el santuario hubiera sido destruido en pos de una motivación cristiana.

Estas explicaciones, sin embargo, no significan que el santuario no haya sido expuesto a modificaciones en la Antigüedad. Los altares votivos muestran, al contrario, una cierta reestructuración y reubicación, puesto que fueron reutilizados - bien en trozos o bien intactos, en una sola pieza- en ubicaciones y recintos. El hecho de que estas piezas reutilizadas no solo permanecieron en el santuario, sino que, por regla general, fueron reutilizadas para erigir altares, nos lleva a dos observaciones relacionadas entre sí. En primer lugar parece que se daba importancia al destino original de las piezas, ya que los fragmentos procedentes de los altares votivos también se usaban en ubicaciones o recintos. Es de suponer que los altares no perdieron su carácter sagrado al ser desmontados y fragmentados. En segundo lugar se impone la idea de una pauta del tipo del 'oux' $\varepsilon x$ $\varphi \circ \alpha^{\prime}$, del que conocemos la existencia gracias a santuarios griegos; y más teniendo en cuenta que los altares votivos estaban concentrados en una pequeña zona como es el corte II.

Tal como indican los hallazgos de las ubicaciones (Fig. 4.5), los altares votivos tenían que haber distado (sección IIb) muy poco entre sí $(30-40 \mathrm{~cm})$ en algunos puntos, de manera que la reconstrucción nos da una imagen de altares votivos muy cercanos entre sí. Estaban situados en ubicaciones, algunas de las cuales estaban dentro de un recinto. Los recintos se concentran en la sección IIb. En la sección IIa no ha aparecido por ahora ningún recinto. Este hecho diferenciador también aparece en las ubicaciones y en la reutilización de piezas. De tal manera que la sección IIb contiene muchas más ubicaciones que IIa, y en cambio en IIa hay muchos más altares como piezas reutilizadas que en IIb. Justamente a partir de estos hechos surge una posible explicación: probablemente se trate en el caso de la sección IIa de una ampliación de la zona más angosta del area sacra. A favor de esta argumentación hablaría el muro Ma5 (Fig. 4), el cual estaría destinado a delimitar la parte sagrada, a la que - teniendo en cuenta el portillo en el Ma5- se accedería por el este.

Debido a su supuesto emplazamiento en la posible confluencia de los dos asentamientos preexistentes, el de la Edad del Bronce y el de la Edad del Hierro (Fig. 1), podría pensarse en una continuidad de culto en el mismo sitio. Queda por saber si esa continuidad no sufrió interrupción alguna desde la Edad del Bronce hasta la Era Romana. En cualquier caso, cabe destacar dentro de este contex to que el santuario descubierto ahora por nosotros en los cortes IIb y IIa (Fig. 2) pertenece al siglo III/IV d.C., conclusión a la que hemos llegado a partir de los hallazgos de cerámica, vidrio y monedas en la capa negra. En lo concerniente a los hallazgos de la época castreña tar- 
día - de los cuales, los más recientes probablemente sean del siglo I d.C.- - existe un vacío de tiempo que va del siglo I al III d.C., pues hasta ahora no hemos encontrado ningún hallazgo perteneciente a ese periodo. Dado que las excavaciones realizadas hasta la fecha todavía no han llegado a alcanzar el fondo del terreno y que aún no hemos llegado a tocar otras posibles capas más antiguas, creemos que esta constatación no tiene por qué ser la última. Posiblemente también se acabe aclarando en el futuro la relación temporal de las terrazas de los altares.

Basándonos en las inscripciones encontradas, creemos que la parte romana podría ser considerada un Lararium. Las inscripciones en los altares fueron realizadas en las cercanías, en el sitio mismo o en el castro. El cambio de sitio de un altar era un acto sagrado de por sí, por lo visto precedido por una ceremonia de culto. Futuras investigaciones quizás puedan aclarar la cuestión de si ese procedimiento sagrado estaba relacionado únicamente con la adopción unilateral de las costumbres romanas o si, y hasta qué punto, estaba influido por cultos y costumbres indígenas.

\section{BIBLIOGRAFÍA ABREVIADA}

ALBERTOS FIRMAT, M.L., El culto a los montes entre los Galaicos, Astures y Berones y algunas de las deidades más significativas, Estudios de Arqueología Alavesa 6, 1974, 147-157.

Id., Organizaciones suprafamiliares en la Hispania antigua, Studia Archaeologica 37, Santiago de Compostela - Valladolid 1975.

ID., Perduraciones indígenas en la Galicia Romana: los castros, las divinidades y las organizaciones gentilicias en la epigrafía, Actas del Coloquio internacional sobre el Bimilenario de Lugo, Lugo 1977, 17-26.

BAÑOS RODRÍGUEZ, G., Corpus de Inscricións Romanos de Galicia (CIRG). II. Provincia de Pontevedra, Santiago de Compostela 1994.

BELTRÁN LLORIS, F., Culto a los Lares y grupos de parentesco en la Hispania indoeuropea, in: Religio Deorum. Actas del Coloquio Internacional de Epigrafía. Culto y Sociedad en Occidente 1988. Barcelona o.J., 59-71.

BÚA CARBALLO, J.C., Estudio linguíístico de la teonimia lusitano-gallega, Tesis doctoral Salamanca.

BALIL ILLANA, A. - PEREIRA MENAUT, G. SÁNCHEZ PALENCIA, F.J., Tabula Imperii Romani, Hoja K-29: Porto, Madrid 1991, s.v. Facho de Donón 55.
BOUZA BREY, F., et. al., Las aras del santuario galaico-romano de Donón (Hio-Cangas), CEG 26, 1971, 64-81.

FARIÑA BUSTO, F. - SUÁREZ OTERO, J., El santuario galaico-romano de O Facho (O Hío, Pontevedra), Boletín Auriense XXXII, 2002, 2552.

GAMER, G., Formen römischer Altäre auf der Hispanischen Halbinsel, MB 12, Mainz 1989.

LEUNISSEN, P.M.M., Römische Götternamen und einheimische Religion in der Provinz Germania Superior, Fundber. BW 10, 1985, 155-192.

MILLÁN GONZÁLEZ-PARDO, I., Sobre las aras del santuario de Donón (Hio, Pontevedra) supuestamente dedicadas a Liber, Publicaciones del Museo «Quiñones de León» Nr. 1, Vigo 1978.

OLIVARES PEDREÑO, J. C., Los dioses de la Hispania céltica. Real Academia de la Historia, Bibliotheca Archaeologica Hispana 15, Madrid 2002, 68 y sig.

RAMÍREZ SÁDABA, J.L., Las creencias religiosas, pervivencia última de las civilizaciones prerromanas en la Península Ibérica, en: La religión romana en Hispania, Madrid 1981, 225 252.

RIVAS FERNÁNDEZ, J.C, Consideraciones sobre la religión galaico-romana. Desmitificación de supuestos mitos, BAur 23, 1993, 21-70.

RODRÍGUEZ COLMENERO, A., Mougás y Donón: Dos santuarios rurales galaico-romanos del litoral atlántico, El Museo de Pontevedra LI, 1997, 383-411.

TRANOY, A., La Galice Romaine, París 1981, 293.

UNTERMANN, J., Los teónimos de la región lusitano-gallega como fuente de las lenguas indígenas, Actas del III Coloquio sobre lenguas y culturas paleohispánicas (Lisboa 1980), Salamanca 1985, 343-363.

UNTERMANN, J., Los teónimos del noroeste peninsular y la gramática de la lengua indígena de la misma región. Manuscrito no publicado 1995 (Coloquio «Interpretatio romana», Sintra 16.18.3.1995).

\section{Procedencia de las figuras}

Fig. 1. Mapa Instituto Arquelógico Alemán, Madrid (Chr. Hartl-Reiter), basado en planos topográfi$\cos (1: 1000)$ cedidos por el ayuntamiento de Cangas de Morrazo.

Fig. 2. Instituto Arqueológico Alemán, Madrid (Chr. Hartl-Reiter). 
Fig. 3. Instituto Arqueológico Alemán, Madrid (Chr. Hartl-Reiter).

Fig. 4-7. Instituto Arqueológico Alemán, Madrid (Foto de obra G. Biecker, M. Méndez, dibujado por L. de Frutos).

Fig. 8-9. Instituto Arqueológico Alemán, Madrid.

Fig. 10. Detalle del plano de piedras, Fig. 4.

Fig. 11. Instituto Arqueológico Alemán, Madrid (Chr. Hartl-Reiter).

Fig. 12. Instituto Arqueológico Alemán, Madrid.

Fig. 13. ....

Fig. 14. ....

Fig. 15. ....

\section{Procedencia de las láminas}

Todas las fotografías Neg. IAA, Madrid (Foto M. Perkovi), siempre que no conste lo contrario.
Lámina 1a: KB6-03-7, b: Foto Oficina de Turismo de Cangas de Morrazo.

Lámina 2a: KB6-03-11, b: KB6-03-3.

Lámina 3a: KB26-03-23, b: KB26-03-20.

Lámina 4a: KB28-03-17, b: KB28-03-14, c: KB28-03-5.

Lámina 5a: KB27-03-7, b: KB 29-03-18, c KB903-16.

Lámina 6a: KB28-03-25, b: KB28-03-31, c: KB28-03-32.

Lámina 7a: KB28-03-33, b KB10-03-18.

Lámina 8a: KB7-03-1, b KB20-03-32, c KB2703-5.

Lámina 9.

Lámina 10a: KB KB27-03-21, b KB12-03-25, c KB12-03-12.

Lámina 11a: KB14-03-20, b KB20-03-4

Lámina 12a: KB23-03-35, b KB24-03-4, c KB 24-03-6.

Lámina 13a: KB17-03-31, b KB17-03-36. 